NBER WORKING PAPER SERIES

\title{
THE SIMPLE GEOMETRY OF TRANSMISSION AND STABILIZATION IN CLOSED AND OPEN ECONOMIES
}

\author{
Giancarlo Corsetti \\ Paolo Pesenti \\ Working Paper 11341 \\ http://www.nber.org/papers/w11341 \\ NATIONAL BUREAU OF ECONOMIC RESEARCH \\ 1050 Massachusetts Avenue \\ Cambridge, MA 02138 \\ May 2005
}

We thank Pierpaolo Benigno, Fabio Ghironi, Galina Hale, Maurice Obstfeld, Ken Rogoff, Lars Svensson, Cedric Tille, and Mike Woodford for useful comments and suggestions. We also thank Alessandro Maravalle, Raymond Guiteras and Kathryn Vasilaky for excellent research assistance. Corsetti's work on this paper is part of the Pierre Werner Chair Programme on Monetary Union, at the Robert Schuman Center of the European University Institute. Financial support from the programme is gratefully acknowledged. Corsetti's work on the project is also part of the research network on "The Analysis of International Capital Markets: Understanding Europe's Role in the Global Economy", funded by the European Commission under the Research Training Network Programme (Contract No. HPRN-CT-1999-00067). The views expressed here are those of the authors, and do not necessarily reflect the position of the Federal Reserve Bank of New York, the Federal Reserve System, or any other institution with which the authors are affiliated. The views expressed herein are those of the author(s) and do not necessarily reflect the views of the National Bureau of Economic Research.

(C)2005 by Giancarlo Corsetti and Paolo Pesenti. All rights reserved. Short sections of text, not to exceed two paragraphs, may be quoted without explicit permission provided that full credit, including $\odot$ notice, is given to the source. 
The Simple Geometry of Transmission and Stabilization in Closed and Open Economies Giancarlo Corsetti and Paolo Pesenti

NBER Working Paper No. 11341

May 2005

JEL No. E31, E52, F42

\begin{abstract}
$\underline{\text { ABSTRACT }}$
This paper provides an introduction to the recent literature on macroeconomic stabilization in closed and open economies. We present a stylized theoretical framework, and illustrate its main properties with the help of an intuitive graphical apparatus. Among the issues we discuss: optimal monetary policy and the welfare gains from macroeconomic stabilization; international transmission of real and monetary shocks and the role of exchange rate pass-through; the design of optimal exchange rate regimes and monetary coordination among interdependent economies.

Giancarlo Corsetti

Robert Schuman Centre

European University Institute

Via dei Roccettini 9

50016 San Domenico di Fiesole

Italy

giancarlo.corsetti@iue.it

Paolo Pesenti

Federal Reserve Bank of New York

33 Liberty Street

New York, NY 10045

and NBER

paolo.pesenti@ny.frb.org
\end{abstract}




\section{Introduction}

The past decade has witnessed rapid and substantial developments in the literature on macroeconomic stabilization in closed and open economies, with potentially far-reaching implications for the design and conduct of monetary policy. Despite important differences in emphasis and style, a number of tightly related research agendas (from the 'new neoclassical' synthesis to the 'neo-Wicksellian' monetary economics to the 'new open-economy macroeconomics', and so on) have focused on the properties of choice-theoretic models with imperfectly competitive labor and/or product markets and nominal rigidities. An explicit attempt to provide a synthesis between elements from real business cycle models and shortrun 'Keynesian' wage and/or price inertias is the minimum common denominator of the vast array of 'Dynamic Stochastic General-Equilibrium' models (in short, DSGE models) that have recently been developed in academic research, and have found fertile grounds among central banks and policy institutions.

This paper is meant to provide an introduction to these new research strands, deliberately (but not exclusively) targeted toward a non-specialist audience. In fact, our objective is to use a stylized theoretical framework to access the literature on policy stabilization and macroeconomic transmission, and visualize some key results with the help of an intuitive graphical apparatus. Without attempting to provide an exhaustive overview of the literature (a task well beyond the scope of a 'simple geometry'), an important goal of our exercise is pedagogical: scholars, practitioners and policy analysts uninterested in unraveling technical details may find in our graphs a useful tool to 'inspect the mechanism' and convey important results from more complex models in a transparent and immediate fashion.

Transparency and immediacy are achieved via restrictions on the specification of preferences and technology, which allow us to maintain analytical tractability and focus on the substance of the argument without sacrificing theoretical coherence. ${ }^{1}$ On the negative side, parametric restrictions may well hamper the degree of generality and robustness of the theoretical framework. Thus, when necessary, in the text we will comment on our key assumptions, to make sure that the general principles conveyed by our analysis are not confused with model-specific results. Very few equations - and only extremely intuitive ones - appear in the main text. Relatively advanced readers are referred to the Appendices where full-fledged versions of the models described in the main text, with complete algebraic details, are available.

This paper is organized as follows. The next three sections delve into building the main analytical and graphical tools in a closed-economy setting, covering both normative and positive issues. Section 2 describes the basic macroeconomic model. Section 3 analyzes the transmission of monetary policy, characterizes macroeconomic stabilization and provides elements for a welfare analysis. Section 4 discusses and extends the basic model, including a brief analysis of fiscal shocks. The following sections of the paper reconsider our conceptual apparatus in the context of a two-country world model. Section 5 describes the global economy and introduces alternative price-setting regimes in the presence of market segmentation. Section 6 revisits the traditional view about the stabilization properties of exchange rate movements. Section 7 discusses the international dimensions of optimal monetary policy, linking them to the choice of the exchange rate regime. Section 8 discusses a few extensions

\footnotetext{
${ }^{1}$ Among the advantages of our approach is the possibility of solving the model in closed form for a generic distribution of stochastic fundamentals, thus paving the way to a straightforward graphical representation of the equilibrium results.
} 
of the model and Section 9 concludes.

\section{A basic macroeconomic model}

We start by developing a stylized closed-economy macroeconomic model. The model is fully specified in Appendix I, which also derives and characterizes the general-equilibrium allocation.

The economy consists of households, firms, and the government. There is no external trade in goods or assets. The population size is normalized to one, so that we can use the same notation for aggregate and per-capita variables.

Households have identical preferences. They derive utility from consuming the products supplied by the firms, and disutility from supplying labor to the firms in exchange for wage incomes. There may be other elements affecting households' utility, for instance real money balances, but in what follows we disregard them as quantitatively negligible. At any point in time, utility $U$ is equal to:

$$
U=\ln C-\kappa \ell
$$

where $C$ is consumption and $\ell$ is hours worked. The parameter $\kappa$ measures the discomfort associated with labor effort, so that the marginal rate of substitution between consumption and leisure is:

$$
\left.\frac{\partial C}{\partial \ell}\right|_{d U=0}=\kappa C
$$

There are many varieties (or 'brands') of the consumption good. Each firm produces a single variety, which is an imperfect substitute to all other varieties. Labor is the only input in production. Productivity (output per unit labor) is subject to economy-wide shocks. The labor market is assumed to be perfectly competitive.

As firms have market power over the supply of their products, they set prices as markups over marginal costs. We allow for nominal price rigidities in the short run. For simplicity, we assume that firms preset the price of their own products at the beginning of each period, and stand ready to meet current demand at this price during the period.

The government includes both the central bank in charge of monetary policy and the fiscal authorities. In most of our analysis we abstract from public consumption, so that fiscal policymakers only redistribute revenue across agents. ${ }^{2}$

\subsection{The structure of the economy}

Our model can be synthesized by means of three schedules, as illustrated in Figure 1: Aggregate Demand $[\mathrm{AD}]$, Aggregate Supply $[\mathrm{AS}]$, and the Natural Rate $[\mathrm{NR}] .^{3}$ Figure 1 plots labor effort $\ell$ on the horizontal axis and consumption $C$ on the vertical axis.

Let $P$ denote the consumer price index associated with the consumption basket $C$, that is, an average of the prices of all consumption varieties. Without investment or government spending, $C$ coincides with aggregate demand in real terms, while $P C$ is aggregate nominal

\footnotetext{
${ }^{2}$ We analyze government spending shocks in Section 4.4 .

${ }^{3}$ Throughout the paper we maintain the Aggregate Demand / Aggregate Supply conceptual apparatus of most macro textbooks, although our graphical approach is closer in spirit to the microeconomic treatment of input/output relations. Thus, readers used to think about 'Aggregate Supply' in reference to the relation between the price level and output, or inflation and the output gap, may prefer to consider our AS schedule as the consumption-employment relation implied by the technology of production.
} 
spending. Let $\mu$ denote a variable that synthesizes the effect of monetary policy (whatever the specific policy instruments used) on aggregate nominal spending $P C$. We can refer to $\mu$ as the aggregate monetary stance of the country. ${ }^{4}$ The Aggregate Demand 'AD' equation can then be written as:

$$
C=\mu / P
$$

A monetary ease (higher $\mu$ ) provides nominal stimulus to the economy. With prices preset in the short run, aggregate demand moves one-to-one with the policy stance. In terms of Figure 1, the 'AD' is a horizontal line: given the price level $P$, a higher monetary stance $\mu$ translates into higher real consumption $C$. By the same token, given the monetary stance $\mu$, consumption is higher the lower is the price level.

Next, let $Z$ denote labor productivity. The Aggregate Supply 'AS' equation relates output (that in closed economy is equal to real domestic expenditure) to total employment measured in terms of hours worked:

$$
C=Z \ell
$$

Holding $C$ constant, shocks to productivity $Z$ lead to fluctuations in aggregate employment $\ell$. In Figure 1, the 'AS' schedule is a ray from the origin with slope determined by the productivity parameter $Z$ : higher productivity translates into a steeper line.

At any point in time, the intersection between 'AD' and 'AS' determines the equilibrium allocation of consumption $C$ and labor $\ell$ for given values of the exogenous variables $\mu$ and $Z$, as well as for a given price level $P$. Of course, the price level is an endogenous variable in our system. We therefore need to analyze how firms optimally set their prices.

Consider first the case in which prices are perfectly flexible and adjust in response to supply and demand interactions in the product market. Imperfectly competitive firms will set prices by charging an optimal markup over their marginal costs. Labor is the only input in production, so that marginal costs are labor costs per unit of product, i.e. the wage rate (here denoted by $W$ ) divided by labor productivity $Z$. The markup charged by the firm is a function of its monopoly power in the product market, which, in itself, is a function of the firm variety's substitutability relative to all other varieties. Let $\theta$ denote the elasticity of substitution between different varieties of the consumption good. We assume that $\theta$ is sufficiently large - to capture the idea that varieties of the same consumption good are good substitutes for each other - but not "too" large (otherwise all varieties would substantially be similar in the eye of the consumers, and a firm would have no monopoly power at all in setting the price of its product). Specifically, we assume $1<\theta<\infty$.

The optimal price charged by the representative firm will then be:

$$
P^{\text {flex }}=\overbrace{\frac{\theta}{\theta-1}}^{\text {markup }} \overbrace{\frac{W}{Z}}^{\text {marg. costs }}
$$

Interpreting the expression above, if the elasticity of substitution $\theta$ were very high, prices would be equal to marginal costs $W / Z$. But if $\theta$ were relatively small (close to one), firms would face very inelastic demand curves for their products, and would be able to exploit their significant market power by charging very high prices relative to the production costs.

Moreover, with a perfectly competitive labor market, the equilibrium wage rate in units of consumption $(W / P)$ must be equal to the marginal rate of substitution between consumption

\footnotetext{
${ }^{4}$ In Section 4.2 we consider some examples of policy instruments corresponding to a given stance $\mu$.
} 
and leisure of the representative agent $(2) .^{5}$ It follows that the nominal wage is proportional to nominal spending:

$$
W=\kappa P C
$$

Combining (5) and (6), in equilibrium the profit-maximizing product price $P^{f l e x}$ is determined as follows:

$$
P^{\text {flex }}=\frac{\theta}{\theta-1} \frac{\kappa P^{\text {flex }} C}{Z}
$$

Now, replacing $C$ with $Z \ell$ according to (4) in the previous expression and rearranging, we obtain:

$$
\ell=\frac{\theta-1}{\theta \kappa} \equiv \bar{\ell}
$$

Equation (8) defines the 'natural' or 'potential' rate of employment, $\bar{\ell}$, as the level of employment that would prevail in an economy without nominal rigidities. ${ }^{6}$ The natural rate depends on agents' preferences about leisure, as captured by the parameter $\kappa$ : the lower is $\kappa$, the higher is households' supply of labor inputs to firms in equilibrium. It also depends on the monopolistic distortions in the economy: the higher is $\theta$, the lower is the equilibrium markup, and the higher is the equilibrium level of employment. Observe that, while the natural rate of employment is constant, the natural rate of output $Z \bar{\ell}$ (defined as output in an economy without nominal rigidities) will fluctuate as a function of productivity shocks $Z$.

In Figure 1, we plot equation (8) as the third schedule 'NR' or 'Natural Rate': a vertical line above the constant $\bar{\ell}$. In the flex-price equilibrium, the 'AD' and 'AS' schedules cross each other corresponding to the natural rate of employment. Once $C$ and $\ell$ are determined at the intersection of 'AS' and 'NR', the price level $P$ adjusts for any level of the current monetary stance $\mu$ to make sure that 'AD' intersects the other two schedules at the equilibrium point.

Macroeconomic adjustment is quite different with nominal price rigidities. In our setting, prices are not flexible in the short run. Rather, firms preset their prices and are unable to modify them once they observe the actual realizations of $W$ and $Z$. Under these conditions, the optimally chosen price level ${ }^{7}$ depends on expected marginal costs: ${ }^{8}$

$$
P=\frac{\theta}{\theta-1} E\left(\frac{W}{Z}\right)
$$

Of course, when prices are preset, unanticipated changes in marginal costs can reduce or raise the ex-post profits of the firm. ${ }^{9}$

\footnotetext{
${ }^{5}$ If the labor market were imperfectly competitive, there would be a wedge (labor market markup) between real wage and marginal rate of substitution, reflecting workers' market power.

${ }^{6}$ This result can be generalized to the case of non-linear disutility of labor effort. Suppose for instance that $U=\ln C-\kappa \ell^{1+\nu} /(1+\nu)$. In this case the natural rate of employment is a constant equal to $[(\theta-1) / \theta \kappa]^{1 / 1+\nu}$. For more general model specifications, the natural rate need not be constant, and consequently the graphical representation of the equilibrium allocation turns out to be less straightforward. For a generalization of our graphical apparatus to the case in which the natural rate depends on consumption see Corsetti and Pesenti (1997).

${ }^{7}$ As discussed in Appendix 1, product prices are optimally preset to maximize the discounted value of the firm's profits. While in general this problem is quite complex, it greatly simplifies in our setting.

${ }^{8}$ In what follows, $E(X)$ will refer to the expected value of the variable $X$ based on information available at the time expectations are taken. With one-period nominal rigidities, the expression $E(X)$ is shorthand for $E_{t-1}\left(X_{t}\right)$.
}

${ }^{9}$ The ex-post gross markup is $P /(W / Z)$, or $\theta(\theta-1)^{-1} E(W / Z) /(W / Z)$. As long as the shocks are not too 
We now show that, in a sticky-price environment, employment is equal to the natural rate only in expected terms. To see this, recall that $W=\kappa P C$ and $P C=\mu$ from (6) and (3). Combine these expressions with (9) to rewrite the optimal product price as follows:

$$
P=\frac{\theta \kappa}{\theta-1} E\left(\frac{\mu}{Z}\right)
$$

Next, multiply both sides by $C$ and use (4) and (3) to write:

$$
\mu=\frac{\theta \kappa}{\theta-1} E\left(\frac{\mu}{Z}\right) Z \ell
$$

Rearranging and taking expectations, we obtain:

$$
E(\ell)=E\left(\frac{\theta-1}{\theta \kappa} \frac{\mu / Z}{E(\mu / Z)}\right)=\frac{\theta-1}{\theta \kappa}=\bar{\ell}
$$

On average, expected employment is equal to its natural rate. An intuitive interpretation of (12) is that, in equilibrium, firms choose prices so as to insure that, on average, they will operate on their flex-price supply curve; we will return to this point in Section $4 .{ }^{10}$

To sum up: the 'Aggregate Demand' equation (3) relates nominal spending to the monetary policy stance. The 'Aggregate Supply' equation (4) relates aggregate supply to employment. Prices in the short run are set such that, in expectation, the economy operates along the 'Natural Rate' equation (12). In the long run, when prices are flexible, the 'NR' equation determines labor $\ell$, the 'AS' equation determines consumption $C$ given $\ell$ and $Z$, and the 'AD' equation (3) determines the price level $P$ given $C$ and $\mu$.

\subsection{Welfare properties of the market allocation}

With the help of our graphical apparatus, we now analyze the welfare implications of macroeconomic shocks and changes in structural parameters that shift the three schedules in Figure 1. Observe that, given the utility function (1), the indifference curves in the space $(\ell, C)$ are convex and upward sloping, with slope proportional to consumption according to (2). In Figure 1 the dashed curve is the indifference curve associated with the equilibrium. Utility is increasing as we move upwards or westwards, corresponding to higher consumption levels for any given labor effort, or lower labor effort for any given consumption level.

In the presence of monopolistic distortions in the product market, an economy operating at the natural rate $\bar{\ell}$ will not be Pareto efficient: ${ }^{11}$ the equilibrium level of employment and output will be suboptimally low, as firms contract their supply of goods to exploit their monopoly power and maximize their profits.

We can provide a simple graphical representation of this point. In Figure 1, the indifference curve that goes through the equilibrium point crosses the 'AS' locus from above. That is, at the equilibrium $C=Z \bar{\ell}$, the marginal rate of substitution (measured by the slope of

large, firms' ex-post markups will remain above one. Note that in a model without monopolistic distortions any increase in marginal cost would lower the ex-post markup below one, prompting firms to adjust their prices in response to the shock: in that framework, nominal rigidities would be inconsistent with the rational behavior of firms.

\footnotetext{
${ }^{10}$ In more complex models, expected employment need not be at the natural rate in any period. Nevertheless, optimal price setting is such that employment converges to the natural rate asymptotically.

${ }^{11}$ An allocation is Pareto efficient if there is no other allocation in which some other individual is better off and no individual is worse off.
} 
the indifference curve of the representative household) is smaller than the marginal rate of transformation (the slope of the aggregate supply locus):

$$
\left.\frac{d C}{d \ell}\right|_{d U=0, C=\bar{\ell}}=\left.\kappa C\right|_{C=\bar{\ell}}=\kappa Z \frac{\theta-1}{\theta \kappa}=Z \frac{\theta-1}{\theta}<Z
$$

This illustrates a general and crucial feature of economies with monopolistic power in production. Intuitively, due to monopolistic distortions, in equilibrium the disutility from a marginal increase in labor effort is lower than the utility from higher revenue.

In the absence of monopolistic distortions, the equilibrium in the model would correspond to a point in which the indifference curve is tangent to the 'AS' locus. To see this, assume that product varieties are highly substitutable, i.e. let $\theta$ become infinitely large, so that the monopoly power of firms is arbitrarily small. Expression (13) shows that in equilibrium the slope of the indifference curve will be identical to the slope of the 'AS' locus, and equal to $Z$. Indeed, the Pareto-efficient level of employment is $1 / \kappa$.

The previous point is illustrated in Figure 2. One can easily visualize the effect of structural reforms reducing monopolistic distortions in the economy as a rightward shift of the 'Natural Rate' vertical locus. The equilibrium moves from point $O$ to point $X$. As is apparent from (12), $\bar{\ell}$ is increasing in $\theta$, the elasticity of substitution across varieties that is inversely related to the size of the equilibrium markup in the economy. For any given productivity $Z$, a reduction in firms' market power raises output, and therefore consumption, towards their Pareto-efficient levels. For any given monetary stance $\mu$, the price level $P$ falls.

\section{Macroeconomic transmission and policy stabilization in closed economy}

In this section we use our apparatus to analyze the macroeconomic effects of productivity and monetary shocks. We address these issues in two steps. We first study the macroeconomic response to shocks when prices are flexible. Next, we reconsider the same shocks in the context of an economy with sticky prices, and compare the two equilibrium allocations. Throughout the analysis, we focus on positive shocks, defined as unexpected increases in $Z$ and $\mu$ (with the understanding that the analysis of negative shocks would be perfectly symmetric). ${ }^{12}$

\subsection{The equilibrium allocation under flexible prices}

Consider first the effects of a productivity boom when prices are fully flexible, as in (7). In this case, an increase in $Z$ does not affect the equilibrium level of employment, which remains constant at $\bar{\ell}$. Instead, a shock to $Z$ raises proportionally the equilibrium level of output for a given $\bar{\ell}$, generating excess supply in the economy. If nominal spending $\mu$ (and the wage rate $W$ ) does not change, marginal costs fall reflecting higher productivity. The price level $P$ then falls enough to boost consumption demand to the new level of output.

Figure 3 illustrates graphically the effect of the positive productivity shock just described. Let $O$ be the initial equilibrium allocation. An increase in $Z$ tilts the 'AS' locus upwards: higher productivity raises the level of consumption that is sustainable for any given employment level. With employment at $\bar{\ell}$ and no change in the monetary stance $\mu$, prices fall in

\footnotetext{
${ }^{12}$ A very preliminary list of references includes Christiano, Eichenbaum and Evans (1999, 2005), Clarida, Gali and Gertler (2000), Gali (2002), Goodfriend and King (2001), Walsh (2003) and Woodford (2003).
} 
response to the excess supply, shifting the 'AD' locus upward. The new equilibrium, $A$ in the Figure, corresponds to higher consumption (measured by the segment $O A$ ) and lower prices, while employment remains unchanged at its natural rate $\bar{\ell}$.

The effects of monetary shocks (exogenous changes in $\mu$ ) are straightforward: under flexible prices they have no effect on the equilibrium allocation. In fact, to the extent that $\mu$ and $P$ move instantaneously in the same proportion, consumption and the 'AD' locus in Figure 3 remain unchanged.

\subsection{Nominal price rigidities and the effectiveness of monetary pol- icy}

The equilibrium response to productivity shocks in an economy where prices are sticky in the short run is quite different from the flexible-price case characterized above. If $P$ cannot adjust, aggregate demand is pinned down by monetary policy $\mu$; without a change in nominal spending, consumption is constant in real terms during the period. Hence, fluctuations in productivity that are not matched by changes in aggregate demand necessarily translate into changes in short-run employment and output. Relative to the natural rate of employment and output, a positive productivity shock opens both an employment gap and an output gap.

Figure 3 illustrates these points. Without price flexibility, a productivity shock that rotates the 'AS' locus upwards does not translate into a fall in prices, and therefore is not matched by a proportional upward movement of the 'AD' locus. Unless $\mu$ is raised by the monetary authorities, the new short-run equilibrium will correspond to the point $B$ in which the new 'AS' locus crosses the (unchanged) 'AD' locus. Employment falls below $\bar{\ell}$ while output falls below $Z \bar{\ell}$. As shown in the Figure, a productivity shock opens an employment gap $O B$, which in our economy is proportional to the output gap $O A .{ }^{13}$ Note that the appropriate measure of output gap in our context is the difference between the amount of resources that could be produced and consumed under flexible prices, and the analogous amount in the presence of nominal rigidities.

Monetary policy can be effective in this framework. Provided monetary authorities are able to observe or predict $Z$ with accuracy, and can use appropriate policy instruments to control nominal spending, they can engineer a monetary expansion to raise $\mu$ and bring the economy to operate exactly as if prices were flexible. Figure 4 shows what happens when policymakers use monetary instruments to raise $\mu$ in proportion with $Z$ : the 'AD' curve shifts up by the amount $O A$ and closes the employment and the output gaps. As a result, the short-run inflexibility of prices does not prevent the economy from operating at the natural rate.

Note that the monetary stance that brings employment and output to their natural rates is expansionary when the economy experiences a productivity shock that opens negative employment and output gaps (by symmetry, it will be contractionary when an adverse productivity shock leads to overheating of the economy at unchanged demand conditions). Intuitively, the productivity boom makes an increased amount of resources potentially available for consumption. But if prices do not fall, consumers whose nominal incomes are un-

\footnotetext{
${ }^{13}$ With $P$ fixed during the period, there is no short-run inflation (deflation) in response to positive (negative) output gaps. However, one could obtain some responsiveness of the 'AD' schedule to productivity shocks by allowing for an imperfect degree of short-run price flexibility - without changing the message from our results above. For instance, if prices could partially respond to excess supply, a fall in the price level would somewhat raise the 'AD' schedule, moving the equilibrium allocation closer to the natural rate.
} 
changed are unable to purchase these additional products. Hence the need for a monetary stimulus, which generates additional aggregate demand and brings the economy back to potential.

Needless to say, once we move beyond the boundaries of our stylized framework and account for additional realistic elements, there are other possible policy trade-offs that make monetary policy less effective than suggested by the above analysis. Namely, monetary policy will not target 'exactly' the flex-price allocation in the presence of cost-push and sectoral shocks, dual wage and price rigidities, investment dynamics etc. Yet, the main principles established in this section remain largely valid.

\subsection{Optimal monetary policy}

To summarize, policymakers informed about the state of the economy $Z$ could use monetary instruments to move aggregate demand $C$ toward its flex-price level for a given price level $P$. Would such a policy conduct be optimal?

To address this question, we need to account for the endogenous response of optimal prices to the expected behavior of the policymakers. So far, we have used our apparatus to analyze the performance of the macroeconomy at given prices. Yet, as shown in (10) above, prices are endogenous: forward-looking firms set the prices of their products on the basis of their expectations about both economic fundamentals and policy variables. In what follows we analyze the implications of this price-setting process, and characterize the 'optimal' monetary stance chosen by welfare-maximizing monetary authorities able to make credible commitments.

To perform such an exercise, we need to specify a welfare metric: in our model, it is natural to assume that the objective function of the policymakers, here denoted by $\mathcal{W}$, coincides with the expected utility of the national representative agent:

$$
\mathcal{W}=E(U)=E(\ln C-\kappa \ell)
$$

Now recall that in a market equilibrium expected employment is constant and equal to its natural rate according to (12). Thus, using the equilibrium expression for optimal preset prices (10), the welfare criterion simplifies to:

$$
\begin{aligned}
\mathcal{W} & =E(\ln C)-\kappa \bar{\ell}=E(\ln \mu)-E(\ln P)-\kappa \bar{\ell} \\
& =E(\ln \mu)-\ln E\left(\frac{\mu}{Z}\right)+\text { constant }
\end{aligned}
$$

Maximizing the above expression with respect to $\mu$ yields:

$$
\frac{1}{\mu}-\frac{1 / Z}{E(\mu / Z)}=0
$$

solved by:

$$
\mu=\alpha Z
$$

where $\alpha$ is an arbitrary positive parameter that firms know when they set their prices. ${ }^{14}$

The previous condition characterizes the optimal monetary policy stance up to the scale of nominal variables in the economy. The optimal policy consists of a commitment to provide

\footnotetext{
${ }^{14}$ In expression (17), $\alpha$ need not be constant over time: it can represent any deterministic process that firms are able to predict at the time they take their expectations.
} 
a nominal anchor for the economy, $\alpha$, and to deviate from such stance only when productivity shocks in the economy threaten to destabilize marginal costs and move employment and output away from their potential levels. In our framework, by responding fully and systematically to $Z$, such policy completely eliminates uncertainty in marginal costs, and thus in profits. Prices are stabilized at the level $P=\alpha \kappa \theta /(\theta-1)$.

It is straightforward to restate the results above in terms of inflation rates, rather than price levels. Suppose that the monetary authorities set the nominal anchor according to:

$$
\alpha=P_{-1}(1+\tilde{\pi})
$$

where $P_{-1}$ is the lagged price level observed at the time expectations are taken, and $\widetilde{\pi}$ is the 'desired' rate of inflation - i.e. the (implicit or explicit) inflation target of the policymakers, which may be equal to zero. Given the above nominal anchor, in the absence of shocks $(Z=1)$ firms would optimally set their prices equal to $\alpha$ in each period: the economy would exhibit a constant inflation rate equal to $\widetilde{\pi}$ :

$$
\frac{P}{P_{-1}}=(1+\widetilde{\pi})
$$

But this is precisely the outcome that would prevail in the presence of shocks to $Z$, provided that the monetary authorities implement (17). In the next subsection, we show that this is not the case when the economy is subject to insufficient stabilization.

If monetary authorities deliver the optimal monetary stance (17), nominal rigidities are inconsequential, in the sense that policymakers can stimulate aggregate demand to close the output gap and push the economy toward potential regardless of stickiness in price adjustment. In terms of Figure 4, any stochastic rotation of the 'AS' locus is perfectly matched by a corresponding shift in the 'AD' locus, so that in the short run the equilibrium always lies along the 'NR' vertical line above the natural rate. Note that, under optimal monetary policy, consumption will not be constant but rather fluctuate with productivity, perfectly matching the flexible-price allocation.

\subsection{The costs of insufficient stabilization: inefficiently high markups and low purchasing power}

Having established what 'optimal policy' means in the framework of our model, we can now turn our attention to a different issue: what are the consequences of adopting a suboptimal monetary policy not aimed at full stabilization? We will show that insufficient stabilization translates into suboptimally high markups and price levels - making a case for 'price stability' in the design of optimal stabilization policies.

To provide a graphical treatment, without loss of generality consider an economy where $Z$ is a random variable that can rise or fall by the same amount with equal probability $1 / 2$, with $E(Z)=1$. Figure 5 depicts the two possible 'AS' lines, corresponding to a high and a low level of $Z$. They intersect the 'NR' locus at points $A$ and $A^{\prime}$, respectively. For convenience, we also draw the 'AS' line corresponding to the average level of productivity $E(Z)=1$. The latter intersects the 'NR' locus at point $O$, with $A O=O^{\prime} A$. Observe that, were the optimal policy (17) in place, employment would be constant at its natural level $\bar{\ell}$, and consumption would be high or low depending on the realization of the productivity shock.

We are interested in studying the equilibrium allocation when policymaking deviates from the optimal monetary stance. For instance, suppose that monetary authorities set the 
current stance according to:

$$
\mu=\alpha Z^{\xi}
$$

where $\xi$ is a constant parameter with $0 \leq \xi \leq 1$. Clearly, $\xi=1$ corresponds to the optimal policy response to shocks (17). For any value of $\xi$ different from one, the monetary response to shocks will be inefficient. We also assume that monetary authorities set $\alpha$ according to (18) above.

To focus sharply on our main message, it is convenient to carry out our analysis under the extreme assumption that $\mu$ does not respond at all to the output gap, i.e. $\xi=0$. With sticky prices, consumption will then be constant but employment will be fluctuating with $Z$ : it will be below the natural rate when the shock is positive, above the natural rate when the shock is negative. These points are illustrated in Figure 5, where we include two 'AD' lines, drawn for different price levels: the upper $\mathrm{AD}$ line is drawn for a price level $P_{B}$, the lower AD line for a higher price level $P_{F}>P_{B}$. The 'AD' locus corresponding to $P_{B}$ intersects the 'NR' locus at point $O$, the 'AD' locus corresponding to $P_{F}$ intersects the 'NR' locus at point $Q$ that lies below $O$.

For a constant monetary stance $\mu=\alpha$, consumption is lower when prices are equal to $P_{F}$. For each level of $P$, the short-run equilibrium lies where the corresponding 'AD' locus crosses either the lower 'AS' (if the shock is negative) or the higher 'AS' (if the shock is positive). When $P=P_{B}$ the economy operates either at $B$ or at $B^{\prime}$. When $P=P_{F}$ the economy operates either at $F$ or at $F^{\prime}$.

What will the equilibrium level of $P$ be? One may be tempted to conjecture that uncertainty does not affect prices: firms set prices equal to $P_{B}$, as if the productivity level were constant and equal to 1, i.e., the average of low and high productivity (recall in fact that $E(Z)=1$ ). The upper 'AD' line in Figure 5 has been drawn precisely under such assumption. Note that, corresponding to this 'AD' line, aggregate consumption is equal to the average of high and low consumption with flexible prices.

Is this an equilibrium? One could easily show that this is not the case by considering the pricing equation directly. ${ }^{15}$ There is however a more intuitive way to approach this issue by using our graphical apparatus. Recall that firms optimally preset prices to ensure that, on average, they operate on their supply schedule. As discussed above, an important implication of such behavior is that expected employment is equal to its natural rate. But Figure 5 clearly suggests that this condition is violated when pricing is done in reference to average productivity, i.e. when $P=P_{B}$. In fact, consider the two possible equilibria on the upper 'AD' line. When the productivity shock is positive, employment falls by the segment $B O$. But when the shock is negative, employment increases by a larger amount, equal to the segment $O B^{\prime}>B O$. Taking the average of the two employment levels with equal probability, it follows that at $P_{B}$ the expected employment gap will be positive, i.e.

${ }^{15}$ Holding $\mu=\alpha$, the equilibrium price level is:

$$
\left.P\right|_{\mu=\alpha}=\frac{\theta \kappa \alpha}{\theta-1} E\left(\frac{1}{Z}\right) \geq \frac{\theta \kappa \alpha}{\theta-1}
$$

since, with $E(Z)=1, E(1 / Z)>1$. As a straigthforward implications of the Jensen's inequality the optimal price is above our candidate expression on the right hand side: the preset price level is increasing in the variance of the productivity shock. An intuitive explanation of this result is the following. Uncertainty about marginal costs tends to reduce expected discounted profits (these are a concave function of productivity). However, by raising the preset price, a firm can reduce the sensitivity of discounted profit to shocks to marginal costs. 
expected employment will be above the natural rate:

$$
\left.E(\ell)\right|_{P=P_{B}}>\bar{\ell}
$$

In other words, at $P_{B}$ each firm is supplying "too much" relative to the level of output that maximizes its expected discounted profits. Each firm has therefore an incentive to cut back on its production plans, raising its price: $P_{B}$ cannot be the equilibrium price level.

Given the distribution of $Z$, equilibrium pricing always equates the average gap between employment and its natural rate to zero. In our example this principle has a simple geometrical interpretation: given the two 'AS' curves corresponding to the two different realizations of the productivity process, and holding $\mu$ constant, prices (and the 'AD' schedule) must be set such that the low and high employment allocations are perfectly symmetric around $\bar{\ell}$. In Figure 5, this happens in correspondence to the lower 'AD' curve, based on the higher price index $P_{F}$. In this case, when the productivity shock is positive employment falls by the segment $F Q$, and when the shock is negative employment increases by the segment $Q F^{\prime}$, where $F Q=Q F^{\prime}{ }^{16}$

Figure 5 sheds light on one of the key reasons why insufficient stabilization can reduce national welfare. Facing uncertainty in marginal costs, firms raise their average markups and charge higher prices for their products. As a result, households' purchasing power is suboptimally low: failure to stabilize the economy does not affect expected disutility from labor effort (which is kept constant by firms' optimal pricing), but does reduce the expected utility from consumption. ${ }^{17}$

By using the expression for optimal pricing, the equilibrium inflation will be:

$$
\frac{P}{P_{-1}}=(1+\widetilde{\pi}) E\left(\frac{1}{Z}\right)>(1+\widetilde{\pi})
$$

The inequality sign follows as a straightforward implications of Jensen's inequality. Higher markups and prices imply that the realized inflation rate will be higher than the targeted rate of inflation. Note that, since the growth of monetary stance is rebased in each period relative to the price level realized in the previous period, monetary authorities de facto let $\mu$ grow at a rate equal to the realized rate of inflation. Comparison of (19) with (22) highlights the reason why macroeconomic stabilization and price stability can be thought of as two faces of the same coin.

Observe that the above results can be easily generalized to economies where the deviation from the optimal policy is 'smaller', for some $0<\xi<1$ in (20). In this case monetary authorities somewhat react to productivity shocks. Yet, to the extent that they fall short

\footnotetext{
${ }^{16}$ Observe that, in our specification, there is an important difference in the macroeconomic implications of productivity uncertainty and noise in the conduct of monetary policy. Holding productivity constant, optimal pricing is not affected by the variance of $\mu$, but only by its expected value:$$
\left.P\right|_{Z \text { constant }}=\frac{\theta \kappa}{\theta-1} \frac{1}{Z} E(\mu)
$$

Hence monetary noise in the form of i.i.d. shocks to $\mu$ do not alter expected marginal costs. In terms of our graph, monetary noise translates into stochastic shifts of the 'AD' curve, raising or lowering consumption along the 'AS' curve. But, different from the case of productivity shocks, i.i.d. shifts of the 'AD' curve do not alter expected employment. This property does not hold for more general specifications of preferences. For instance, with a power utility in consumption, the level of prices will depend on monetary noise.

${ }^{17}$ In principle, one cannot rule out that for particular parameterizations of preferences and technology, suboptimal stabilization policies put downward pressure on prices. However, the specifications commonly adopted by the literature yield results consistent with the one discussed in the text.
} 
of stabilizing marginal costs and output completely, average markups and prices remain excessively and suboptimally high.

Furthermore, for any given suboptimal monetary policy, the higher the variance of the shock (the further away are the two 'AS' lines from each other in Figure 5), the higher the equilibrium price level (thus, the lower the equilibrium 'AD'). It follows that, for a given monetary stance, changes in the variance of the shocks from one period to another lead to adjustment in prices, creating temporary fluctuations of inflation.

\section{The closed-economy model: discussion and exten- sions}

\subsection{Time consistency and optimal policy}

Consider once again Figure 2, depicting an equilibrium at point $O$ where actual employment is at its natural rate. From our discussion above, we know that this allocation would prevail if the monetary authorities followed the policy rule (17). The problem with such allocation is that monopoly distortions result in a socially suboptimal level of welfare: in equilibrium the indifference curve cuts the 'AS' curve from above. Once prices are set, ex-post utility could be increased through a monetary expansion that moves the equilibrium to the right of $\bar{\ell}$, up to the point $X$ at which the indifference curve is tangent to the 'AS' locus. In other words, the 'optimal' monetary policy stance characterized above is not 'time consistent'.

To shed light on this point, consider what policymakers would do if they re-optimized their monetary stance in a discretionary manner once prices have been set. Define as $\mu_{\text {discretion }}$ the monetary stance that solves the problem:

$$
\max _{\mu}[\ln \mu-\ln P-\kappa \ell]
$$

Comparing (15) with the above expression, note that there is no expectation operator in (23): the monetary authorities now take expectations and prices as given, independent of their decisions. Accounting for (3) and (4), the first order condition of the above problem is:

$$
\frac{\mu_{\text {discretion }}}{P Z}=\frac{1}{\kappa}
$$

according to which the optimal monetary policy under discretion pushes labor effort $\ell$ towards its Pareto-efficient level $1 / \kappa$, as discussed in Section 2.2.

There is however a crucial problem in solving for an equilibrium with discretionary monetary policy in our setting. Using (24) to solve for $P$ in (10), we obtain:

$$
\frac{\mu_{\text {discretion }}}{Z}=\frac{\theta}{\theta-1} E\left(\frac{\mu_{\text {discretion }}}{Z}\right)
$$

This condition cannot be part of a rational-expectations equilibrium. In fact, take expectations on both sides of (25): the two sides are equal only when $\theta /(\theta-1)=1$, i.e. for $\theta \rightarrow \infty$. Otherwise, whatever the price level chosen by the firms, there is always an incentive for the policymakers to expand monetary policy above private expectations.

To obtain a rational expectations equilibrium, the above model could be modified to account for welfare costs from realized inflation in (23). ${ }^{18}$ This would correspond to the tra-

\footnotetext{
${ }^{18}$ For instance, in Albanesi, Chari and Christiano (2003) inflation leads to a costly reduction in consumption purchases because of the operation of the cash in advance constraint.
} 
ditional Kydland-Prescott/Barro-Gordon model of inflationary bias. ${ }^{19}$ Other contributions in the literature analyze monetary policy in economies where distortionary (Pigouvian) tax and subsidies can eliminate the distortions caused by monopoly power, hence making the optimal policy time-consistent. Suppose that the government could subsidize firms' production at the rate $(1-\zeta)^{-1}$, with $\zeta=1 / \theta$, raising tax revenue in a lump-sum fashion. Then firms' optimality will ensure that prices are equal to:

$$
P=\frac{\theta}{\theta-1}(1-\zeta) E\left(\frac{W}{Z}\right)=E\left(\frac{\kappa \mu}{Z}\right)
$$

Under these conditions, the monetary stance $\mu=\alpha Z$ is both the optimal rule as defined in (17) and the optimal monetary policy under discretion $\mu_{\text {discretion }}$ as derived in (24). The price level $P$ is equal to $\kappa \alpha$ and in equilibrium there is no longer an incentive for the policymakers to deviate from the optimal stabilization policy. The economy operates at an efficient (first-best) natural rate of employment, equal to $1 / \kappa$, such that the indifference curve in our graph is tangent to the 'AS' curve in equilibrium.

The intuition underlying this result is straightforward. There are two distortions in the economy: nominal price rigidities and monopoly power in production. The government needs at least two instruments to achieve efficiency: on the demand side of the economy, monetary policy eliminates the negative consequences of fixed prices; on the supply side of the economy, fiscal policy eliminates distortions due to monopolistic competition. The appropriate monetary and fiscal stance allows the policymakers to bring the economy to a first-best allocation.

\subsection{Monetary policy and interest rates}

So far we have characterized monetary policy in terms of an index of monetary stance $\mu$, but have intentionally left unspecified the issue of how policymakers can control $\mu$. We now provide some examples of policy instruments corresponding to a given stance $\mu$.

The most immediate case is one in which policymakers control money supply, while private agents' demand for real balances is proportional to consumption. In other words, the stock of money supply is set by the government at some level $M$, while aggregate money demand is equal to $\chi P C$, where $\chi$ is a positive constant. ${ }^{20}$ Now, by defining $\mu=M / \chi$, equilibrium in the money market takes the form of the 'AD' schedule (3). In this case, $\mu$ is simply proportional to the money stock: a monetary expansion leads to a one-to-one change in nominal spending.

What if the monetary authorities do not control monetary aggregates but rather set short-term nominal interest rates? Referring the reader to Appendix 1 for details, when private agents hold nominal bonds, their optimal consumption and bond holdings plans imply:

$$
\frac{1}{P C}=\beta(1+i) E\left(\frac{1}{P_{+1} C_{+1}}\right)
$$

In terms of our notation, this equation introduces two new terms. The parameter $\beta$ is the discount factor of the representative household: the lower is $\beta$, the higher the household's

\footnotetext{
${ }^{19}$ See the original articles Kydland and Prescott (1977), Barro and Gordon (1983a,b).

${ }^{20}$ Appendix 1 shows how this equation could be derived in terms of a straightforward optimization problem with logarithmic utility of consumption, as in expression (1), and real balances providing utility also in logarithmic form.
} 
impatience to consume. The term $1 / \beta$ can then be thought of as the 'natural' real interest rate in the economy. The term $1+i$ is the gross return on a nominal bond denominated in domestic currency, assumed to be directly controlled by the government. The optimality condition (27) is a standard Euler equation. On the left hand side we have the marginal utility of nominal wealth today. This has to be equal to the expected marginal utility of nominal wealth tomorrow (the term under expectations), adjusted to account for deviations of the current nominal interest rate $1+i$ from the 'natural' real rate of interest $1 / \beta$.

Using our definition $\mu=P C$, we can use (27) to derive the nominal interest rate corresponding to the implementation of monetary policies $\mu=\alpha Z^{\xi}$. We obtain:

$$
1+i=\frac{1}{\beta} \frac{\alpha_{+1}}{\alpha} \frac{1}{Z^{\xi} E\left(1 / Z_{+1}^{\xi}\right)}
$$

The nominal interest depends on three elements: the 'natural' real interest rate, $1 / \beta$; the evolution of the nominal anchor $\alpha_{+1} / \alpha$, reflecting the policy response to current and expected inflation or deflation; and the policy response to productivity shocks, both current and anticipated. The first element is exogenously given, independent of policymakers' decisions. The last element has been characterized in our analysis above: the nominal interest rate falls when $Z$ increases above its average, opening an output gap. ${ }^{21}$ This translates into a lower real interest rate, raising consumption demand in the short run. ${ }^{22}$

Regarding the evolution of $\alpha$, interest rate policy has to be chosen to rule out selfvalidating increases in inflation, and to guarantee a unique stationary rational expectations equilibrium. In other words, it is necessary that $P_{+1} / P$ converges to the inflation target $1+\widetilde{\pi}$ regardless of the current, observed level of inflation. When inflation grows above target, monetary authorities must react by raising nominal rates in the current period, and in all the future period until the price level has completely converged to the nominal anchor - counteracting the effect of expected inflation on current demand. This is the essence of the 'Taylor principle'. ${ }^{23}$ The economy will then approach a steady state such that:

$$
1+i=\frac{1+\tilde{\pi}}{\beta}
$$

\subsection{Inflation variability and the Phillips curve}

In the previous sections we have proceeded under the extreme assumption that no price adjustment is possible in the short run. However, we could revisit our analysis by allowing some partial adjustment of short run-prices towards their equilibrium levels. In doing so, we would derive a Phillips curve - that is, a positive relation between the output gap and current inflation.

Suppose that firms enter the period with a given price, but now this price can be modified after observing the realization of the shocks. Adjusting prices, however, entails costs that are increasing in the size of the adjustment. In this case each firm would choose to adjust its

\footnotetext{
${ }^{21}$ If the model allowed for productivity growth, the analysis would remain subtantially similar once the natural real interest rate is appropriately adjusted for the underlying trend.

${ }^{22}$ If the inflation target and the associated path for $a_{+1} / \alpha$ were too low, the fact that the nominal interest rate cannot be negative (a zero lower bound on the interest rate $i>0$ ) may complicate the implementation of optimal stabilization policy. See Clouse, Henderson, Orphanides, Small and Tinsley (2000), Krugman (1998), and Svensson (2003).

${ }^{23}$ See Taylor (1993) and Woodford (2001).
} 
price only partially. For simplicity, we can initially discuss the case in which the adjustment is symmetric across all firms. This slight modification of our setup enables us to discuss a few important results.

First, provided that the monetary authorities implement the optimal policy stance $\mu=$ $\alpha Z$, there will be no price adjustment in equilibrium. As shown above, the optimal monetary policy reacts to shocks by stabilizing marginal costs completely. But with constant marginal costs, there is no incentive for firms to change prices in the short run. We have seen above that optimal monetary policies make nominal rigidities irrelevant in equilibrium: the other side of the coin is that price flexibility is irrelevant too. At an optimum, the inflation rate will be constant, and equal to the desired inflation rate $\widetilde{\pi}$. There will be no inflation variability.

A second result is that insufficient stabilization will induce some short-run variability of inflation rates. Suppose in fact that monetary authorities deviate from the optimal rule (17), so that marginal costs are not completely stabilized. Facing unexpected fluctuations in their production costs, firms now have an incentive to modify their prices. Consider the case of a productivity slowdown (a fall in $Z$ ) that raises marginal costs. If prices do not adjust at all, we are back to the case discussed in Section 3, with large positive employment and output gaps. If prices adjust fully, the economy operates at potential and inflation rises above trend. In the intermediate case of partial price adjustment, the higher is the deviation of employment from the 'natural' rate, the higher is the pressure on prices to increase. The opposite will be true when marginal costs are low. From this vantage point, with partial adjustment of prices, our model generates a Phillips curve. ${ }^{24}$ Hence, productivity shocks that are not completely offset by monetary policymakers open output gaps. The latter are associated with fluctuations of inflation, above and below trend. In addition to raising the average markups, imperfect stabilization also raises the variability of inflation.

We have seen above that suboptimally high average markups are a component of the welfare costs of insufficient stabilization - leading to deviations of employment and consumption from their benchmark levels under price flexibility. However, there are other welfare components related to inflation variability. To the extent that the process of price adjustment requires real resources and absorbs labor inputs that would otherwise be employed in the production sector, inflation variability per se raises the average disutility of labor for any level of consumption. Most importantly, when price adjustment is asymmetric across firms, goods that are symmetric in preferences and technology - i.e., should have the same price in equilibrium - will have different prices in response to a shock. In this case, the dispersion of inflation rates in the economy will induce distortions in relative prices, reducing welfare. ${ }^{25}$

Throughout our exercise, we have considered economies where optimally designed stabilization policies can eliminate distortions associated with nominal rigidities. However, it is worth reiterating that this is generally not the case, as policymakers usually do not have enough instruments to reach their objectives, and therefore face policy trade-offs. For instance, among the examples most frequently discussed in the literature, cost-push inflation may prevent monetary policies from supporting efficient allocation with complete price stability.

\footnotetext{
${ }^{24}$ It is easy to verify that a positive exogenous monetary shocks will raise employment above its natural rate, inducing a temporary increase in inflation.

${ }^{25}$ Many contributions in the literature introduce nominal rigidities allowing for staggered price adjustment. In the popular model of Calvo adjustment - after Calvo (1983) - price dispersion and inflation dynamics are directly linked.
} 


\subsection{Fiscal shocks}

To conclude the presentation of the closed-economy model, we consider two modifications of our baseline setup. First, we modify the specification of the utility function (1) and pose:

$$
U=\ln C-\kappa \frac{\ell^{1+\nu}}{1+\nu}
$$

To the extent that $\nu$ is positive, the marginal disutility of labor effort is no longer a constant. The key implication of this modification is that an increase in labor effort is now associated with an increase in the real wage (and marginal cost). In fact, the wage equation (6) is now:

$$
W=\kappa P C \ell^{\nu}
$$

Second, we introduce public demand in the model and consider the macroeconomic effects of government purchases of goods financed with lump-sum taxes. ${ }^{26}$ In what follows, we define $g$ as the ratio of government spending to aggregate consumption, or:

$$
g=\frac{G}{C}
$$

How does our graphical apparatus change under the new assumptions? In the presence of government spending, the 'AS' equation (4) becomes:

$$
C(1+g)=Z \ell
$$

An increase in government spending tilts the 'AS' locus downward (similar to a negative productivity shock): for any given level of private consumption, agents need to work more to accommodate both private and public demand. There is no effect on the 'AD' locus, according to which only private nominal spending $P C$ is affected by the monetary stance $\mu$. In light of the previous section, this point is straightforward when the instrument of monetary policy is the nominal interest rate (in fact, equation (27) holds regardless of the presence of government spending). ${ }^{27}$ Finally, both modifications of the baseline model affect the natural rate 'NR' locus. In fact, it is possible to show that under flexible prices the natural rate is:

$$
\ell^{f l e x}=\bar{\ell}^{\frac{1}{1+\nu}}(1+g)^{\frac{1}{1+\nu}}
$$

where $\bar{\ell}$ is the same constant defined in (8). ${ }^{28}$

Figure 6 illustrates the effects of an unanticipated permanent fiscal expansion. The economy starts off at point $O$. In the short run, the increase in $g$ tilts the 'AS' locus downward. Since short-run prices are predetermined and (by assumption) there is no change

\footnotetext{
${ }^{26}$ Public spending can be assumed to be purely dissipative, with no impact on households' utility. Alternatively, it can be assumed that government spending enters households' utility in an additively separable way, so that an increase in public spending has no effect on the marginal utility of consumption or the marginal disutility of labor effort.

${ }^{27}$ Aggregate money demand may be a function of both private and public consumption. Under this assumption the 'AD' locus could still be independent of government spending, provided that fiscal expansions are accommodated by monetary policy.

${ }^{28}$ As the natural rate is now a stochastic function of fiscal shocks $g, E(\ell)$ can no longer be equal to the natural rate. In fact, one can show that:

$$
E(\ell)=\bar{\ell}^{\frac{1}{1+\nu}}[E(1+g)]^{\frac{2+\nu}{1+\nu}}\left[E(1+g)^{1+\nu}\right]^{-\frac{1}{1+\nu}}
$$
}


in the monetary stance, consumption does not change either. Instead, the economy moves along the 'AD' locus, and employment increases in tandem with government spending by an amount $O A .{ }^{29}$ In the long run, real wages and marginal costs adjust upward to reflect the permanent increase in demand for goods. As a result, output increases by less than public spending, so that the supply of goods available for private consumption goods falls while prices increase.

In Figure 6, the higher real wages shift the 'NR' locus to the right: for any level of consumption, agents are now willing to supply more labor. At the same time, prices $P$ increase for any level of the monetary stance $\mu$, so that the 'AD' locus shifts downward. Thus, the economy reaches an equilibrium such as point $\mathrm{B}$, corresponding to lower consumption and higher output levels relative to the initial allocation (point $O$ ): higher public spending crowds out private spending and generates inflation. In welfare terms the new allocation is Pareto inferior to the previous equilibrium, unless there are direct utility gains from higher public consumption.

\section{Exchange rates and prices in open economy: more building blocks}

We now extend our analysis to the study of interdependent, open economies. Relative to the closed-economy model analyzed above, there are at least two new important features to consider.

First, firms sell now in two markets, both domestically and abroad. Modelling nominal rigidities thus raises important issues about firms' pricing behavior. Are product prices preset in the domestic currency only? Or, rather, do firms fix two sets of prices, one for the domestic market and the other for the export market (provided that product markets are sufficiently segmented so that agents cannot arbitrage price differentials)?

A second difference is that, in addition to the macroeconomic distortions associated with nominal rigidities and monopoly power in production, there is now a new distortion related to a country's monopoly power on its terms of trade, that is, the relative price of foreign traded goods in terms of domestic traded goods. In fact, firms ignore the impact of their pricing and production decisions on the country's overall terms of trade. A decentralized equilibrium reflects this inefficiency, adding a further dimension to the policy problem.

In what follows we build a two-country general-equilibrium theoretical framework. Our graphical apparatus in the two-country case is to a large extent similar to the one developed for closed-economy analysis. However, because of a number of features specific to interdependent economies, we will modify the interpretation of several variables, and reconsider our results about the design of efficient stabilization policies.

\subsection{Extending the basic model to the world economy}

The world economy consists of two countries of equal size, Home and Foreign, each producing a country-specific type of good that is traded worldwide. ${ }^{30}$ Countries and types of goods are denoted by the same letter, $H$ and $F$, respectively. Similar to the closed-economy

\footnotetext{
${ }^{29}$ Notice that the output multiplier of a government expansion is 1. To obtain 'Keynesian' fiscal multipliers above one the model needs to be modified e.g. to allow for non-optimizing agents, or overlapping generations of households.

${ }^{30}$ For a multi-country extension of the model see Corsetti, Pesenti, Roubini and Tille (2000).
} 
case, in each country monopolistic competitors produce imperfectly substitutable varieties of the same national good, employing a linear technology with labor as the only input in production.

Households consume both national and foreign goods. In both countries the elasticity of substitution between different varieties of the same type of goods $(\theta)$ is higher than the elasticity of substitution between types of goods $H$ and $F$, that we posit equal to one. ${ }^{31}$

In each country there is a country-specific productivity shock. To the extent that macroeconomic shocks are not perfectly correlated across countries, national residents in the two countries benefit from having access to some kind of risk-sharing mechanism. For simplicity, and to minimize analytical differences with respect to the closed-economy case, we proceed by positing from the start that assets markets are complete, so that agents can achieve full consumption risk-sharing through a system of transfers contingent to the realization of the shocks. ${ }^{32}$

In terms of notation, we adopt the convention that prices denominated in Foreign currency as well as quantities chosen by Foreign firms and households are denoted with a star. So, the Home and Foreign consumer price indexes are denoted by $P$ and $P^{*}$ respectively, employment levels by $\ell$ and $\ell^{*}$, aggregate consumption levels by $C$ and $C^{*}$. Home consumption $C$ is a symmetric basket of the two country-specific goods: $C_{H}$ is Home consumption of the Home good, and $C_{F}$ is Home consumption of the Foreign good. By the same token, $C_{F}^{*}$ is Foreign consumption of local varieties and $C_{H}^{*}$ denotes Foreign imports from the Home country. The prices of the two goods are $P_{H}$ and $P_{F}$ in the Home countries, and $P_{H}^{*}$, and $P_{F}^{*}$ in the Foreign country. The nominal exchange rate is $\mathcal{E}$, defined as Home currency per unit of Foreign currency - so that an increase in $\mathcal{E}$ represents a depreciation of the Home currency. The two country-specific productivity shocks are $Z$ and $Z^{*}$. Finally, we denote the country-specific monetary stances with $\mu$ and $\mu^{*}$.

A synthesis of the model (except the equations determining prices) is given in Table 1. It is also illustrated in Figure 7, with the Home country on the left and the Foreign country on the right. As for the closed-economy case, the monetary stance in each country synthesizes the effect of monetary policy on nominal spending. Hence the 'AD' schedule (first row of Table 1) is formally identical to the 'AD' in the previous sections. However, private spending on consumption now falls on both Home and Foreign goods. As shown by the second and third rows in Table 1, nominal spending on consumption is equally divided between domestically produced goods and imports, consistent with the assumption of symmetric consumption baskets. Hence, relative to the closed economy case, the domestic price level is an equally-weighted index of domestic and import prices (fourth row of Table 1). ${ }^{33}$

The 'AS' schedule (fifth row of Table 1) is also different from the closed-economy case, since it now translates the supply of domestic goods into the consumption of both domestic

\footnotetext{
${ }^{31}$ See Tille (2001) for a theoretical extension of this setup and Bergin (2003) for an empirical assessment of similar models.

${ }^{32}$ Appendix II however discusses an important property of our model: if the initial net wealth is equal to zero in both countries, our results below are independent of the asset market structure.

${ }^{33}$ For this reason, nominal price rigidities do not necessarily rule out endogenous fluctuations in the consumer price indexes $P$ and $P^{*}$, which may reflect movements in import prices in response to appreciation or depreciation of the currency. For instance, given $\mu$, an increase in $\mathcal{E}$ may raise the Foreign good price in domestic currency, thus reducing Home aggregate demand. However, such 'imported inflation' would affect not only the level, but also the composition of consumer demand. In fact, Home consumption would switch in favor of the now cheaper domestic good.
} 
Table 1: The open-economy model

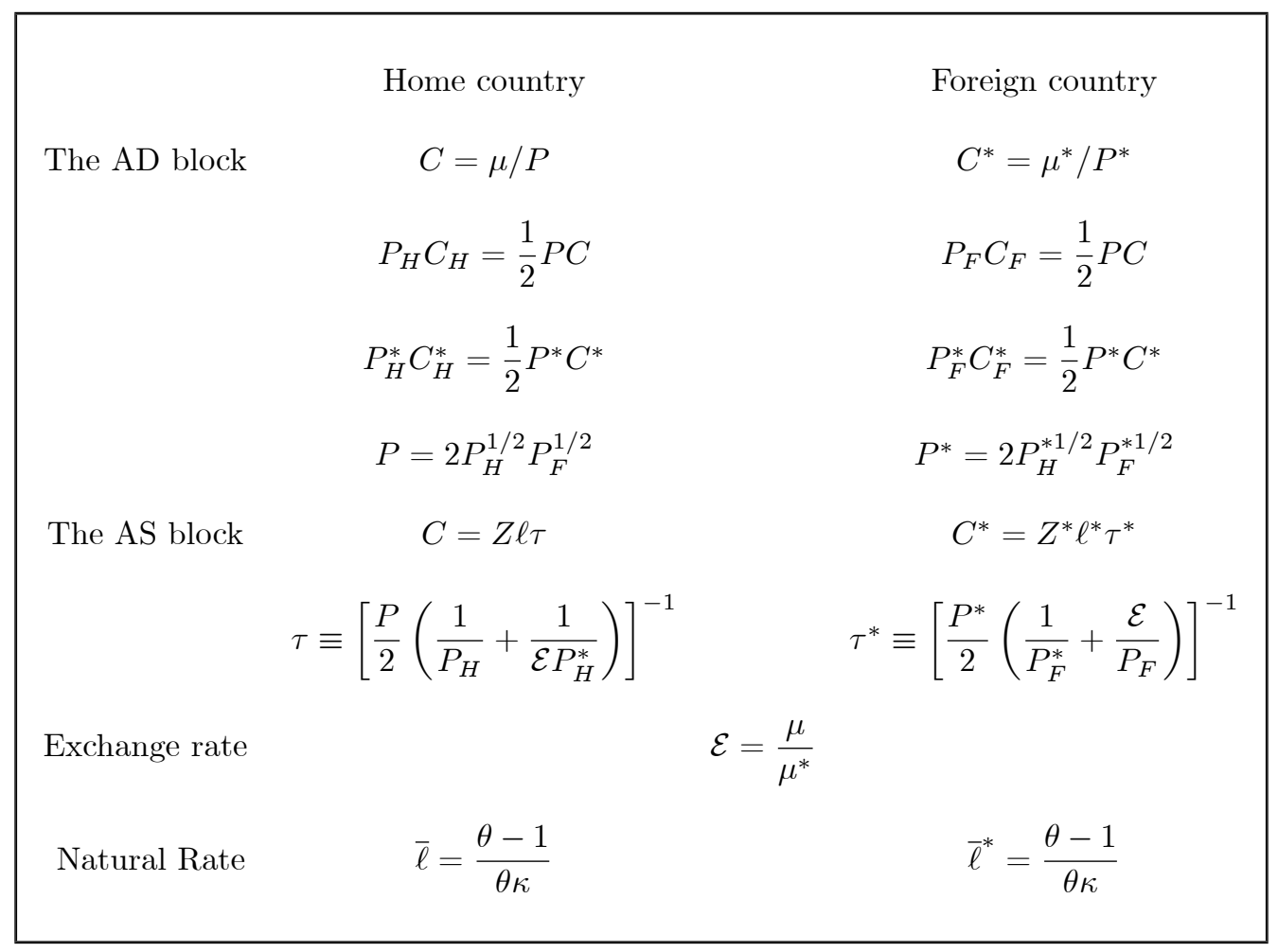

and imported goods. The Home (Foreign) 'AS' schedule includes the new term $\tau\left(\tau^{*}\right)$, defined in the sixth row of Table 1. To understand this term, observe that at current prices it takes $1 / \tau$ units of Home output to buy one unit of the Home consumption basket $C$ (a symmetric definition applies to the Foreign economy).

Clearly, the price of consumption in terms of output is a function of the terms of trade between the two countries, customarily defined as the price of imports in terms of the price of exports, or $P_{F} /\left(\mathcal{E} P_{H}^{*}\right)$. For instance, a lower international price for the Home good (an increase in $P_{F} /\left(\mathcal{E} P_{H}^{*}\right)$ ) worsens the Home terms of trade and reduces $\tau$, causing a downward rotation of the 'AS' schedule. For any level of Home consumption, Home output and employment must now rise. So, in an open-economy context the 'AS' can tilt downward either because of negative productivity shocks (which are exogenous), or because of relative price movements worsening the terms of trade (which are endogenous).

Finally, in our economy the nominal exchange rate only depends on the relative monetary stance (last row of Table 1). This result is a direct consequence of complete markets, as with full risk-sharing the ratio of the marginal utilities of Home and Foreign consumption in any state of nature must be proportional to the relative price of consumption (i.e. the 
real exchange rate). ${ }^{34}$ In terms of our notation we have:

$$
\frac{\partial U / \partial C}{\partial U^{*} / \partial C^{*}}=\frac{P^{*} \mathcal{E}}{P}
$$

Given the specification of utility in (1) and its Foreign analog, the previous expression can be written as:

$$
\frac{C^{*}}{C}=\frac{P^{*} \mathcal{E}}{P}
$$

so that, accounting for the 'AD' equations, $\mathcal{E}=\mu / \mu^{*}{ }^{35}$

As in the closed-economy model, in the absence of nominal rigidities firms charge an optimal fixed markup over marginal costs. It is straightforward to show that with linear technologies and constant-elasticity demand functions, there is no incentive for a firm to price-discriminate across markets. Thus, the four equations determining the four (flexible) prices $P_{H}^{\text {flex }}, P_{F}^{\text {flex }}, P_{H}^{* \text { flex }}, P_{F}^{* \text { flex }}$ are:

$$
\begin{aligned}
P_{H}^{\text {flex }} & =\mathcal{E} P_{H}^{* \text { flex }}=\frac{\theta \kappa}{\theta-1} \frac{\mu}{Z} \\
P_{F}^{* \text { flex }} & =\frac{P_{F}^{\text {flex }}}{\mathcal{E}}=\frac{\theta \kappa}{\theta-1} \frac{\mu^{*}}{Z^{*}}
\end{aligned}
$$

Once again, the natural employment rates in both countries can be easily calculated using these expressions together with the 'AD' and 'AS' equations.

\subsection{Nominal rigidities and the pricing of exports}

To sum up: the 'AS' is a line through the origin. Its slope includes a term reflecting movements in the terms of trade of a country. The natural rate locus is identical in both the closed- and open-economy versions of our model - a property that will be very useful in carrying out comparative analysis of our results. The 'AD' is formally identical to the closed-economy case - it draws a horizontal line in the $(\ell, C)$ or $\left(\ell^{*}, C^{*}\right)$ space depicted in Figure 7. However, in a closed economy, one-period nominal rigidities imply that the consumer price index is fixed in the short run. This may not be necessarily the case in an economy open to international trade: the price level may now adjust in the short run - despite nominal rigidities - per effect of fluctuations in import prices driven by the exchange rate.

The recent literature has revived an important debate about the empirical evidence on the response of prices to exchange rate movements, providing different possible approaches to model nominal rigidities in an open economy. Empirically, we have a limited knowledge of the elasticity of exchange rate pass-through onto import (export) prices. What we know is that it is on average below 1 , that it varies across sectors and countries, and is different for consumer goods and wholesale prices. ${ }^{36}$ Considered as a decision variable of the exporter, the determinants of exchange rate pass-through may clearly include some of the variables

\footnotetext{
${ }^{34}$ The constant of proportionality depends on structural parameters such as asymmetric degrees of openness. In our model it is equal to 1 .

${ }^{35} \mathrm{With}$ complete markets, the current account is implicitly defined as the change in net asset positions required to achieve the allocation (35). Therefore, in the solution of the model there is no need to add the current account equation explicitly.

${ }^{36}$ See the discussion in Goldberg and Knetter (1997) and Obstfeld and Rogoff (2000). Campa and Goldberg (2002) provide updated estimates of exchange rate pass-through across countries.
} 
considered in our model - such as the volatility of monetary and real shocks, as suggested by Taylor (2000) and analyzed by Corsetti and Pesenti (2002) in the context of optimal monetary rules, and by Devereux, Engel and Storgaard (2004) in non-optimizing models. But it may reasonably depend on many other factors outside the scope of our contribution - such as the exporter-importer working relationship stressed in the relationship-marketing literature, the presence of distribution costs as in Corsetti and Dedola (2005) and Laxton and Pesenti (2003), the size of the market share as in Bacchetta and Van Wincoop (2005), or the availability of financial strategies to limit exposure of exporters' profits to exchange rate fluctuations as in Friberg (1998).

In this paper, however, we mainly link the degree of pass-through to the invoice currency in the presence of nominal rigidities. We will discuss three possible specifications of export prices consistent with such an approach — we assess policy implications in more general models in Section 8.2. below.

'Producer Currency Pricing' (PCP) In a first class of models, firms preset prices in their own currency and let prices abroad move one-to-one with the exchange rate. ${ }^{37}$ Since export prices are set in the producer's currency, the literature often refers to this case as 'Producer Currency Pricing', or PCP. With PCP, firms optimally set:

$$
\begin{aligned}
& P_{\mathrm{H}}=\mathcal{E} P_{\mathrm{H}}^{*}=\frac{\theta \kappa}{\theta-1} E\left(\frac{\mu}{Z}\right) \\
& P_{\mathrm{F}}^{*}=\frac{P_{\mathrm{F}}}{\mathcal{E}}=\frac{\theta \kappa}{\theta-1} E\left(\frac{\mu^{*}}{Z^{*}}\right)
\end{aligned}
$$

Observe that there is one-to-one pass-through of exchange rate movements onto the price of imports, at both the border and the consumer-price level. Hence, once measured in the same currency, goods prices are identical in all markets and the 'law of one price' holds.

Under PCP, the terms of trade $P_{F} / \mathcal{E} P_{H}^{*}$ are equal to $P_{F}^{*} \mathcal{E} / P_{H}$. Since $P_{H}$ and $P_{F}^{*}$ in (39) and (40) are preset, the Home terms of trade worsen with a nominal depreciation of the Home currency (i.e. a higher $\mathcal{E}$ ). The same nominal depreciation of the Home currency will instead appreciate the Foreign terms of trade. Thus, when the Home currency weakens, Home goods are cheaper relative to Foreign goods in both the Home and the Foreign country. As demand shifts in favor of the goods with the lowest relative price, world consumption of Home goods increases relative to consumption of Foreign goods. These are referred to as 'expenditure switching' effects of exchange rate movements.

'Local currency pricing' (LCP) According to a second class of models, firms preset a price in domestic currency for the domestic market, and a price in foreign currency for the export markets. ${ }^{38}$ Since export prices are preset in the consumers' currency, the literature often dubs this case as 'Local Currency Pricing', or LCP. With LCP firms optimally set:

$$
\begin{array}{ll}
P_{H}=\frac{\theta \kappa}{\theta-1} E\left(\frac{\mu}{Z}\right) & P_{H}^{*}=\frac{\theta \kappa}{\theta-1} E\left(\frac{\mu}{\mathcal{E} Z}\right) \\
P_{F}^{*}=\frac{\theta \kappa}{\theta-1} E\left(\frac{\mu^{*}}{Z^{*}}\right) & P_{F}=\frac{\theta \kappa}{\theta-1} E\left(\frac{\mu^{*} \mathcal{E}}{Z^{*}}\right)
\end{array}
$$

\footnotetext{
${ }^{37}$ See e.g. Obstfeld and Rogoff (1995, 1996 ch.10) and Corsetti and Pesenti (2001).

${ }^{38}$ See e.g. Bacchetta and van Wincoop (2000), Betts and Devereux (2000), Chari, Kehoe and McGrattan (2002), and Duarte and Stockman (2005).
} 
Exchange rate pass-through onto import prices is zero both at the border- and the consumerprice level. The law of one price is violated with any unanticipated fluctuation of the exchange rate: unless the exchange rate is fixed or perfectly forecastable, the consumer price of the Home good in domestic currency $P_{H}$ will be different from its export price in Home currency $\mathcal{E} P_{H}^{*}$. Analogously, the consumer price of the Foreign good in Foreign currency $P_{F}^{*}$ will be different from its export price in Foreign currency $P_{F} / \mathcal{E}^{39}$

Observe that, with $P_{H}^{*}$ and $P_{F}$ predetermined and therefore fixed in the short run, a nominal depreciation of the Home currency improves the Home terms of trade $P_{F} / \mathcal{E} P_{H}^{*}$. Correspondingly, the Foreign terms of trade worsen. The effects of currency movements on the terms of trade go in the opposite direction relative to the PCP case. Since prices are preset in local currency, exchange rate fluctuations do not affect the relative price faced by importers and consumers. There is no 'expenditure switching' effect of exchange rate movements.

'Dollar pricing' (DP) While the literature has mainly focused on the previous two polar cases, there is also a third possibility (probably the most relevant one from an empirical viewpoint): the world export prices are set in one 'vehicle' currency only, say, in the Home country's currency. Home firms preset all prices in their own currency; Foreign firms preset export prices in the Home currency. ${ }^{40}$ In this case - that we dub 'dollar pricing' or DP we have:

$$
\begin{aligned}
& P_{H}=\mathcal{E} P_{H}^{*}=\frac{\theta \kappa}{\theta-1} E\left(\frac{\mu}{Z}\right) \\
& P_{F}^{*}=\frac{\theta \kappa}{\theta-1} E\left(\frac{\mu^{*}}{Z^{*}}\right) \quad P_{F}=\frac{\theta \kappa}{\theta-1} E\left(\frac{\mu^{*} \mathcal{E}}{Z^{*}}\right)
\end{aligned}
$$

In the DP case the law of one price only holds for the Home country products. Exchange rate pass-through is asymmetric: it is zero in the Home country, but complete in the Foreign country. Thus, a Home depreciation does not affect the price of imports in the Home country, but lowers the price of imports in the Foreign country. Interestingly, however, the benefits of lower prices and higher purchasing power for the Foreign country consumers are offset by the profit losses of Foreign firms and shareholders. In fact, Foreign firms that export to the Home country sell their products at the price $P_{F}$ - which is fixed in the short run - but repatriate their export sales revenue at the rate $1 / \mathcal{E}$ - which falls with the Home currency depreciation.

Export pricing and the natural rate We conclude this section by noting an important property of the model. Independent of which pricing specification is selected among the three possibilities described above, expected employment is always equal to its natural rate - exactly as in the closed economy. As a straightforward implication of the equations presented above, we have in fact:

$$
E(\ell)=E\left(\ell^{*}\right)=\frac{\theta-1}{\theta \kappa}
$$

for any characterization of the nominal rigidities in the export markets.

\footnotetext{
${ }^{39}$ It is worth restating that, for these differences to be a feature of a market equilibrium, one needs to assume that no agent in the economy can take advantage of arbitrage opportunities in the goods markets.

${ }^{40}$ A similar framework is considered in Devereux, Engel and Tille (2003).
} 


\section{Macroeconomic transmission and policy stabilization in open economy}

In this section we study the international transmission of country-specific productivity shocks. Similar to the closed-economy case, we start by considering the allocation with flexible prices, which provides a benchmark to guide our policy analysis below. Next, we study the equilibrium allocation when policymakers react to shocks by pursuing policies that stabilize output and employment at their natural rate - the policy conduct that we found 'optimal' in a closed-economy context. We conclude by discussing whether and to what extent optimal rules in open economy deviate from their closed-economy counterparts.

\subsection{The equilibrium allocation under flexible prices revisited}

Figure 8 illustrates the macroeconomic response to a positive productivity shock in the Home country, assuming that prices are perfectly flexible. On impact, a positive shock to $Z$ rotates the 'AS' schedule upward. We have seen that the natural rate of employment is independent of productivity shocks. Hence, in an equilibrium without price rigidities higher productivity raises consumption along the 'NR' locus. Different from the closed economy case, however, the higher supply of Home goods lowers their international price: the terms of trade move against the Home country. ${ }^{41}$

The fall in $\tau$, that reflects worsening terms of trade, tilts the 'AS' schedule downward, partially offsetting the upward rotation of the 'AS' due to a positive $Z$ shock. In other words, relative to the closed-economy case, a shock to $Z$ makes the 'AS' rotate by less. For any given Home monetary stance $\mu$, the Home CPI $P$ falls, although by less than the domestic price of Home goods $P_{H}$. Hence the 'AD' shifts upwards, but not as far as it would in a closed economy. The equilibrium moves from point $O$ to point $A$.

Part of the gains from higher productivity in the Home country accrue to consumers abroad. The fall in the international price of Home goods raises Foreign incomes in real terms. Because of lower import prices, the Foreign terms of trade are stronger, raising $\tau^{*}$ : the 'AS*' rotates upward. Lower import prices also lower the Foreign CPI $P^{*}$, raising consumption demand along with the 'AD*' schedule. The equilibrium in the Foreign country moves from point $O^{*}$ to point $A^{*}$. Overall, Foreign consumption increases while employment remains at its natural level. This is an unambiguous welfare gain for the Foreign economy. The international transmission of productivity shocks is clearly positive.

Similarly, we can use our graph to analyze the international implications of structural policies that reduce the degree of monopoly power asymmetrically in the Home country. In Figure 9, lower distortions in the Home economy raise the natural rate of employment domestically. For a given productivity, a higher supply of Home goods leads to a drop in the equilibrium terms of trade of the Home country: the 'AS' is now less steep. Moving from point $O$ to point $A$, Home households consume and work more, as in the closed economy case. ${ }^{42}$ But some of the benefits of the reform leak abroad: better terms of trade for the

\footnotetext{
${ }^{41} \mathrm{~A}$ new generation of models are revisiting the implications of productivity shocks on the terms of trade when accounting for creation and trade of new product varieties. The analysis of this section only focuses on the 'intensive' margin of trade, that is the international performance of sectors producing a given set of varieties, without studying the 'extensive' margin associated with new traded products. See Bergin and Glick (2003), Ghironi and Melitz (2004), and Corsetti, Martin and Pesenti (2005).

${ }^{42}$ Observe however that worsening terms of trade reduce the Home benefit from the reform, relative to the closed economy case.
} 
Foreign country (an upward shift in 'AS') enable Foreign households to consume more at an unchanged natural rate of employment: the Foreign equilibrium moves from $O^{*}$ to $A^{*}$, with a net welfare gain. This is an example of (long-run) positive spillovers from structural reforms or supply-side policies that are effective in reducing monopolistic distortions. ${ }^{43}$

\subsection{Productivity shocks in open economies with nominal rigidities}

As in the closed-economy model, with nominal rigidities the macroeconomic impact of country-specific productivity shocks is sharply different. An unexpected increase in Home productivity does not move the nominal exchange rate, which only responds to monetary factors. Hence the shock has no impact on import prices, which are either sticky (as in LCP case) or move with the exchange rate (as in the PCP case). With no changes in prices and the CPI, aggregate demand is constant in real terms in both countries. Higher domestic productivity at Home therefore translates into a lower level of domestic employment precisely as in the closed-economy case. Without changes in the exchange rate, there are no consequences for the Foreign economy.

The previous point can be restated in graphical terms (see Figure 10): other things equal, a positive shock to Home productivity rotates the 'AS' upward and opens an employment/output gap. The equilibrium moves from point $O$ to point $B$. Consumption is not affected, economic activity is too low - exactly as in Figure 3. The Foreign economy remains completely unchanged at point $O^{*}$.

Note that this result holds regardless of the specification of nominal rigidities in the export markets (i.e. PCP or LCP or DP). In all cases, productivity shocks have no direct effect on prices and exchange rates. But as for the closed economy, shocks that translate into undesirable employment fluctuations, and open employment and output gaps, invite a monetary policy response. Thus, productivity shocks may have an indirect effects on prices, via changes in the monetary stance aimed at stabilizing the macroeconomy.

\subsection{Stabilization properties of the exchange rate (the PCP model)}

In our analysis of the closed economy we have seen that, when monetary authorities react to productivity shocks by closing the output gap completely, the market equilibrium coincides with the flex-price allocation. Is monetary policy equally effective in our open-economy setting? To answer this question we need to focus on the role of exchange rate movements in the international transmission.

The conventional wisdom exemplified by the enduring contributions of Friedman (1953) and Mundell (1963) suggests that, in a world with nominal price rigidities, exchange rate movements facilitate the efficient adjustment of international relative prices. With flexible prices, the relative price of Home goods falls in response to a positive productivity shock. With sticky prices, adjustment can be achieved via an exchange rate depreciation (corresponding to Home monetary expansion relative to Foreign), that lowers the international price of the Home goods relative to Foreign goods.

To revisit the theoretical foundations of the conventional wisdom, we now consider our open-economy model with PCP (the first of the three export pricing specifications discussed above): Home (Foreign) firms preset their prices in domestic currency and let the Foreign(Home-) currency export price fluctuate with the nominal exchange rate. We focus on the

\footnotetext{
${ }^{43}$ See Bayoumi, Laxton and Pesenti (2004) for an application of this analysis to the net benefits of structural reforms in the euro area and their spillovers to the trading partners.
} 
following scenario. There is an unexpected, positive increase in productivity in the Home country. Home monetary policymakers are assumed to adopt an 'inward-looking' policy rule, and set the monetary stance to stabilize the domestic markup and close the output gap opened by productivity fluctuations. Foreign monetary policymakers maintain a constant monetary stance. This scenario provides a useful baseline for our analysis of the international transmission mechanism. Note that we have said nothing about the optimality of the policy responses described above: in this and the next two sections we take these monetary rules as given and analyze their macroeconomic properties. Later, we discuss whether these policies can be rationalized as welfare-maximizing.

The experiment is illustrated in Figure 11. The positive productivity shock at Home rotates the 'AS' upward, but when the monetary authorities respond to the shock by loosening the monetary stance, the exchange rate depreciates and the terms of trade fall, lowering $\tau$ : a drop in $\tau$ offsets in part the rotation of the 'AS' due to $Z$. At the same time, looser monetary conditions (a higher $\mu$ ) shift the 'AD' upward, but less than one-to-one. This is because, to the extent that import prices rise with exchange rate depreciation, the country experiences some CPI inflation. The Home economy moves from $O$ to $P$ along the 'NR' schedule.

The exchange rate depreciation in the Home country improves the terms of trade abroad: a higher $\tau^{*}$ rotates the 'AS*' upward. Note that the 'AS*' rotation does not reflect any improvement in Foreign productivity ( $Z^{*}$ remains constant). Lower import prices translate into a fall of the Foreign CPI. For a given Foreign monetary stance $\mu^{*}$, a fall in the price level raises demand, shifting the 'AD"' curve upwards. The Foreign economy moves from point $O^{*}$ to point $P^{*}$ along the ' $\mathrm{NR}^{*}$ ' schedule, mirroring the adjustment of the Home economy. In the new equilibrium, Foreign households enjoy a higher level of consumption for an unchanged level of labor effort. The international transmission of Home shocks is unambiguously positive.

In our open-economy model with PCP, the same policy prescription as in the closedeconomy case $(\mu=\alpha Z)$ replicates the allocation with flexible prices: while closing the Home employment gap completely, it raises consumption at Home and abroad in proportion to productivity. Given that employment remains constant in equilibrium, higher Home productivity $Z$ means a higher world supply of Home goods. In an efficient allocation, their prices must drop. With nominal prices sticky in domestic currency, it is the exchange rate that induces the efficient adjustment in relative prices, re-directing world demand towards the more abundant product. Thus, under PCP exchange rate movements are stabilizing. We should note however that, since the exchange rate is equal to the relative monetary stance, the 'right' price adjustment through the exchange rate depends on the 'right' conduct of monetary policy. ${ }^{44}$

\subsection{Market segmentation and imperfect pass-through (the LCP model)}

According to the conventional view, exchange rate movements modify the relative price of domestic and imported goods. However, empirical studies and casual observation suggest

\footnotetext{
${ }^{44}$ From a global perspective, the effect of the Home monetary expansion can be broken down into two components. The first component is symmetric and affects the level of world demand: a looser monetary stance at Home translates into a looser monetary stance for the world economy as a whole, raising consumption worldwide. The second component is instead asymmetric and affects the composition of world demand. The monetary stance is relatively more expansionary at Home, depreciating the exchange rate, and redirecting world demand towards Home goods.
} 
that, in practice, the prices of most imported goods at the consumer level are rather inelastic to exchange rate movements. ${ }^{45}$ Then, exchange rate movements may not induce the important expenditure switching-effects that the conventional view places at the heart of the transmission mechanism. ${ }^{46}$

Consider our model under the assumption that firms preset prices in domestic currency for the national market, and in foreign currency for the export market (the LCP case discussed above). With nominal rigidities, all prices in the world economy are fixed in the short run regardless of currency fluctuations. In contrast to the PCP case, exchange rate movements neither affect the price of the Home goods abroad, nor redirect world demand towards them. The crucial effect of exchange rate movements in this economy is on firms' markups and profits. Since the Foreign-currency price of the Home goods is preset, a depreciation of the Home exchange rate raises the revenue in domestic currency of each unit of product sold abroad: hence the markup over marginal costs increases with depreciation. But this means that nominal depreciation improves — instead of worsening - the Home terms of trade.

Let's reconsider the equilibrium effects of a productivity shock when Home monetary authorities stabilize the output gap in the new framework (Figure 12). As in the PCP case above, a positive productivity shock rotates the 'AS' upward, and a Home monetary expansion raises Home nominal spending. However, their macroeconomic effects differ from the PCP case in two important respects. First, raising $\mu$ now has a much stronger impact on the aggregate demand, since all consumer prices are sticky in the short run. Even if the exchange rate depreciates, there is no 'imported inflation.' The 'AD' shifts one-to-one with $\mu$ (as in the closed economy case). Second, the Home depreciation improves the terms of trade: $\tau$ rises with the exchange rate and the 'AS' rotates upwards even further, reinforcing the initial impact of the productivity shock.

The Home economy moves from point $O$ to point $L$. In the new equilibrium, employment is at its natural rate (this is because of our assumption about Home monetary policy), but stronger terms of trade allow domestic households to increase their consumption much more than in the PCP case (even more than in the closed-economy case). For any given shock to $Z$, the segment $O L$ in Figure 12 is larger than the segment $O P$ in Figure 11. The economy operates away from its flex-price benchmark allocation, delivering higher utility to domestic households.

The extra gains for the Home economy come at the expense of the Foreign country. A Home expansion has no effect on Foreign consumption. Foreign consumer prices are preset in Foreign currency and are therefore inelastic to exchange rate movements in the short run: the Foreign ' $A D^{*}$ ' schedule does not move. Conversely, the Foreign terms of trade now worsen with the Home currency depreciation. The 'AS*' rotates downward and hours worked increase: Foreigners need to work more to sustain an unchanged level of consumption. A higher level of effort at an unchanged level of consumption unambiguously worsens Foreign households' welfare. The international transmission of policy shock is clearly negative, that is 'beggar-thy-neighbor'.

Overall, the main predictions of the LCP model are quite distant from the PCP case. The sign of policy transmission is different: positive in the PCP case, negative in the LCP case. Also far apart are the responses of international prices: in a world with PCP, monetary

\footnotetext{
${ }^{45}$ See e.g. Engel (1999), Engel and Rogers (1996), Goldberg and Knetter (1997), Parsley and Wei (2001), Rogoff (1996).

${ }^{46}$ See e.g. Engel (2002).
} 
expansions worsen the terms of trade; they improve it in the LCP case. In the PCP case, exchange rate movements affect relative prices for a given consumption level, switching demand across different categories of goods. In the LCP case, there is no expenditureswitching effect from exchange rate movements. If anything, what is switched is the labor burden to sustain world consumption.

\subsection{A case of asymmetric transmission (the DP model)}

Transmission in an economy where all export prices are set in one currency (the DP case) somewhat combines the two cases discussed above. The crucial feature of such an economy is that different mechanisms mute the response of $\tau$ nor $\tau^{*}$ to shocks to productivity and/or the monetary stance. In the Home country, consumer prices do not respond to the exchange rate, while dollar pricing insulate exporters' markups from exchange rate movements. In the Foreign country, the positive effects of lower import prices are offset by a fall in profits from exports: the local-currency value of export sales fall with the Home depreciation.

We can visualize these effects in Figure 13. Once again, the shock to $Z$ tilts the 'AS' upward and prompts an increase in $\mu$ to close the output gap. In the Home country, where all prices are preset in Home currency, the monetary expansion raises domestic demand one-to-one. The ensuing Home depreciation has no implications for the profits of domestic firms, since pass-through of exchange rate movements onto Home export prices is complete. Consumption rises above the natural rate, while employment remains at the natural rate. The Home economy moves from $O$ to $D$, where the length of the segment $O D$ lies somewhere between $O P$ in Figure 11 and $O L$ in Figure 12.

In the Foreign country, Home depreciation translates into lower import prices, hence into a lower CPI. For a given domestic monetary stance, the 'AD*' shifts upward. But since there is no effect on the relative price of consumption in terms of output $\tau^{*}$, the 'AS*' does not rotate. The Foreign economy moves from point $O^{*}$ to point $D^{*}$ along the unchanged 'AS*' schedule. Thus, in the new equilibrium Foreign households enjoy higher consumption (actually, as high as in the PCP case: $O^{*} D^{*}$ in Figure 13 is equal to $O^{*} P^{*}$ in Figure 10), but also work more. In other words, the international transmission is positive as regards consumption, negative as regards labor effort. However, because of monopolistic distortions in production, the first component dominates and the international transmission is overall positive. $^{47}$

Note that, from the point of view of Foreign consumers, the exchange rate plays a stabilizing role in the product market: a Home depreciation lowers the price of Home goods. The sign of the adjustment is consistent with the flexible-price benchmark. But the negative implications of exchange rate movements on Foreign firms' profits are clearly 'destabilizing.' Vis-a-vis the received wisdom on international transmission (corresponding to the PCP case) and its strongest critique (the LCP case), the case of 'dollar pricing' stresses the realistic possibility of counteracting effects from exchange rate movements within an economy.

To conclude our analysis of transmission in the DP case, it is worth noticing that the Home economy is fully insulated from external shocks: for any given $\mu$ and $Z$, exchange rate shocks or cyclical developments abroad have no macroeconomic effects on output, consumption and terms of trade in the Home country. Thus, when Home policymakers respond to local productivity shocks there are repercussions in the rest of the world as illustrated

\footnotetext{
${ }^{47}$ Because of monopoly power in production, the representative agent's indifference curve in the pre-shock equilibrium cuts the 'AS*' from above. Hence a movement along the ' $\mathrm{AS}^{*}$ ' raises welfare (as long as it is not too large).
} 
in Figure 13, but when Foreign policymakers react to local shocks there are no spillovers to the Home country economy. This asymmetry stems from the predominant role in global trade of the 'vehicle' currency issued by the Home country.

\section{International dimensions of optimal policy}

Do optimal stabilization rules in an open economy deviate from their counterparts in closed economy? How do openness and trade affect the design and conduct of monetary policy? In this section we take a first pass at these issues by studying optimal policies for each of the three specifications of export pricing, i.e. PCP, LCP and DP. We discuss both the case in which national policymakers design their policies independently of each other, and the case in which they do so in a cooperative way. ${ }^{48}$

\subsection{Optimal monetary rules and the gains from international coor- dination}

In the absence of international coordination, Home policymakers determine their welfareoptimizing monetary stance by maximizing $\mathcal{W}$ as defined in (14) with respect to $\mu$, while taking the monetary policy in the other country $\mu^{*}$ as given. Similarly, Foreign authorities maximixe $\mathcal{W}^{*}$ with respect to $\mu^{*}$ given $\mu$. We denote the monetary stances independently chosen by the two authorities with $\mu_{N o n-C o o p}$ and $\mu_{N o n-C o o p}^{*}$. In a cooperative equilibrium, instead, national authorities jointly maximize a weighted average of Home and Foreign welfare $0.5 \mathcal{W}+0.5 \mathcal{W}^{*}$, whereas the weights coincide with the share of each country in world consumption. The cooperative monetary stances are denoted $\mu_{\text {Coop }}$ and $\mu_{\text {Coop }}^{*}$.

The PCP model Our model with PCP provides an example in which the optimal policy in open economy is identical to the optimal policy in closed economy: domestic policymakers focus exclusively on the domestic output gap, offsetting any fluctuation in employment and output around their natural level.

In the context of a non-cooperative equilibrium, using the pricing equilibrium expressions with PCP, the policy problem in the Home country can be written as

$$
\begin{gathered}
\max _{\mu} E[\ln C-\ell]= \\
\max _{\mu}\left[E \ln \mu+\frac{1}{2} E \ln \mu^{*}-\frac{1}{2} \ln E(\mu / Z)-\frac{1}{2} \ln E\left(\mu^{*} / Z^{*}\right)+\text { constant }\right]
\end{gathered}
$$

The optimal monetary policy satisfies $\mu_{N o n-C o o p}^{P C P}=\alpha Z$, precisely the same expression as in the closed economy. ${ }^{49}$ The optimal policy is completely 'inward looking,' in the sense that it is only concerned with domestic shocks. Symmetrically, in the Foreign country the policy problem is:

$$
\begin{gathered}
\max _{\mu} E\left[\ln C^{*}-\ell\right]= \\
\max _{\mu}\left[\frac{1}{2} E \ln \mu+\frac{1}{2} E \ln \mu^{*}-\frac{1}{2} \ln E(\mu / Z)-\frac{1}{2} \ln E\left(\mu^{*} / Z^{*}\right)+\text { constant }\right]
\end{gathered}
$$

\footnotetext{
${ }^{48}$ Selected references on policy rules for open economies include Ball (1999), Benigno (2002, 2004), Gali and Monacelli (2005), Ghironi and Rebucci (2002), Lombardo and Sutherland (2004), Monacelli (2005), Obstfeld (2002), Sutherland (2005), Svensson (2000). This section builds on the synthesis model by Corsetti and Pesenti (2005).

${ }^{49}$ See e.g. Clarida, Gali and Gertler (2001).
} 
which yields $\mu_{N o n-C o o p}^{* P C P}=\alpha^{*} Z^{*}$. Note that $\alpha$ and $\alpha^{*}$ may differ, reflecting national preferences over the desired rate of inflation. If the two steady-state inflation rates are different, there will be a trend for the nominal exchange rate equal to the inflation differential, without effects on the steady-state real exchange rate.

Are there gains from international policy cooperation? To answer this question note that, with PCP, the objective function of the Home policymakers in (46) is identical to the Foreign objective function (47): in other words, $\mathcal{W}=\mathcal{W}^{*}$. Maximizing an average of $\mathcal{W}$ and $\mathcal{W}^{*}$ yields exactly the the same optimal policy prescriptions $\mu_{C o o p}^{P C P}=\alpha Z$ and $\mu_{C o o p}^{* P C P}=\alpha^{*} Z^{*}$. The non-cooperative rules remain the best policy rules also under cooperation: by 'keeping one's house in order', policymakers are already able to achieve economic efficiency. ${ }^{50}$ This result provides an extreme version of the case for flexible exchange rates made by Friedman (1953): even without price flexibility, monetary authorities can engineer the right adjustment in relative prices through exchange rate movements. In our model with PCP, expenditureswitching effects make exchange rate and price movements perfect substitutes. ${ }^{51}$

The LCP model The optimality of 'inward-looking' policy rules, however, is not a general result. Notably, with LCP, the optimal policy rule still prescribes some degree of output gap stabilization, but complete stabilization is not desirable. Under LCP the Home policy problem in a non-cooperative equilibrium can be written as:

$$
\max _{\mu}\left[E \ln \mu-\frac{1}{2} \ln E(\mu / Z)-\frac{1}{2} \ln E\left(\mu / Z^{*}\right)+\text { constant }\right]
$$

The optimal policy satisfies:

$$
\frac{1}{2} \frac{\mu_{\text {Non-Coop }}^{L C P} / Z}{E\left(\mu_{\text {Non-Coop }}^{L C P} / Z\right)}+\frac{1}{2} \frac{\mu_{\text {Non-Coop }}^{L C P} / Z^{*}}{E\left(\mu_{\text {Non-Coop }}^{L C P} / Z^{*}\right)}=1
$$

Home policymakers stabilize a weighted average of Home and Foreign marginal costs, using the CPI weights for the Home and the Foreign goods.

Why? Suppose that the Home monetary authorities followed an 'inward looking' rule, i.e. they completely stabilized Home marginal costs, moving $\mu$ to offset productivity shocks as in Figure 11. While such conduct would completely stabilize domestic producers' markups, Foreign firms selling in the Home country would face a high degree of exchange rate variability, affecting the expected discounted profits from the Home market (with reference to Figure 11, they would suffer large fluctuations of employment away from the flexible-price natural level). Foreign firms will then react to volatility of profits by raising their average markups in their export markets, charging higher prices for their products sold in the Home country. The intuition underlying this result is the same as discussed in the closed-economy case, with reference to Figure 5.

Home policymakers thus face a trade-off between stabilizing the marginal costs/markups of domestic producers (translating into lower Home good prices) and stabilizing the marginal costs/markups of Foreign producers' (translating into lower import prices). At an optimum, they will pursue some average between the two, depending on the weight of imports in the consumption basket of Home households. This is precisely the interpretation of (49).

\footnotetext{
${ }^{50}$ See Obstfeld and Rogoff (2002).

${ }^{51}$ The equivalence between Nash equilibrium and flex-price allocation need not go through under more general conditions, e,g. with less restrictive preference specifications as shown by Benigno and Benigno (2003).
} 
The magnitude of the optimal deviation from 'inward looking' rules depends on a country's degree of trade openness. In our stylized model, half of the domestic consumption expenditure falls on foreign goods. In the case of small and very open economies, there is a strong incentive to pursue policy rules that are quite 'outward oriented.' In large and less open economies, these considerations may affect policy design only marginally.

Because of the international spillovers of monetary policy on international pricing, one may expect that with LCP there will always be an incentive to cooperate. Surprisingly, however, this is not the case in our model. To see why, note that the objective function of Foreign policymakers is identical to (48), except that $\ln \mu$ is replaced by $\ln \mu^{*}$. Hence the non-cooperative optimal policy satisfies:

$$
\frac{1}{2} \frac{\mu_{N o n-C o o p}^{* L C P} / Z}{E\left(\mu_{N o n-C o o p}^{* L C P} / Z\right)}+\frac{1}{2} \frac{\mu_{N o n-C o o p}^{* L C P} / Z^{*}}{E\left(\mu_{N o n-C o o p}^{* L C P} / Z^{*}\right)}=1
$$

Comparing (49) with (50) shows that both policymakers stabilize exactly the same weighted average of Home and Foreign marginal costs. Hence they pursue exactly the same monetary policy, $\mu_{N o n-C o o p}^{L C P}=\mu_{N o n-C o o p}^{* L C P}$, implying that the nominal exchange rate does not react to shocks. Instead of closing the domestic output gap completely, national policymakers take into account the effects of their policies on exchange rate variability. In equilibrium, an efficient monetary rule limits exchange rate fluctuations. ${ }^{52}$

Solving the cooperative problem does not change this prescription at all. There are no gains from cooperation not because domestic policymaking is already efficient (as in the PCP case, where there are no spillovers in equilibrium), but because what can be achieved by cooperating (the stability or predictability of the exchange rate) is already achieved in the absence of cooperation. As the only spillovers in the world economy stem from exchange rate movements, the world economy cannot gain by pursuing asymmetric policies that imply exchange rate fluctuations. Once again, 'keeping one house in order' is the best rule of conduct.

The DP model An interesting case of asymmetric deviation from inward-looking rules is provided by an economy with Dollar Pricing. In this case, Home welfare is equal to (48), so that Home optimal monetary policy must satisfy (49). Foreign welfare is (46). Correspondingly, the Foreign optimal policy is completely inward-looking. So, the country that issues the currency used worldwide for export pricing (the Home country) optimally responds to shocks hitting the global economy. The other country only needs to stabilize domestic markups.

The interest in this case mainly concerns its implication for the desirability of international policy cooperation. World welfare indeed increases when monetary policy rules are designed in a cooperative way (by maximizing an equally weighted average of the two national welfare functions). However, the cooperative and noncooperative optimal policy rules coincide for the Foreign country, but not for the Home country. The 'contribution' to cooperation is therefore unilateral: only the Home country is expected to modify its rules. This raises an interesting issue, as to whether there is any incentive for this country to enter any binding cooperative agreement regarding stabilization policy.

\footnotetext{
${ }^{52}$ This point is emphasized by Devereux and Engel (2003).
} 


\subsection{Exchange rate regimes and the macroeconomy}

Comparing models We conclude our analysis of optimal monetary policies with a brief assessment of the implications for international business cycles and the choice of an exchange rate regime. In what follows we assume that monetary authorities implement the optimal monetary stances characterized above.

According to the PCP model, exchange rate movements contribute to stabilization and welfare, hence exchange rate flexibility is desirable. In the long run, national inflation rates are equal to the desired rates set by policymakers and the exchange rate depreciates at a rate equal to the inflation differential. In the short-run, the exchange rate evolves stochastically around its long-run trend, and monetary authorities let the domestic currency depreciate when the country is hit by a positive productivity shock. Exchange rate flexibility is desirable to the extent that it is driven exclusively by optimal state-contingent monetary policies.

According to the LCP model, exchange rate movements do not contribute to efficient relative price adjustment. On the contrary, exchange rate movements create negative spillovers that are rationally avoided by welfare-maximizing policymakers. Observe, however, that this result does not necessarily coincide with optimality of fixed exchange rate regimes. Differences in desired national inflation rates may still be optimally accommodated by policymakers, inducing predictable trend depreciation. What is welfare-reducing is exchange rate stochastic variability around such trend.

With PCP, cross-border output correlation depends on the joint distribution of fundamentals - GDP changes only in the country experiencing productivity shocks. With LCP instead, Home and Foreign monetary authorities optimally react to the same average of Home and Foreign shocks. This implies that when the Home country experiences productivity gains and its employment falls, employment increases in the Foreign country with stable productivity. Because of adverse terms of trade movements, the equilibrium allocation coincides with an inefficient level of output expansions in both countries. An important implication is that, for any given exogenous distribution of productivity shocks, cross-border output correlation is higher under the fixed exchange rate system consistent with LCP than under the floating exchange rate system consistent with PCP.

The DP economy is once again an intermediate case between the previous two. Exchange rate flexibility is desirable, although one country finds it optimal to stabilize to some extent currency fluctuations (depending on its openness). Both consumption and output are positively correlated.

Conditional on implementing optimal monetary policy rules, welfare under PCP is always above welfare in the other two cases. Optimal exchange rate flexibility and producer currency pricing is actually the best possible combination of policy and pricing regimes for our economies. ${ }^{53}$

Welfare and macroeconomic comparison across models are more complex, however, when monetary authorities do not adopt optimal rules. The main consequences of insufficient stabilization on markups and the price level are the same as in the closed economy, and need not be repeated here. We only observe that in open economy insufficient stabilization will also affect the level of the real exchange rate. ${ }^{54}$ With LCP, for instance, the real

\footnotetext{
${ }^{53}$ Corsetti and Pesenti (2002) however point out the possibility of self-validating equilibria where firms choose to price in local currency, and monetary authorities implement the optimal rule under LCP. The exchange rate regime, the monetary policy rule and pricing behavior are all endogenous in this equilibrium.

${ }^{54}$ See Broda (2004) for an empirical assessment.
} 
exchange of the country adopting inefficient policies will be excessively appreciated relative to its trading partner.

Domestic and international policy trade-offs Most contributions to the international macro literature on stabilization have focused on economies that are perfectly specialized in the production of a single tradable good. The analysis of policy dilemmas has therefore been centered on the trade-off between stabilizing domestic prices and output gap, and containing the volatility of exchange rates and Foreign exporters' profits - as this may translate into higher average prices of their products.

However, other policy trade-offs may be relevant. For instance, in imperfectly specialized or multi-sector economies with nominal rigidities, industry-specific shocks rule out the possibility that exchange rate movements be perfect substitute for relative price adjustment. Policymakers face higher-dimensional trade-offs between stabilizing marginal costs and production in different sectors of the economy. ${ }^{55}$

Consider a version of our simple model including a non-traded goods sector in each country. Both traded and nontraded goods are subject to nominal price rigidities, and are subject to sector-specific productivity shocks. In addition, exporters preset prices in local currency. Now, when the nontraded good sector is hit by a positive idiosyncratic shock, monetary authorities find it optimal to expand domestic monetary policy even if the implied exchange rate depreciation has no desirable effects on domestic welfare, i.e., even if there are no expenditure-switching effects stemming from exchange rate movements. In other words, optimal policies will imply some exchange rate movements - although with LCP these movements are not efficient. ${ }^{56}$ The benefits from stabilizing the domestic output gap outweigh the costs of deviating from exchange rate stability. It follows that the absence of expenditure switching effects is not a sufficient argument against exchange rate flexibility.

\section{The open-economy model: discussion and extensions}

\subsection{Discretion vs. commitment in open economy}

In this section, we compare the policy problem under commitment with the policy problem under discretion. As for the closed-economy case, we will show that the optimal policy, in general, is not time-consistent. In an open economy, however, terms of trade considerations mitigate and possibly offset the inflationary bias analyzed in Section 4.1.

Consider once again the policy problem under discretion: Home policymakers maximize agents' current utility with respect to $\mu$ after observing the shocks $Z$ and $Z^{*}$, taking firms' prices as well as Foreign policy as given. Foreign policymakers solve a similar problem.

In the PCP model, the welfare-maximizing monetary policies under discretion are as follows:

$$
\frac{\mu}{Z}=\frac{1}{2} \frac{\theta}{\theta-1} E\left(\frac{\mu}{Z}\right) ; \quad \frac{\mu^{*}}{Z^{*}}=\frac{1}{2} \frac{\theta}{\theta-1} E\left(\frac{\mu^{*}}{Z^{*}}\right)
$$

\footnotetext{
${ }^{55}$ See e.g. Canzoneri, Cumby and Diba (2005), Clarida, Gali and Gertler (2002), and Tille (2002).

${ }^{56}$ See e.g. Duarte and Obstfeld (2004). Similarly, Devereux and Engel (2004) stress the possibility of 'competing objectives' for monetary policy (i.e. policy trade-offs) that potentially undermine optimality of fixed rates in models with LCP. These authors contrast aggregate demand effects of monetary policy with relative price effects under different assumptions about the degree of nominal rigidities and the elasticity of substitution in the goods market, distinguishing between intermediate goods and final goods.
} 
We have seen that in a closed economy, monopolistic distortions in production create an incentive for the policymakers to expand demand and bring output to its Pareto-efficient level $1 / k$. This need not be true in an open economy. The above expressions make clear that policymakers will have an incentive to either expand or contract aggregate demand (given prices) depending on whether the import share in consumption, equal to $1 / 2$ in our specification, is above or below the reciprocal of the markup $(\theta-1) / \theta$.

Intuitively, in an open economy monopolistic distortions in production coexist with terms of trade distortions, whose magnitude depends - among other things - on the degree of openness of the economy. Under discretion, welfare-maximizing policymakers expand aggregate demand if the former distortions are sufficiently important relative to the latter. When monopoly power in production is sufficiently high $(\theta<2$ in our specification), policymakers are less concerned with adverse import price movements due to an exchange rate depreciation than with the inefficient level of domestic output. By the same token, in economies that are relatively closed to trade, the exchange rate affects the price of a relatively small share of consumption goods. Also in this case, benevolent policymakers will have an incentive to raise output above market equilibrium.

The reverse is true when monopolistic distortions in production are relatively low $(\theta>2)$, or the economy is sufficiently open. In the latter case, while raising output and employment, a monetary expansion would also increase the price of a substantial proportion of consumption goods. When terms of trade movements become the dominant concern in discretionary policy making, monetary authorities actually prefer to engineer surprise re-valuations, as a way to improve the relative prices of their country's output. ${ }^{57}$ It follows that the above conditions cannot be part of a rational expectations equilibrium, except in the special case in which $\theta=2$.

Reducing the degree of pass-through would clearly blunt the terms of trade effects of monetary policy. For instance, the solutions to the policy problems in the LCP model under discretion are:

$$
\frac{\mu}{Z}=\frac{2 \theta}{\theta-1} E\left(\frac{\mu}{Z}\right) ; \quad \frac{\mu^{*}}{Z^{*}}=\frac{2 \theta}{\theta-1} E\left(\frac{\mu^{*}}{Z^{*}}\right)
$$

In this case, discretionary policy is unambiguously biased towards surprise monetary expansions.

Suppose now that governments can use a fiscal instrument to correct average domestic monopolistic distortions. Suppose that it sets a subsidy to production at the rate $(1-\zeta)^{-1}$ such that the average markup is driven to zero:

$$
\frac{1}{2}\left(\frac{\theta}{\theta-1}\right)(1-\zeta)=1
$$

Observe that the subsidy rate is smaller than in the closed-economy case (in our specification, it is half the size than in closed economy). It is easy to verify that, in the PCP model with the above subsidy in place, the first order conditions of the policy problems under discretion coincide with the first order conditions under commitment. They both imply $\mu=\alpha Z$.

But the equivalence between discretionary policy and optimal policy under commitment does not hold in general - as firms' profits may still be exposed to exchange rate variability. In fact, rewrite discretionary policy in the LCP model accounting for production subsidies:

$$
\frac{\mu}{Z}=\frac{2 \theta}{\theta-1}(1-\zeta) E\left(\frac{\mu}{Z}\right) ; \quad \frac{\mu^{*}}{Z^{*}}=\frac{2 \theta}{\theta-1}\left(1-\zeta^{*}\right) E\left(\frac{\mu^{*}}{Z^{*}}\right)
$$

\footnotetext{
${ }^{57}$ On the relation between openness and inflation see e.g. Romer (1993) and Lane (1997).
} 
Clearly, setting $\zeta$ and $\zeta^{*}$ according to (53) and its Foreign analog does not eliminate the incentive to resort systematically to surprise expansions. The reason is that, under discretion, national policymakers take goods' prices as given, and therefore find it optimal to respond to domestic productivity shocks while ignoring the effects of domestic monetary policy on the markup of producers abroad. In that case, however, Foreign exporters would react to an increase in the variability of their markups by raising average prices in the Home country.

Under commitment, instead, Home policymakers take these effects into account and respond to both Home and Foreign shocks. They contain exchange rate and terms of trade movements so as to reduce their effects on the income of Foreign producers, trading off complete stabilization of Home producers' profits with lower import prices.

\subsection{Determinants of pass-through}

As discussed above, the literature has stressed vast differences among transmission mechanisms and welfare properties in economies characterized by different degrees of pass-through. Before drawing strong conclusions from the LCP vs. PCP debate, however, it is worth addressing a few additional empirical dimensions of the link between prices and exchange rates.

First and foremost, the elasticity of prices with respect to exchange rate movements varies between the import- and the consumer-price levels. Even if consumer prices are sticky in the short run, fluctuations of import (border) prices may still bring about substantial expenditure-switching effects.

Second, the degree of nominal rigidity varies with the time horizon, and firms' pricing decisions have an inherent dynamics. Even if inflation inertia is highly relevant in the short term, we may expect a gradual adjustment of prices over time. As both domestic and foreign prices change in response to shocks that also move the exchange rate, the impact of exchange rate movements on the terms of trade may change depending on whether one focuses on the very short run, or allow for longer horizons.

A promising way to address these issues above is taken in recent models that allow for distribution services intensive in local inputs or local assembling of imported intermediate inputs. ${ }^{58}$ Namely, let the Home-currency consumer price of one unit of Home imports be the sum of the producer price (denoted by a bar) and the cost of nontraded distribution services in local currency, $D S_{t}$ :

$$
P_{F}=\overline{P_{F}}+D S=\mathcal{E} \overline{P_{F}^{*}}+D S .
$$

Even if the law of one price holds at the border and $\overline{P_{F}}=\mathcal{E} \overline{P_{F}^{*}}$, the elasticity of consumer prices to exchange rate movements will be less than one, reflecting the weight of distribution in the consumer price. In addition, distribution costs in the consumer market are likely to make the price elasticity of consumption demand market-specific, thus providing monopolistic firms with an incentive to discriminate prices across borders regardless of nominal rigidities. ${ }^{59}$

\footnotetext{
${ }^{58}$ See Erceg and Levin (1995), McCallum and Nelson (1999), MacDonald and Ricci (2001), Burstein, Neves and Rebelo (2003), Corsetti, Dedola and Leduc (2004) and Corsetti and Dedola (2005). According to the estimates by Anderson and van Wincoop (2005) and Burstein, Neves and Rebelo (2003), in the US the average distribution margin is as high as 50 percent - i.e. distributive trade accounts for 50 percent of the retail price of consumption goods. This includes wholesale and retail services, marketing, advertising and local transportation.

${ }^{59}$ This point is developed by Corsetti and Dedola (2005). Of course, in addition to distribution costs,
} 
This is an important result, in light of substantial evidence of price discrimination: ${ }^{60}$ models where deviations from the law of one price are an exclusive implication of nominal rigidities (and therefore a short-run phenomenon) miss features of the international economy that are quite consequential for model building and policy analysis. Namely, they may overlook persistent price discrepancies across regions or over time, and/or overestimate the degree of nominal price rigidities required to explain the stability in local currency of import prices. Assessing the relative importance of optimal price discrimination and monetary frictions in generating incomplete pass-through is clearly a relevant goal for future research.

Last, we should observe that, facing constraints on price adjustment, firms are nonetheless free to choose whether to post preset prices in domestic currency only, or in both domestic and foreign currencies. What are the determinants of this choice? We have considered above some of the factors intervening in this choice, but the set of determinants is clearly larger. A substantial body of literature is moving in these directions, with promising results. ${ }^{61}$

\section{Conclusion}

This paper has presented a stylized but rigorous framework that illustrates fundamental traits of the recent stabilization literature, and sheds light on the architecture of fully-fledged quantitative models in international macroeconomics. As DSGE models are increasingly used as tools for policy evaluation by domestic and international institutions, one of the goals of this paper is to provide an introductory set of analytical instruments to convey the main ideas about international transmission and stabilization policies underlying these models, as well as to provide a smorgasbord of basic questions and intuitions that are developed in quantitative work.

This paper does not provide an exhaustive account of the literature. Several contributions are currently building rich analytical and quantitative frameworks to address crucial stylized facts of the international economy — such as the low degree of international risksharing documented by Backus and Smith (1993), the excess volatility of real exchange rates relative to standard macro variables, or the dynamics of comparative advantages in the world economy. The literature is also exploring macroeconomic implications of frictions in the asset and credit markets, with the goal of integrating financial and real aspects of the international transmission. At the same time, pressing policy issues are raising the hurdles for DSGE models, e.g. current account dynamics and the adjustment to global imbalances.

Empirical and theoretical research is clearly needed to shed light on the international transmission of productivity, monetary and financial shocks - determining the sign and magnitude of cross-border spillovers - as well as on the determinants and cyclical properties of net exports of goods, services and factors. Nonetheless, it is hard to deny that the new paradigm of choice-theoretic models has already been contributing many empirical and theoretical elements to our understanding of the international economy.

there are other possible reasons why the price elasticity may be market specific. See for instance Bergin and Feenstra (2001).

\footnotetext{
${ }^{60}$ See Dornbusch (1987), Krugman (1987), Knetter (1989, 1993), Marston (1990) and Goldberg and Verboven (2001).

${ }^{61}$ See Engel (2005) for a recent synthesis.
} 


\section{References}

[1] Albanesi S., Chari V.V., and Christiano L., 2003. Expectation Traps and Monetary Policy. Review of Economic Studies 70 (4), 715-741.

[2] Anderson J., van Wincoop E., 2005. Trade Costs. Journal of Economic Literature forthcoming.

[3] Bacchetta, P., Van Wincoop E., 2000. Does Exchange-Rate Stability Increase Trade and Welfare? American Economic Review 90 (5), 1093-1109.

[4] Bacchetta, P., Van Wincoop E., 2005. A Theory of the Currency Denomination of International Trade. Journal of International Economics forthcoming.

[5] Backus, D.K., Smith G. W., 1993. Consumption and Real Exchange Rates in Dynamic Economies with Non-traded Goods. Journal of International Economics 35 (3-4), 297316.

[6] Ball, L., 1999. Policy Rules for Open Economies, in J.B. Taylor (ed.) Monetary Policy Rules. Chicago, IL: University of Chicago Press.

[7] Barro, R. J., Gordon D., 1983a. Rules, Discretion, and Reputation in a Model of Monetary Policy. Journal of Monetary Economics 12, 101-121.

[8] Barro, R. J., Gordon D., 1983b. A Positive Theory of Monetary Policy in a NaturalRate Model. Journal of Political Economy 91, 589-610.

[9] Bayoumi T., Laxton D. and Pesenti P., 2004. Benefits and Spillovers of Greater Competition in Europe: A Macroeconomic Assessment. National Bureau of Economic Research Working Paper No. 10416.

[10] Benigno, P. 2002. A Simple Approach to International Monetary Policy Coordination. Journal of International Economics 57 (1), 177-196

[11] Benigno, P. 2004. Optimal Monetary Policy in a Currency Area. Journal of International Economics 63 (2), 293-320

[12] Benigno, G., Benigno, P., 2003. Price Stability in Open Economies. Review of Economic Studies 70 (4), 743-764.

[13] Bergin, P., 2003. Putting the New Open Economy Macroeconomics to a Test. Journal of International Economics 60 (1), 3-34.

[14] Bergin, P., Feenstra R., 2001. Pricing-to-market, Staggered Contracts, and Real Exchange Rate Persistence. Journal of International Economics 54, 333-359.

[15] Bergin P., Glick R., 2003. Endogenous Nontradability and Macroeconomic Implications. National Bureau of Economic Research Working Paper No. 9739.

[16] Betts, C., Devereux, M.B., 2000. Exchange Rate Dynamics in a Model of Pricing-toMarket. Journal of International Economics 50 (1), 215-244.

[17] Broda, C., 2004. Exchange Rate Regimes and National Price Levels. Working paper, Federal Reserve Bank of New York. 
[18] Burstein, A.T., Neves J., and Rebelo S., 2003. Distribution Costs and Real Exchange Rate Dynamics During Exchange-Rate-Based Stabilizations. Journal of Monetary Economics 50 (6), 1189-1214

[19] Calvo, G., 1983. Staggered Prices in a Utility-Maximizing Framework. Journal of Monetary Economics 12, 983-998.

[20] Campa, J., Goldberg, L., 2002. Exchange Rate Pass-Through into Import Prices. National Bureau of Economic Research Working Paper No. 8934

[21] Canzoneri, M. B., Cumby R., Diba B., 2005. The Need for International Policy Coordination: What's Old, What's New, What's Yet to Come? Journal of International Economics, forthcoming.

[22] Chari, V.V., Kehoe P., McGrattan E., 2002. Can Sticky Prices Generate Volatile and Persistent Real Exchange Rates? Review of Economic Studies 69 (3), 533-63.

[23] Christiano L.J., Eichenbaum M., and Evans C., 1999. Monetary Policy Shocks: What Have we Learned and to What End?, in J. Taylor and M. Woodford (eds.), The Handbook of Macroeconomics Vol. 1A, Elsevier Science, North Holland.

[24] Christiano L.J., Eichenbaum M., and Evans C., 2005. Nominal Rigidities and the Dynamic Effects of a Shock to Monetary Policy. Journal of Political Economy forthcoming.

[25] Clarida R., Gali J., and Gertler M., 2000. Monetary Policy Rules and Macroeconomic Stability: Evidence and Some Theory. Quarterly Journal of Economics 115 (1), 147-80.

[26] Clarida R., Gali J., and Gertler M., 2001. Optimal Monetary Policy in Open vs. Closed Economies: An Integrated Approach. American Economic Review Papers and Proceedings 91 (2), 248-252.

[27] Clarida R., Gali J., Gertler M., 2002. A Simple Framework for International Monetary Policy Analysis. Journal of Monetary Economics 49, 879-904.

[28] Clouse, J., Henderson D., Orphanides A., Small D., and Tinsley P., 2000. Monetary Policy when the Nominal Short-Term Interest Rate is Zero, Finance and Economics Discussion Series no. 2000-51, Federal Reserve Board.

[29] Corsetti G., Dedola L., 2005. Macroeconomics of International Price Discrimination. Journal of International Economics forthcoming.

[30] Corsetti G., Dedola L. and Leduc S., 2004. International Risk Sharing and the Transmission of Productivity Shocks. Working paper, European University Institute, European Central Bank and Board of Governors of the Federal Reserve System.

[31] Corsetti G., Martin P., and Pesenti P., 2005. Productivity Spillovers, Terms of Trade and the "Home Market Effect". National Bureau of Economic Research Working Paper No. 11165 .

[32] Corsetti G., Pesenti, P., 1997. Welfare and Macroeconomic Interdependence. Working paper version of [33]. National Bureau of Economic Research Working Paper No. 6307.

[33] Corsetti G., Pesenti, P., 2001. Welfare and Macroeconomic Interdependence. Quarterly Journal of Economics 116 (2), 421-446. 
[34] Corsetti, G., Pesenti, P., 2002. Self-Validating Optimum Currency Areas. National Bureau of Economic Research Working Paper No. 8783.

[35] Corsetti, G., Pesenti P., 2005. International Dimensions of Optimal Monetary Policy. Journal of Monetary Economics 52 (2), 281-305.

[36] Corsetti, G., Pesenti, P., Roubini, N., Tille, C., 2000. Competitive Devaluations: Toward a Welfare-Based Approach. Journal of International Economics 51 (1), 217-241.

[37] Devereux, M.B., Engel, C., 2003. Monetary Policy in the Open Economy Revisited: Price Setting and Exchange Rate Flexibility. Review of Economic Studies 70, 765-783.

[38] Devereux, M.B., Engel, C., 2004. Expenditure Switching vs. Real Exchange Rate Stabilization: Competing Objectives for Exchange Rate Policy. Working paper, University of British Columbia and University of Wisconsin.

[39] Devereux, M.B., Engel C., Storgaard, P.E., 2004. Endogenous Exchange Rate Passthrough when Nominal Prices are Set in Advance. Journal of International Economics 63, 263-291.

[40] Devereux, M.B., Engel, C., Tille, C., 2003. Exchange Rate Pass-Through and the Welfare Effects of the Euro. International Economic Review 44 (1), 223-242.

[41] Dornbusch R., 1987. Exchange Rate and Prices. American Economic Review 77, 93-106

[42] Duarte M., Obstfeld M., 2004. Monetary Policy in the Open Economy Revisited: The Case for Exchange-Rate Flexibility Restored. Working paper, Federal Reserve Bank of Richmond and University of California at Berkeley.

[43] Duarte, M., Stockman, A.C., 2005. Rational Speculation and Exchange Rates. Journal of Monetary Economics 52 (1), 3-29.

[44] Engel, C., 1999. Accounting for Real Exchange Rate Changes. Journal of Political Economy 107, 507-38.

[45] Engel, C., 2002. Expenditure Switching and Exchange-Rate Policy, in B. Bernanke and K. Rogoff (eds.), NBER Macroeconomics Annual 2002, Cambridge, MA: MIT Press.

[46] Engel, C., 2005. Equivalence Results for Optimal Pass-Through, Optimal Indexing to Exchange Rates, and Optimal Choice of Currency for Export Pricing. National Bureau of Economic Research Working Paper No. 11209.

[47] Engel, C., Rogers J., 1996. How Wide is the Border? American Economic Review 86 (5), 1112-1125.

[48] Erceg, C., Levin A., 1995. Structures and the Dynamic Behavior of the Real Exchange Rate. Working paper, Board of Governors of the Federal Reserve System.

[49] Friberg, R., 1998. In Which Currency Should Exporters Set their Prices? Journal of International Economics 45 (1), 59-76.

[50] Friedman, M., 1953. The Case for Flexible Exchange Rates, in: Essays in Positive Economics. Chicago, IL: University of Chicago Press, 157-203. 
[51] Gali, J., 2002. New Perspectives on Monetary Policy, Inflation and the Business Cycle. National Bureau of Economic Research Working Paper No. 8767.

[52] Gali, J., Monacelli, T., 2005. Monetary Policy and Exchange Rate Volatility in a Small Open Economy. Review of Economic Studies, forthcoming.

[53] Ghironi F., Melitz M., 2004. International Trade and Macroeconomic Dynamics with Heterogeneous Firms. National Bureau of Economic Research Working Paper No. 10540 .

[54] Ghironi, F., Rebucci, A., 2002. Monetary Rules for Emerging Market Economies. International Monetary Fund Working Paper WP/02/34.

[55] Goldberg, P., Knetter, M.M., 1997. Goods Prices and Exchange Rates: What Have We Learned? Journal of Economic Literature 35, 1243-1272.

[56] Goldberg, P. K., Verboven F., 2001. The Evolution of Price Dispersion in the European Car Market. Review of Economic Studies 68, 811-48.

[57] Goodfriend, M., King, R.G., 2001. The Case for Price Stability. National Bureau of Economic Research Working Paper No. 8423.

[58] Knetter, M. M., 1989. Price Discrimination by U.S. and German Exporters. American Economic Review 79, 198-210.

[59] Knetter, M. M., 1993. International Comparisons of Price-to-Market Behavior. American Economic Review 83, 473-86.

[60] Krugman, P., 1987. Pricing to Market When the Exchange Rate Changes, in S.W. Arndt and J. D. Richardson (eds.), Real-Financial Linkages among Open Economies. Cambridge, MA: MIT Press, 49-70.

[61] Krugman, P., 1998. It's Baaack: Japan's Slump and the Return of the Liquidity Trap. Brookings Papers on Economic Activity 2, 137-205.

[62] Kydland, F. E., Prescott E. C., 1977. Rules rather than Discretion: The Inconsistency of Optimal Plans. Journal of Political Economy 85, 473-491.

[63] Lane, P., 1997. Inflation in Open Economies. Journal of International Economics 42 (3-4), 327-347.

[64] Laxton, D., Pesenti, P., 2003. Monetary Rules for Small, Open, Emerging Economies. Journal of Monetary Economics 50 (5), 1109-1146.

[65] Lombardo G., Sutherland A., 2004. Monetary and Fiscal Interactions in Open Economies. Journal of Macroeconomics 26, 319-348.

[66] MacDonald, R., Ricci L., 2001. PPP and the Balassa-Samuelson Effect: The Role of the Distribution Sector. International Monetary Fund Working Paper WP/01/38.

[67] Marston, R., 1990. Pricing to Market in Japanese Manufacturing. Journal of International Economics 29, 217-36.

[68] McCallum, B., Nelson, E., 1999. Nominal Income Targeting in an Open Economy Optimizing Model. Journal of Monetary Economics 43 (3), 553-578. 
[69] Monacelli, T., 2005. Monetary Policy in a Low Pass-Through Environment. Journal of Money, Credit, and Banking, forthcoming.

[70] Mundell, R.A., 1963. Capital Mobility and Stabilization Policy under Fixed and Flexible Exchange Rates. Canadian Journal of Economics and Political Science 29, 475-85.

[71] Obstfeld, M., 2002. Inflation-Targeting, Exchange-Rate Pass-Through, and Volatility. American Economic Review Papers and Proceedings 92 (2), 102-07.

[72] Obstfeld, M., Rogoff, K., 1995. Exchange Rate Dynamics Redux. Journal of Political Economy 103, 624-660.

[73] Obstfeld, M., Rogoff, K., 1996. Foundations of International Macroeconomics. Cambridge, MA: MIT Press.

[74] Obstfeld, M., Rogoff, K., 2000. New Directions for Stochastic Open Economy Models. Journal of International Economics 50 (1), 117-153.

[75] Obstfeld, M., Rogoff, K., 2002. Global Implications of Self-Oriented National Monetary Rules. Quarterly Journal of Economics 117, 503-36.

[76] Parsley, D. C., Wei S., 2001. Explaining the Border Effect: The Role of Exchange Rate Variability, Shipping Costs and Geography. Journal of International Economics 55 (1), 87-105.

[77] Rogoff, K., 1996. The Purchasing Power Parity Puzzle. Journal of Economic Literature 34 (2), 647-68.

[78] Romer, D., 1993. Openness and Inflation: Theory and Evidence. Quarterly Journal of Economics 108, 870-903.

[79] Sutherland, A., 2005. Incomplete Pass-Through and the Welfare Effects of Exchange Rate Variability. Journal of International Economics 65 (2), 375-400.

[80] Svensson, L., 2000. Open-Economy Inflation Targeting. Journal of International Economics 50 (1), 155-183.

[81] Svensson, L., 2003. Escaping from a Liquidity Trap and Deflation: The Foolproof Way and Others. Journal of Economic Perspectives 17 (4), 145-166.

[82] Taylor, J. B., 1993. Discretion versus Policy Rules in Practice. Carnegie-Rochester Conference Series on Public Policy 39, 195-214.

[83] Taylor, J.B., 2000. Low Inflation, Pass-Through, and the Pricing Power of Firms. European Economic Review 44 (7), 1389-1408.

[84] Tille, C., 2001. The Role of Consumption Substitutability in the International Transmission of Shocks. Journal of International Economics 53 (2), 421-444.

[85] Tille, C., 2002. How Valuable Is Exchange Rate Flexibility? Optimal Monetary Policy under Sectoral Shocks. Federal Reserve Bank of New York Staff Report No. 147.

[86] Walsh, C.E., 2003. Monetary Theory and Policy. II edition. Cambridge, MA: MIT Press. 
[87] Woodford, M., 2001. The Taylor Rule and Optimal Monetary Policy. American Economic Review Papers and Proceedings 91, 232-237.

[88] Woodford, M., 2003. Interest and Prices: Foundations of a Theory of Monetary Policy Princeton, NJ: Princeton University Press. 
Figure 1

Equilibrium in closed economy

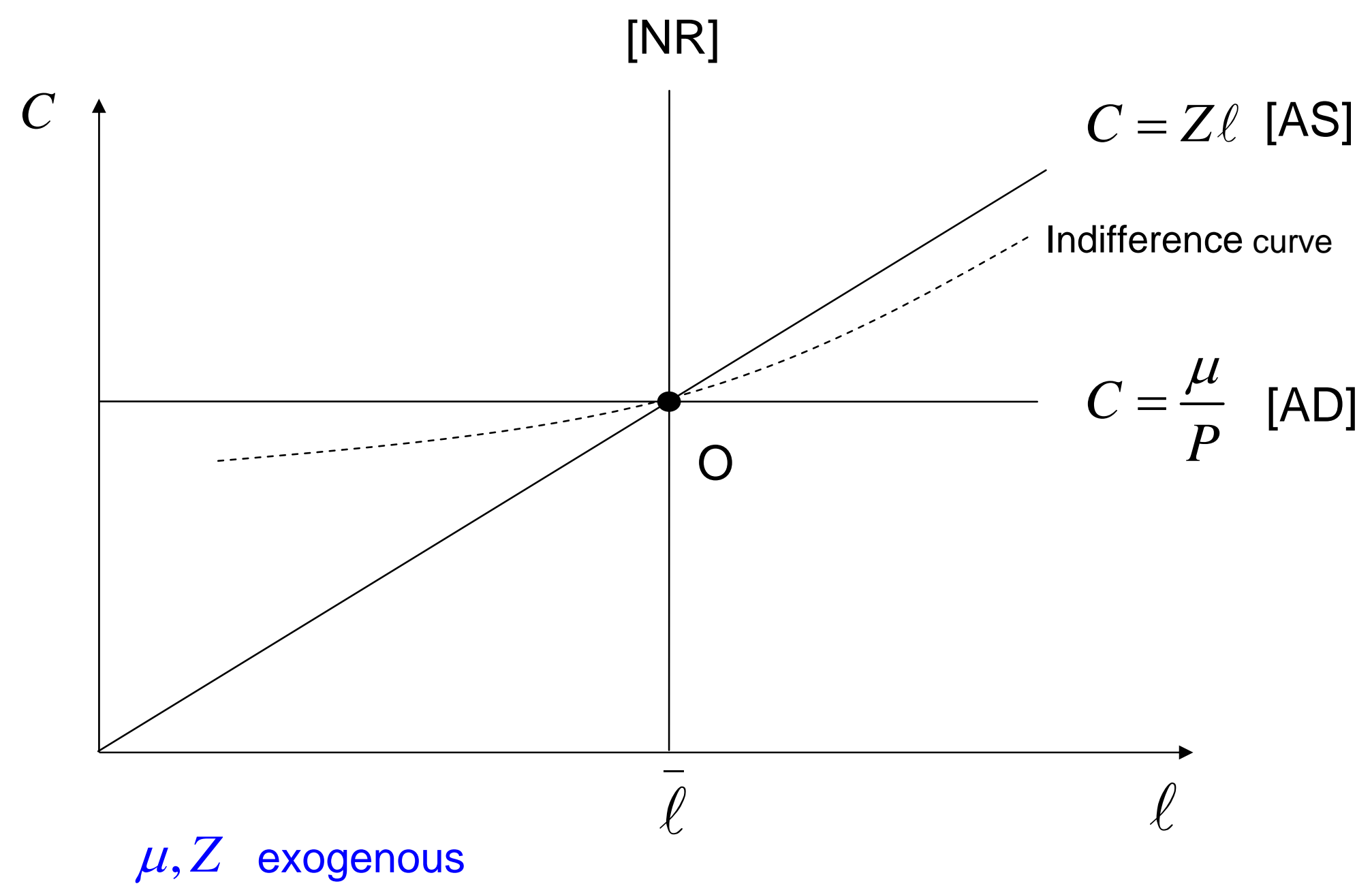


Figure 2

Structural reforms: a reduction in monopolistic distortions

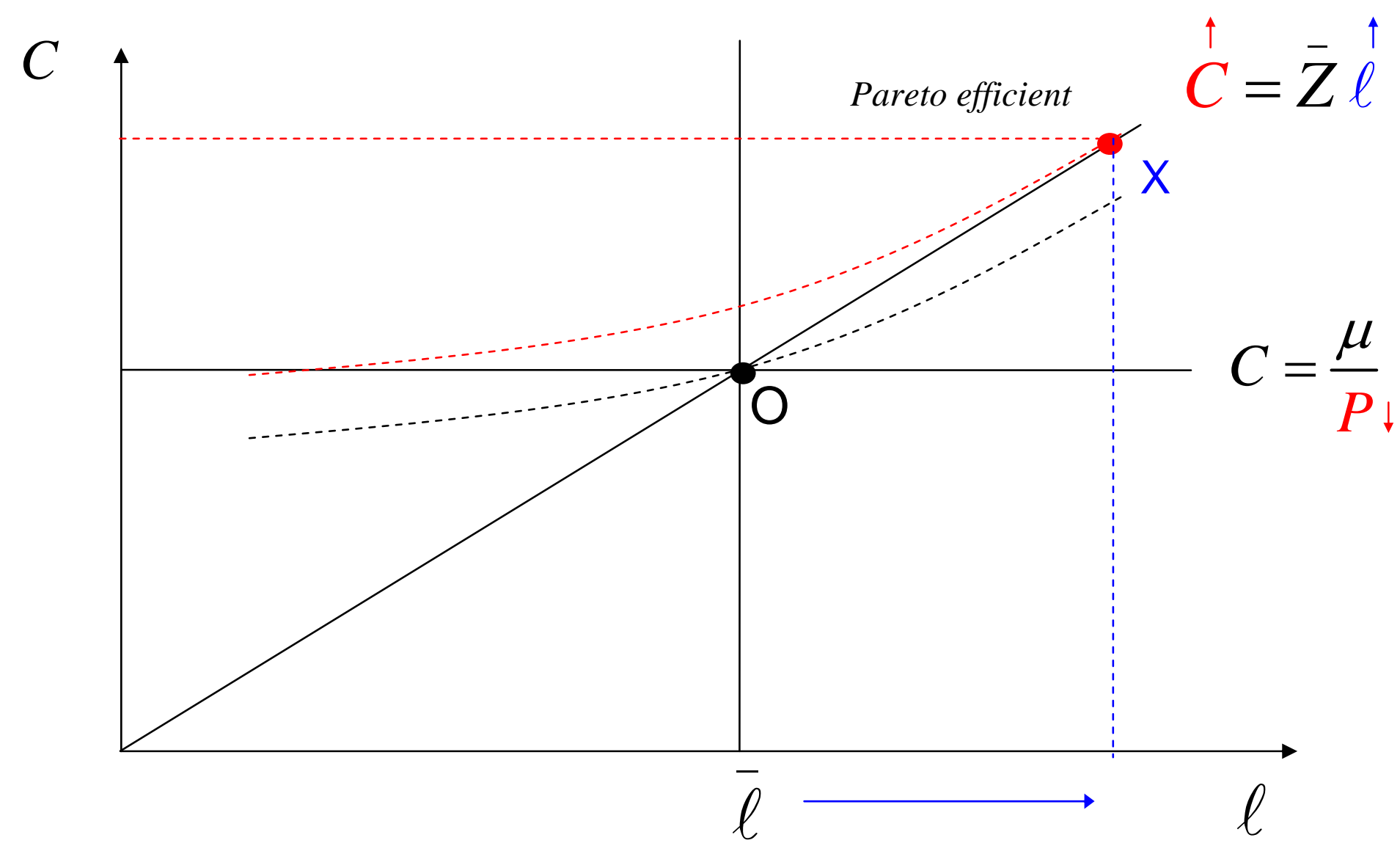


Figure 3

Positive productivity shock with and without price rigidities

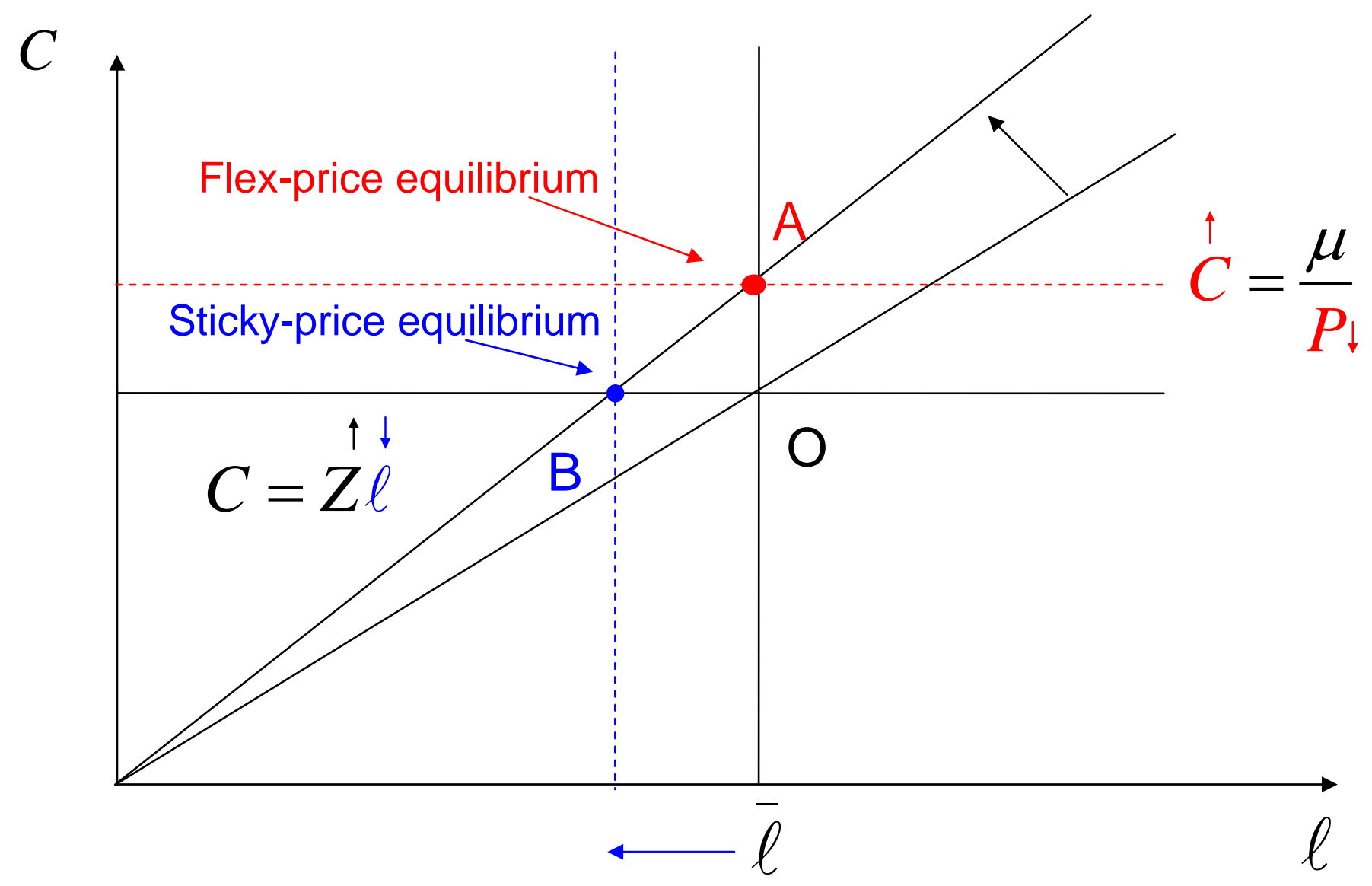


Figure 4

Optimal policy response to shocks under price rigidities

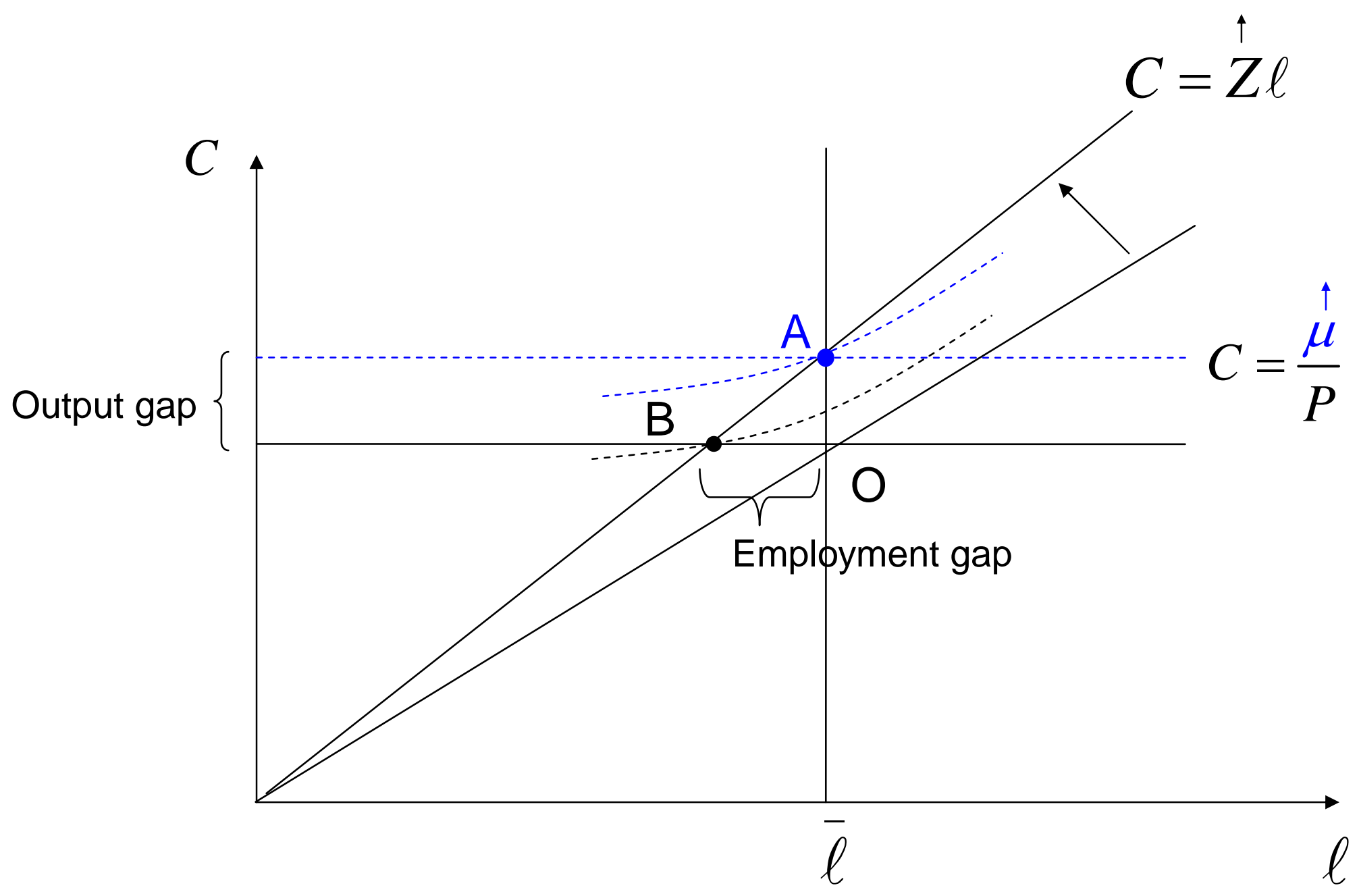


Figure 5

Price setting under uncertainty

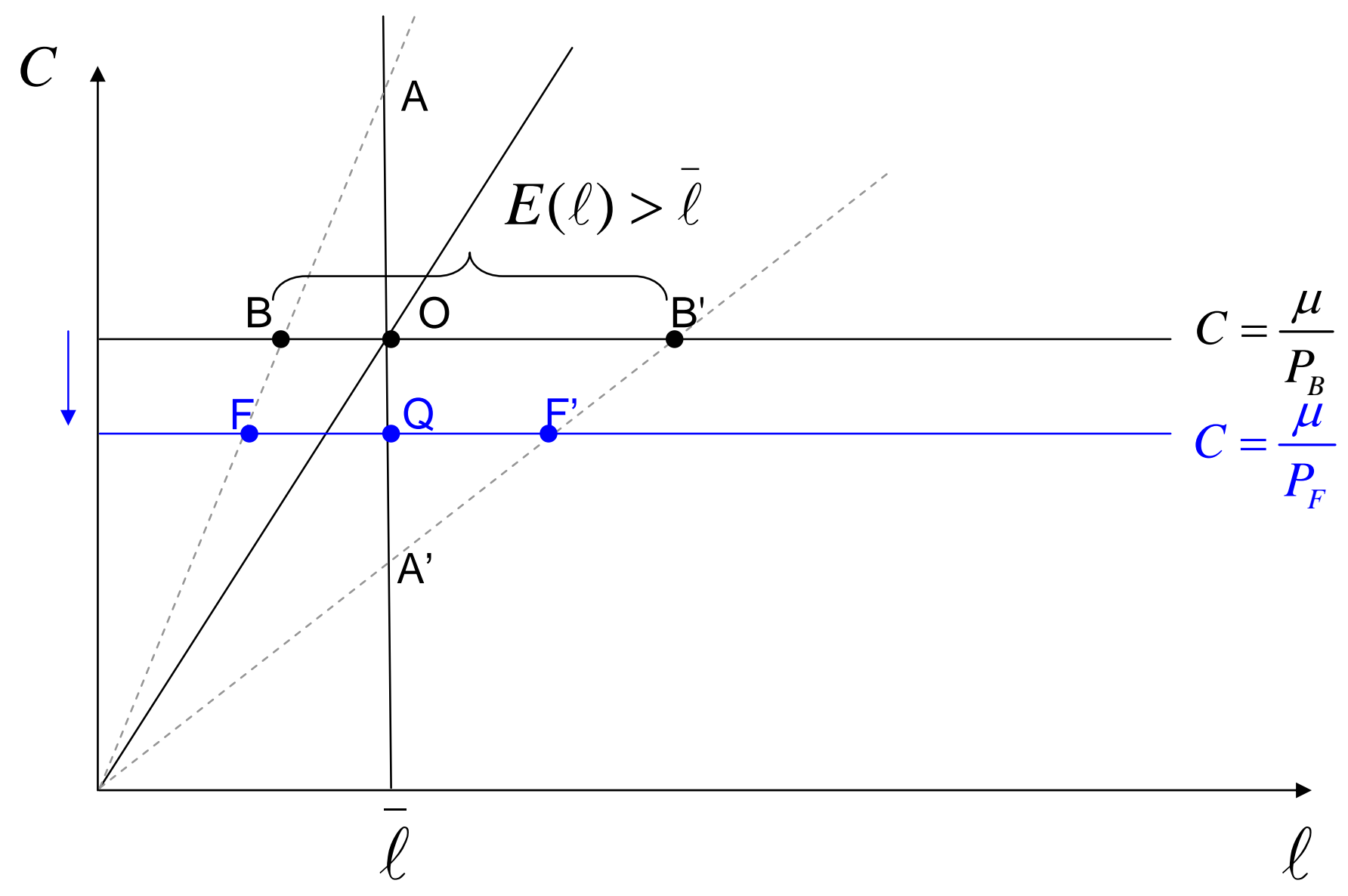


Figure 6

Permanent fiscal expansion

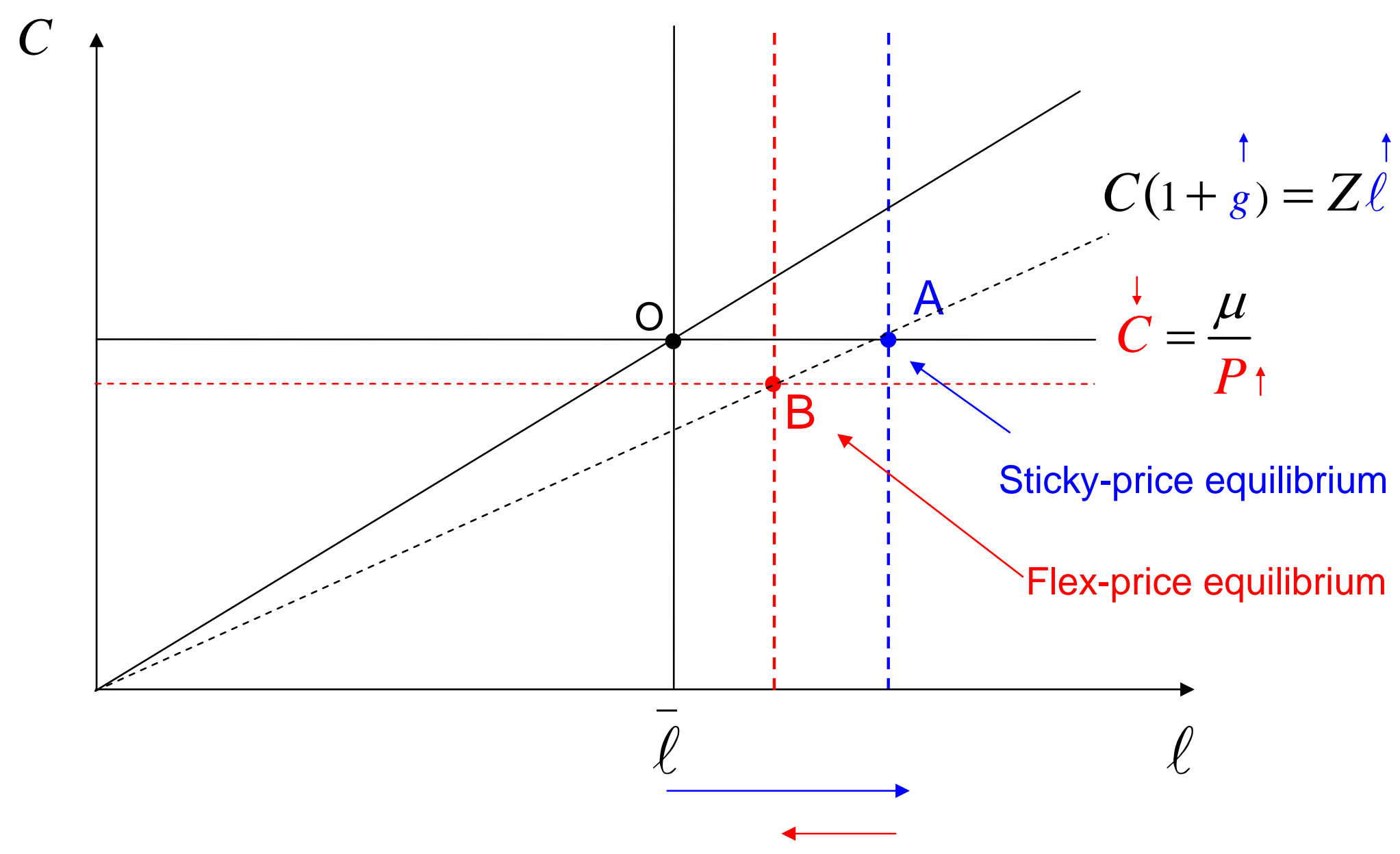


Figure 7

World-economy model

Home

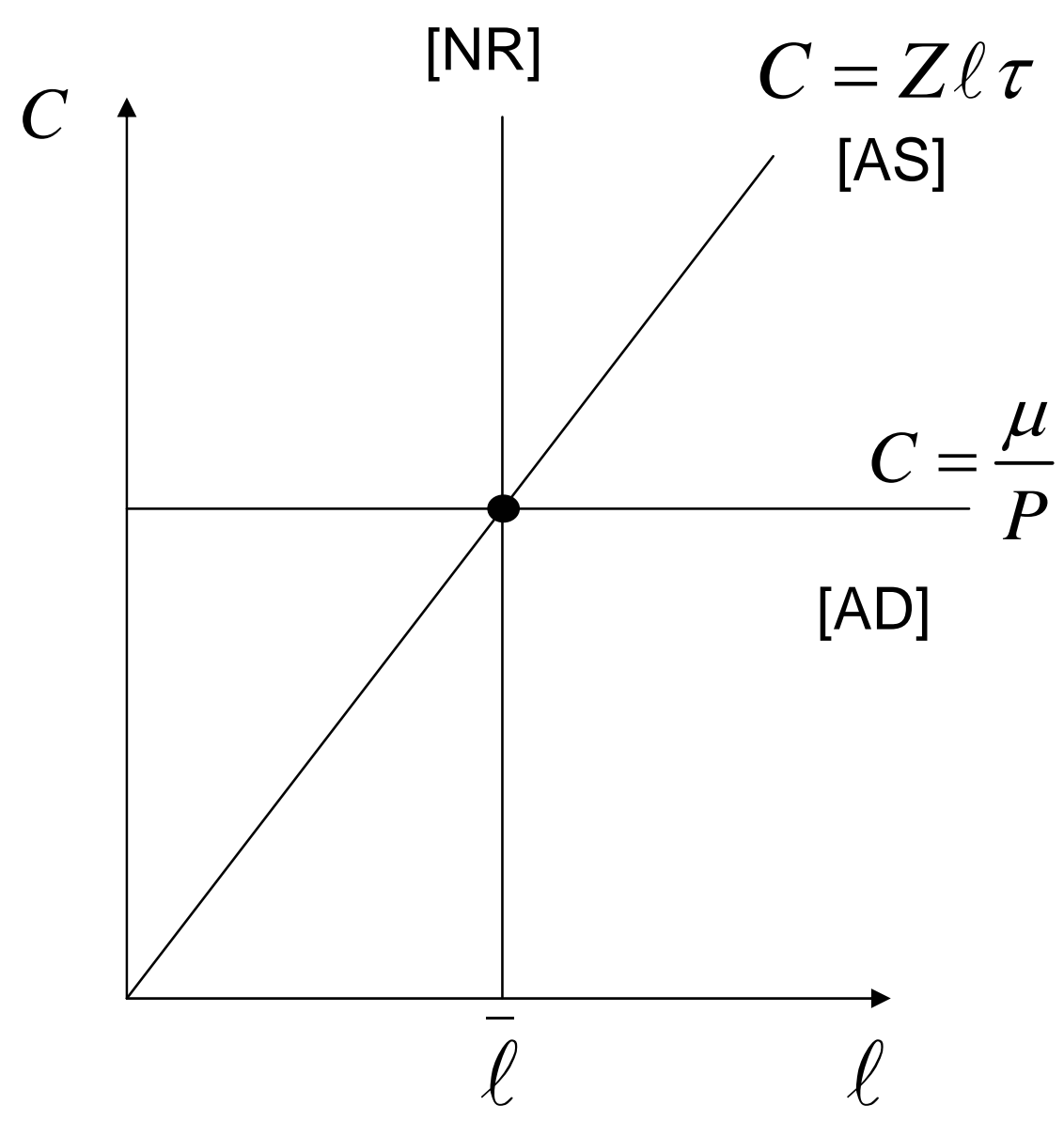

Foreign

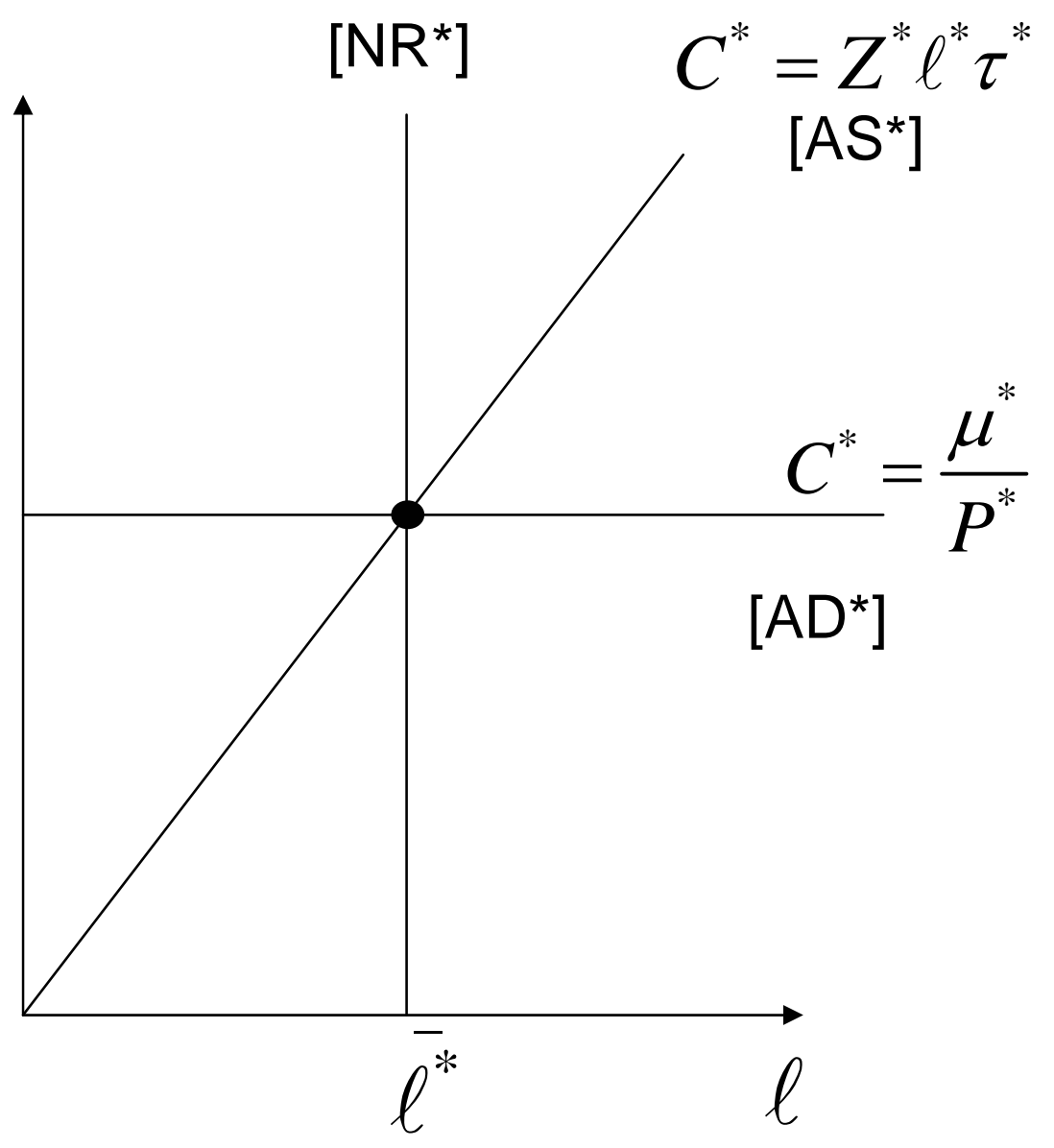


Figure 8

International transmission of productivity shocks under flexible prices
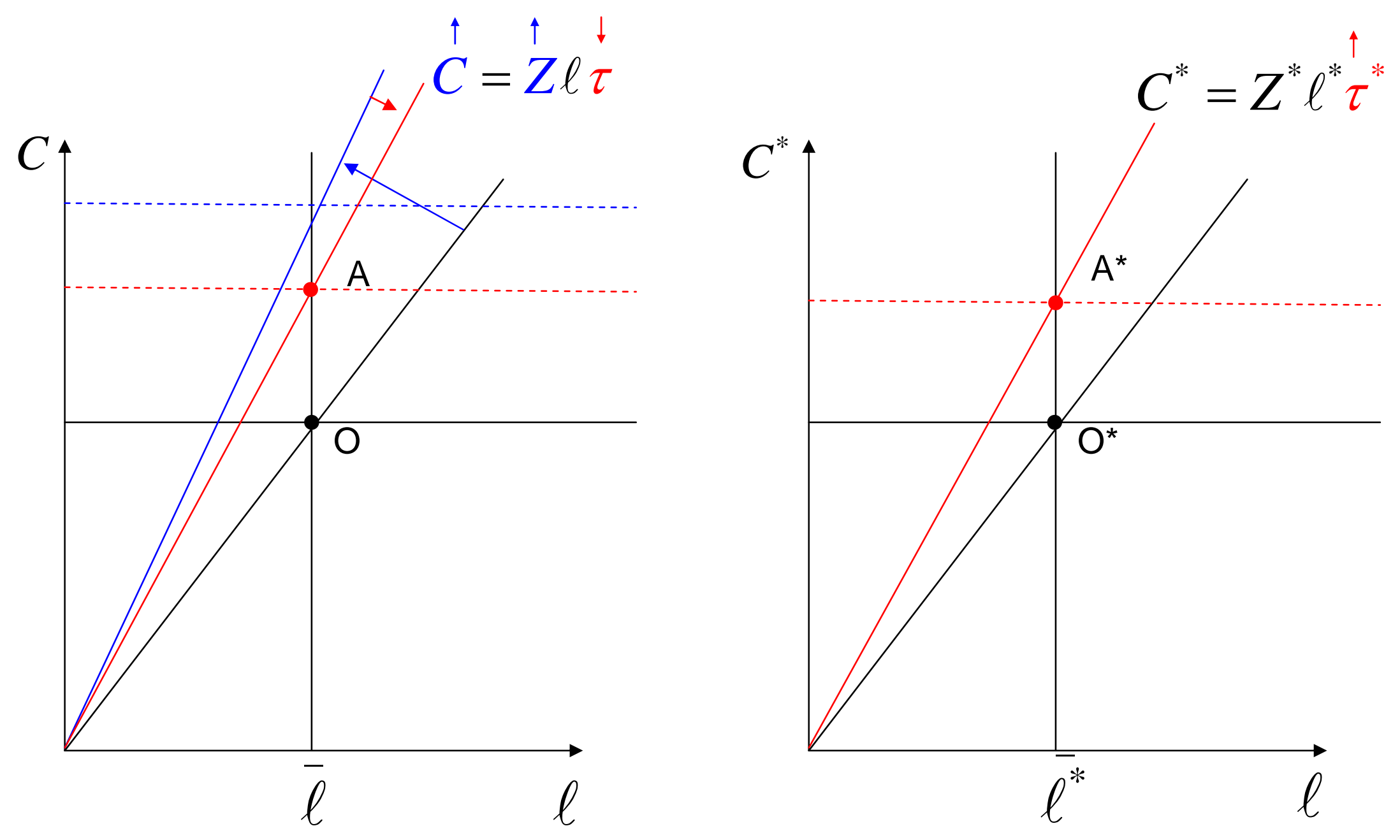
Figure 9

International spillovers of structural reforms
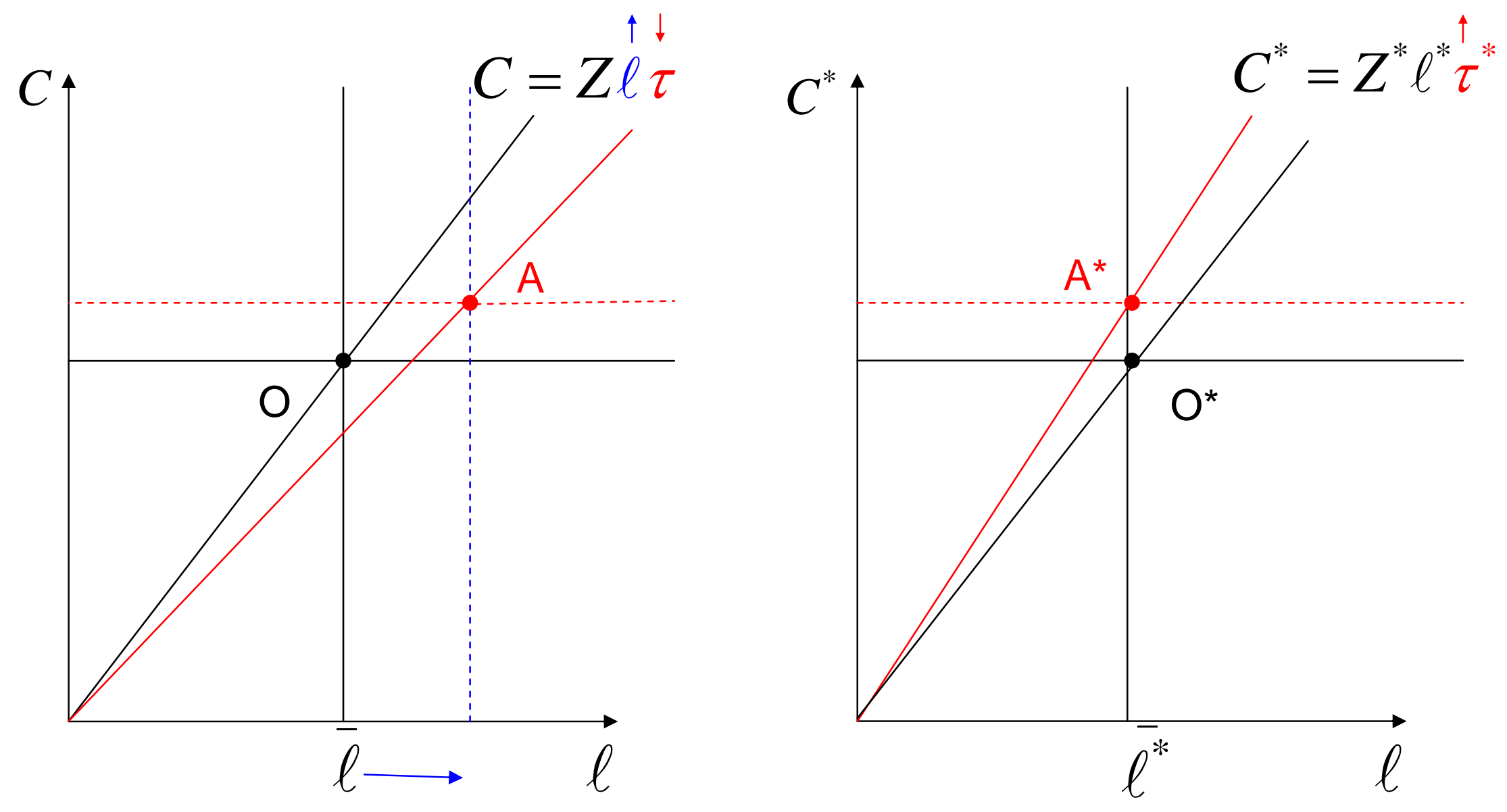
Figure 10

International (non-)transmission of productivity shocks under sticky prices
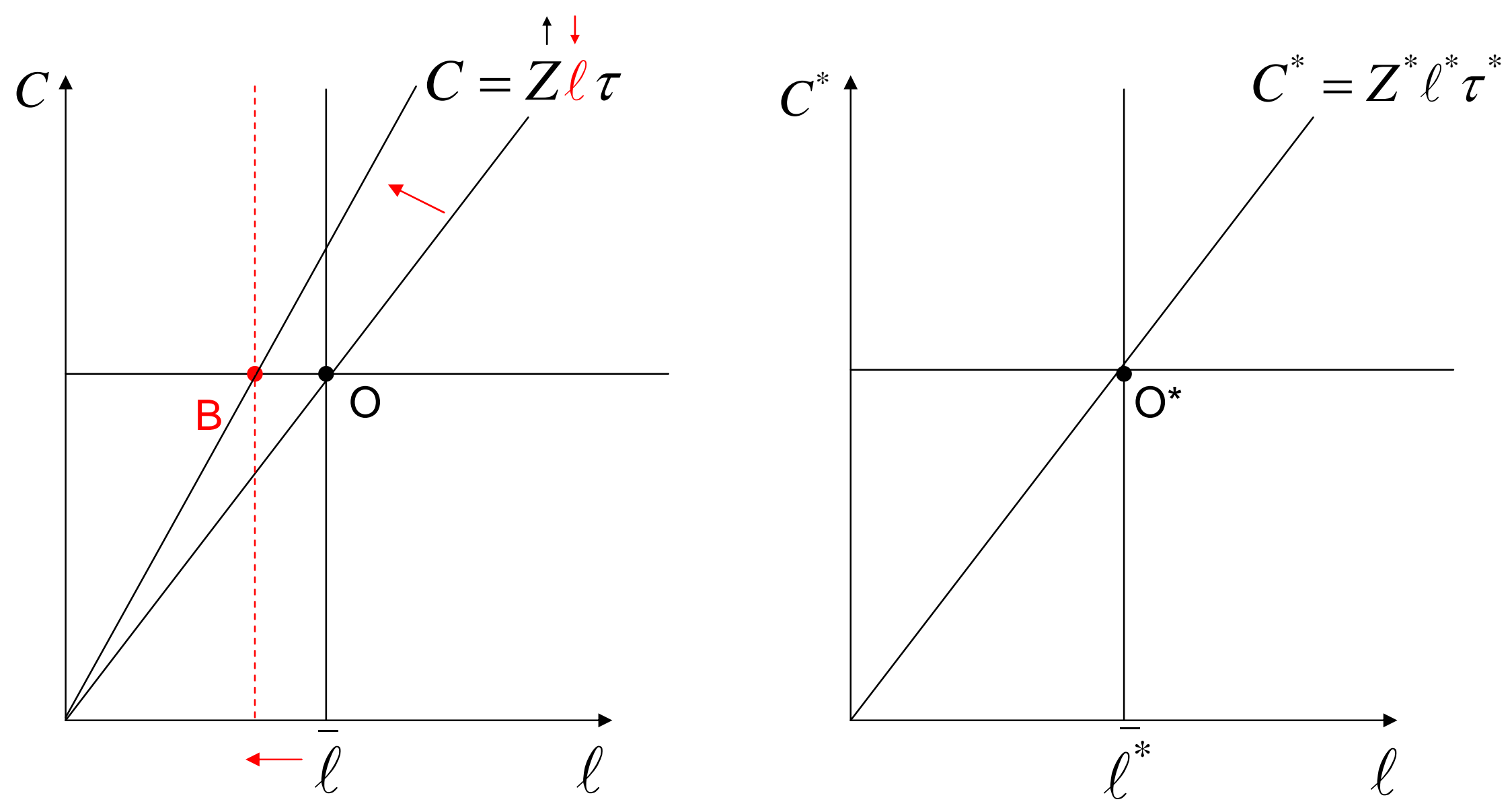
Figure 11

International effects of domestic stabilization policy under high pass-through (PCP)
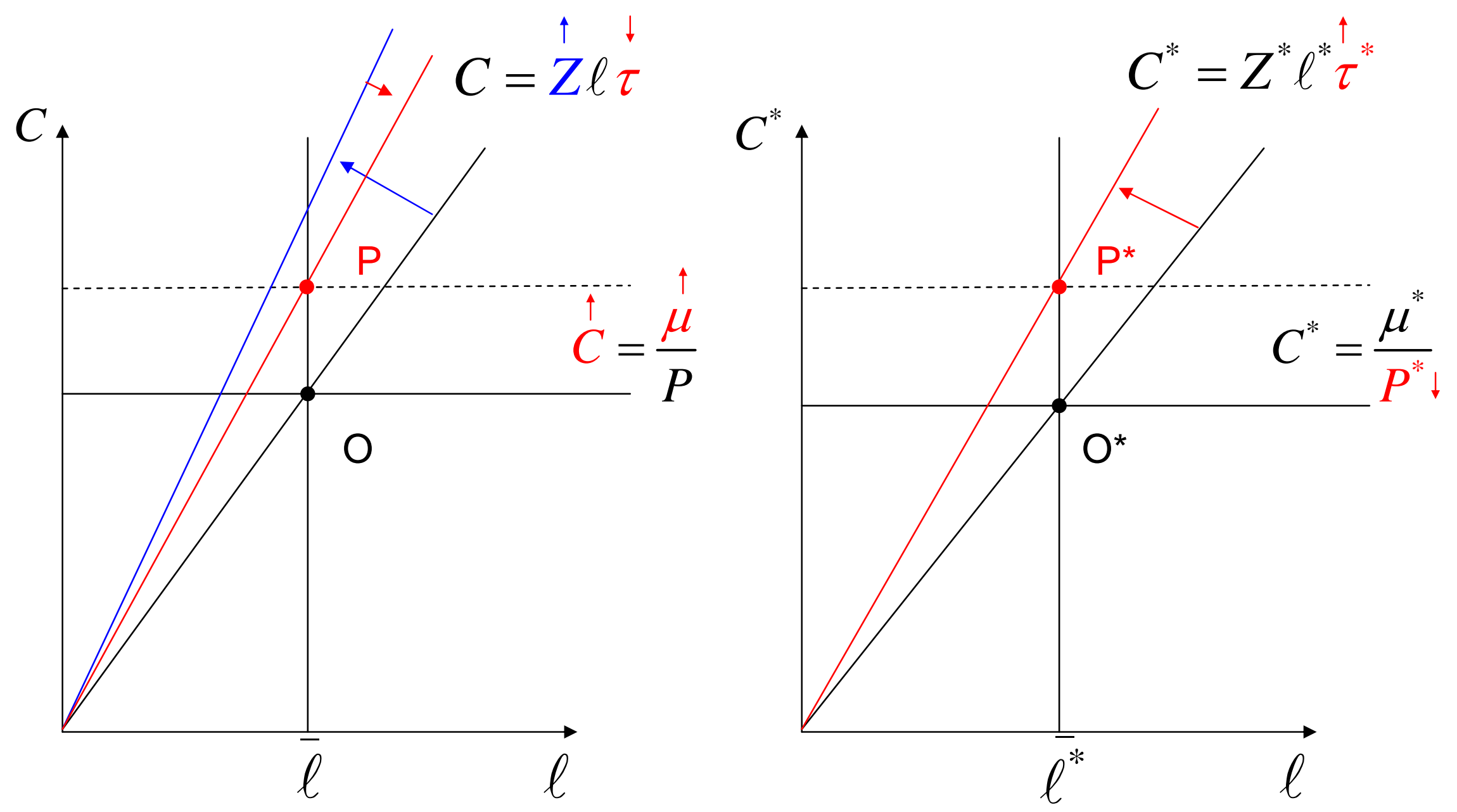
Figure 12

International effects of domestic stabilization policy under low pass-through (LCP)
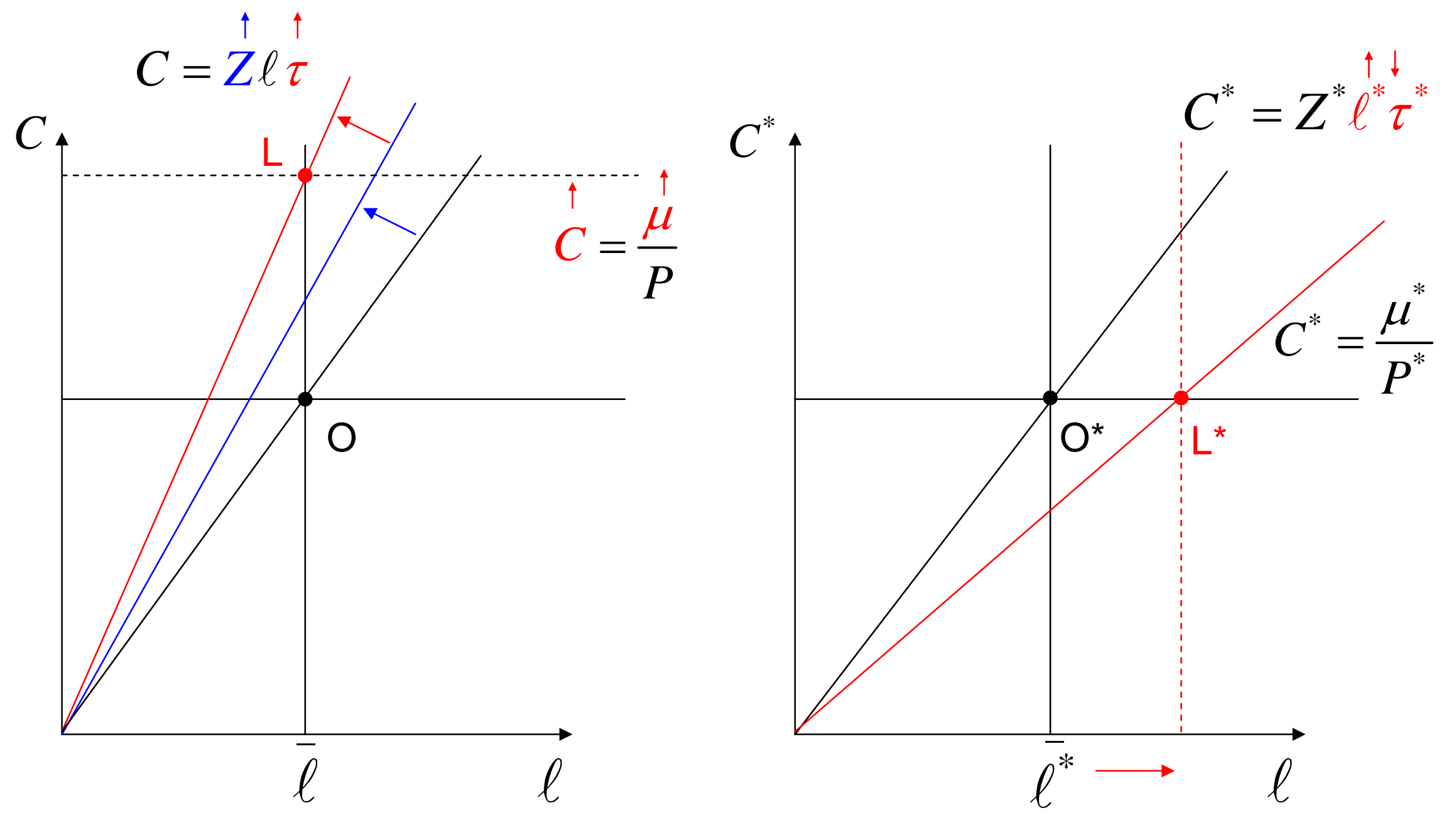
Figure 13

International effects of domestic stabilization policy under asymmetric pass-through (DP)
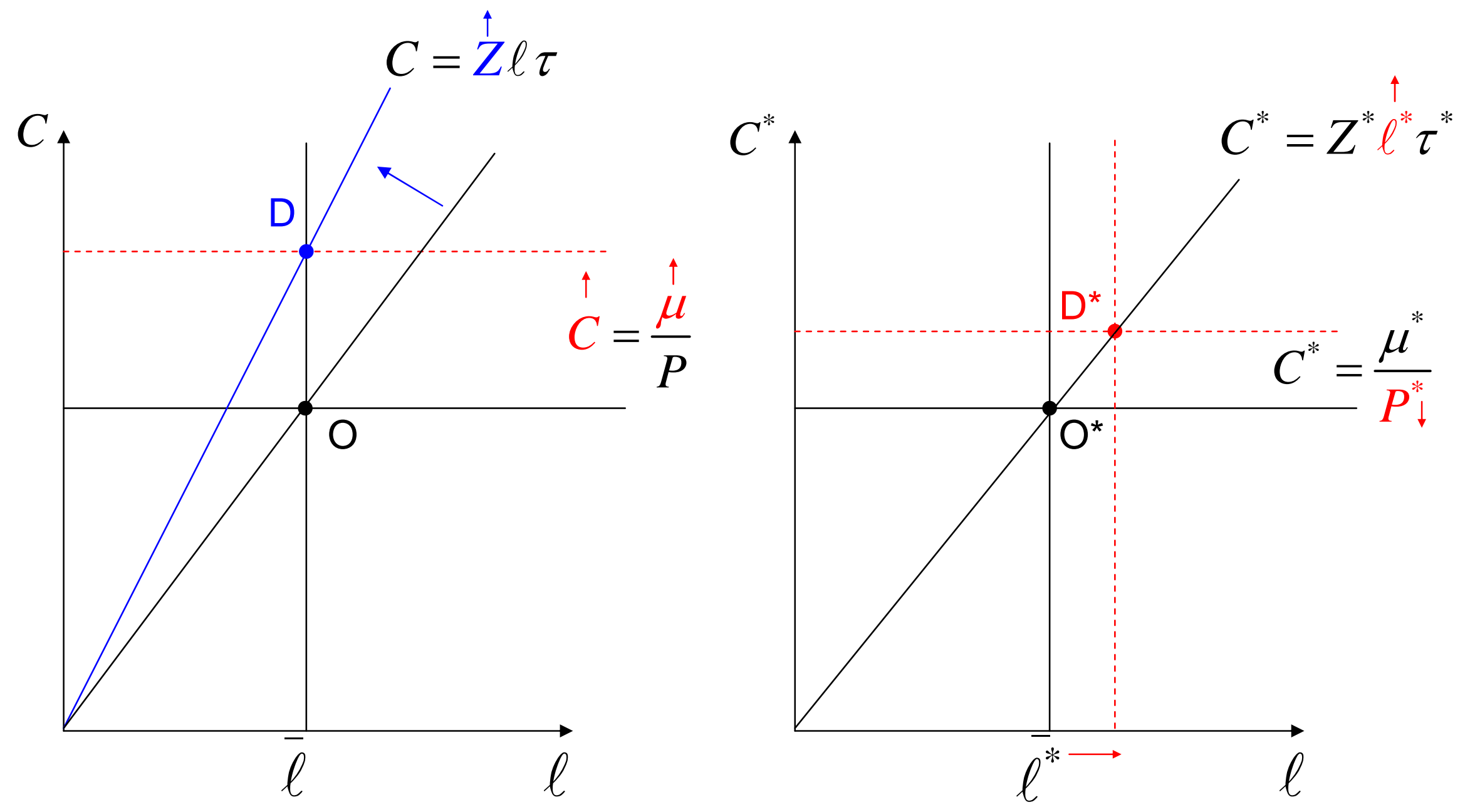


\section{Appendix 1 Algebra of the closed-economy model}

The economy consists of households, firms, and the government. Households and firms are defined over a continuum of unit mass. Households are indexed by $j \in[0,1]$, firms are indexed by $h \in[0,1]$. Each firm produces a variety (brand), which is an imperfect substitute to all other varieties under conditions of monopolistic competition.

Households The lifetime expected utility of household $j$ is:

$$
\mathcal{U}_{t}(j) \equiv E_{t} \sum_{\tau=t}^{\infty} \beta^{\tau-t} U_{\tau}(j) \equiv E_{t} \sum_{\tau=t}^{\infty} \beta^{\tau-t}\left[\ln C_{\tau}(j)-\kappa \ell_{\tau}(j)+\chi \ln \frac{M_{\tau}(j)}{P_{\tau}}\right]
$$

where $\beta<1$ is the discount rate, $C_{t}(j)$ is consumption, $\ell_{t}(j)$ labor effort, $M_{t}(j)$ money holdings, $P_{t}$ is the price of one unit of consumption (the Consumer Price Index, or CPI), $\chi$ is a positive parameter measuring utility from real balances, and $\kappa$ is a positive parameter measuring disutility of labor effort.

Consumption $C_{t}(j)$ is a constant-elasticity-of-substitution (CES) basket of all varieties produced by the firms:

$$
C_{t}(j)=\left(\int_{0}^{1} C_{t}(h, j)^{1-\frac{1}{\theta}} d h\right)^{\frac{\theta}{\theta-1}} \quad \theta>1
$$

where $C_{t}(h, j)$ is consumption of variety $h$ by household $j$, and $\theta$ is the elasticity of substitution across varieties. Note that $\theta$ is bounded from below by 1 . When $\theta$ tends to infinity all varieties are perfect substitutes for each other.

Properties of the Consumer Price Index The price of a variety $h$ is denoted $p(h)$. The price of a consumption basket $P$ is defined as a CES index with elasticity $1 / \theta$, that is:

$$
P_{t} \equiv\left(\int_{0}^{1} p_{t}(h)^{1-\theta} d h\right)^{\frac{1}{1-\theta}}
$$

This specific functional form for the CPI is not chosen arbitrarily. In fact, the above price index is the minimum expenditure required to buy a given amount of the composite consumption good, given product prices. To show this, we minimize $\int_{0}^{1} p(h) C(h, j) d h$ subject to $C(j)=\left(\int_{0}^{1} C(h, j)^{1-\frac{1}{\theta}} d h\right)^{\frac{\theta}{\theta-1}}$.

Consider the following Lagrangian:

$$
L_{t}^{C P I}(j)=\min _{C_{t}(h, j)} \int_{0}^{1} p_{t}(h) C_{t}(h, j) d h+\lambda_{t}\left[C_{t}(j)-\left(\int_{0}^{1} C_{t}(h, j)^{1-\frac{1}{\theta}} d h\right)^{\frac{\theta}{\theta-1}}\right]
$$

where $\lambda_{t}$ is a Lagrange multiplier (whose economic interpretation will be clear in few passages). The first order condition is:

$$
\frac{\partial L_{t}^{C P I}(j)}{\partial C_{t}(h, j)}=p_{t}(h)-\lambda_{t} \frac{\theta}{\theta-1}\left(\int_{0}^{1} C_{t}(h, j)^{1-\frac{1}{\theta}} d h\right)^{\frac{\theta}{\theta-1}-1}\left(1-\frac{1}{\theta}\right) C_{t}(h, j)^{-\frac{1}{\theta}}=0
$$

which can be rearranged as:

$$
p_{t}(h)=\lambda_{t} C_{t}(j)^{\frac{1}{\theta}} C_{t}(h, j)^{-\frac{1}{\theta}}
$$


or:

$$
C_{t}(h, j)=\left(\frac{p_{t}(h)}{\lambda_{t}}\right)^{-\theta} C_{t}(j)
$$

Now raise both sides of the equation to the $1-1 / \theta$ power and take the integral over the $h$ brands:

$$
\int_{0}^{1} C_{t}(h, j)^{1-\frac{1}{\theta}} d h=\lambda_{t}^{\theta-1}\left(\int_{0}^{1} p_{t}(h)^{1-\theta} d h\right) C_{t}(j)^{1-\frac{1}{\theta}}
$$

which can be rewritten as:

$$
C_{t}(j)^{\frac{\theta-1}{\theta}}=\lambda_{t}^{\theta-1} P_{t}^{1-\theta} C_{t}(j)^{1-\frac{1}{\theta}}
$$

implying:

$$
\lambda_{t}=P_{t}
$$

so that the Lagrangian multiplier is the CPI itself.

Now we can finally write:

$$
C_{t}(h, j)=\left(\frac{p_{t}(h)}{P_{t}}\right)^{-\theta} C_{t}(j)
$$

Consumption of variety $h$ depends on two elements: the price of variety $h$ relative to all other varieties, with price elasticity $\theta$, and the size of household $j$ 's total consumption. Note that nominal spending can be written as:

$$
\begin{aligned}
& \int_{0}^{1} p_{t}(h) C_{t}(h, j) d h=\left(\int_{0}^{1} p_{t}(h)\left(\frac{p_{t}(h)}{P_{t}}\right)^{-\theta} d h\right) C_{t}(j) \\
= & \left(\int_{0}^{1} p_{t}(h)^{1-\theta} P_{t}^{\theta} d h\right) C_{t}(j)=P_{t}^{\theta}\left(\int_{0}^{1} p_{t}(h)^{1-\theta} d h\right) C_{t}(j) \\
= & P_{t}^{\theta} P_{t}^{1-\theta} C_{t}(j)=P_{t} C_{t}(j)
\end{aligned}
$$

Total demand for variety $h$ is obtained by aggregating individual consumption over households $j$ :

$$
\int_{0}^{1} C_{t}(h, j) d j=\left(\frac{p_{t}(h)}{P_{t}}\right)^{-\theta} C_{t}
$$

In the previous expression $C_{t}$ is defined as:

$$
C_{t} \equiv \int_{0}^{1} C_{t}(j) d j
$$

The convention throughout this Appendix is that variables without an index $(j)$ are expressed in per-capita terms.

Budget constraint and consumer optimization Household $j$ receives a wage income and dividends from the firms, pays taxes to the government, purchases consumption goods, and accumulates money and a nominal bond. The individual flow budget constraint at time $\tau$ is therefore:

$M_{\tau}(j)+B_{\tau}(j) \leq M_{\tau-1}(j)+\left(1+i_{\tau-1}\right) B_{\tau-1}(j)+W_{\tau} \ell_{\tau}(j)+\mathcal{P}_{\tau}(j)-N E T T_{\tau}(j)-P_{\tau} C_{\tau}(j)$

where $B_{\tau}$ are holdings of the bond, $i_{\tau}$ the nominal interest rate, $W_{\tau}$ is the nominal wage, $\mathcal{P}_{\tau}(j)$ are nominal dividends, and $N E T T(j)$ are non-distortionary (lump-sum) net 
taxes denominated in national currency. As households own the portfolio of all firms, $\mathcal{P}_{\tau}(j)=\int_{0}^{1} \mathcal{P}_{\tau}(h) d h$. In the expression above, the nominal yield $i_{\tau-1}$ is paid at the beginning of period $\tau$ and is known at time $\tau-1$.

Taking prices and wages as given, Home agent $j$ maximizes (A.1) subject to the sequence of flow budget constraints (A.14) for $\{\tau\}_{t}^{\infty}$ with respect to consumption, labor effort, and asset holdings. The problem can be stated in terms of the following Lagrangian:

$$
\begin{aligned}
& L_{t}(j)=\max _{\left\{C_{\tau}(j), B_{\tau}(j), M_{\tau}(j), \ell_{\tau}(j)\right\}_{\tau=t}^{\infty}} \mathcal{U}_{t}(j) \\
& -E_{t} \sum_{\tau=t}^{\infty} \beta^{\tau-t}\left\{D _ { \tau } ( j ) \left[M_{\tau}(j)+B_{\tau}(j)-M_{\tau-1}(j)-\left(1+i_{\tau-1}\right) B_{\tau-1}(j)\right.\right. \\
& \left.\left.-W_{\tau} \ell_{\tau}(j)-\mathcal{P}_{\tau}(j)+N E T T_{\tau}(j)+P_{\tau} C_{\tau}(j)\right]\right\}
\end{aligned}
$$

where $D_{\tau}(j)$ is the Lagrangian multiplier associated with the flow budget constraint at time $\tau$.

The first order condition with respect to $C_{t}(j)$ yields

$$
\frac{\partial L_{t}(j)}{\partial C_{t}(j)}=\frac{1}{C_{t}(j)}-D_{t}(j) P_{t}=0
$$

The multiplier $D_{t}(j)$ measures the increase in household $j$ 's utility (shadow price) associated with one additional unit of nominal wealth. It is the product of two terms: $1 / P_{t}$ transforms nominal wealth into consumption baskets, and $1 / C_{t}(j)$ accounts for household $j$ 's need for additional real wealth (a decreasing function of current consumption).

The first order condition with respect to $B_{t}(j)$ (Euler equation) determines the intertemporal allocation:

$$
\frac{\partial L_{t}(j)}{\partial B_{t}(j)}=-D_{t}(j)+\beta\left(1+i_{t}\right) E_{t} D_{t+1}(j)=0
$$

Define the nominal discount rate between time $t$ and $t+\tau$ for the household $j$ as

$$
Q_{t, t+\tau}(j)=\beta \frac{D_{t+\tau}(j)}{D_{t}(j)}=\beta^{\tau} \frac{C_{t}(j)}{C_{t+\tau}(j)} \frac{P_{t}}{P_{t+\tau}}
$$

The Euler equation (A.17) can then be written as:

$$
\frac{1}{\left(1+i_{t}\right)}=\beta E_{t}\left(\frac{C_{t}(j)}{C_{t+1}(j)} \frac{1}{1+\pi_{t+1}}\right)=E_{t}\left(Q_{t, t+1}(j)\right)
$$

where $\pi_{t+1} \equiv P_{t+1} / P_{t}-1$ is the inflation rate.

The first order condition with respect to $M_{t}(j)$ yields:

$$
\frac{\partial L_{t}(j)}{\partial M_{t}(j)}=\frac{\chi}{M_{t}(j)}-D_{t}(j)+\beta E_{t} D_{t+1}(j)=0
$$

according to which money holdings are proportional to nominal spending.

Finally, the first order condition with respect to $\ell_{t}(j)$ yields:

$$
\frac{\partial L_{t}(j)}{\partial \ell_{t}(j)}=-\kappa+W_{t} D_{t}(j)=0
$$

Workers equate the marginal rate of substitution between consumption and leisure, $\kappa C_{t}(j)$, to the real wage in consumption units, $W_{t} / P_{t}$. Note that, with a common CPI index, the previous expression implies equalization of consumption across agents, or:

$$
C_{t}(j)=C_{t}, \quad D_{t}(j)=D_{t}, \quad Q_{t, t+\tau}(j)=Q_{t, t+\tau} .
$$


Firms Each firm produces a variety $h$ employing labor supplied by the households. The technology of production is linear in labor effort:

$$
Y_{t}(h)=Z_{t} \ell_{t}(h)
$$

where $Y_{t}(h)$ is the output of firm $h, \ell_{t}(h)$ is the labor input used by firm $h$, and $Z_{t}$ is a productivity process common to all firms.

Firm $h$ minimizes costs $W_{t} \ell_{t}(h)$ subject to the above technology. The Lagrangian multiplier associated with this problem is the nominal marginal cost $M C_{t}(h)$, equal to:

$$
M C_{t}(h)=M C_{t}=\frac{W_{t}}{Z_{t}}
$$

Note that marginal costs are symmetric across firms. In equilibrium the supply of variety $h$ is equal to its demand:

$$
Y_{t}(h)=\int_{0}^{1} C_{t}(h, j) d j
$$

Profit maximization and price setting Firms operating under conditions of monopolistic competition take into account the downward-sloping demand for their product (A.12) and set prices to maximize their value. Firms are small, in the sense that they ignore the impact of their pricing and production decisions on aggregate variables and price indexes.

Let $\mathcal{P}_{t}(h)$ denote firm $h$ 's nominal dividends:

$$
\begin{aligned}
\mathcal{P}_{t}(h) & \equiv p_{t}(h) Y_{t}(h)-W_{t} \ell_{t}(h)=\left(p_{t}(h)-\frac{W_{t}}{Z_{t}}\right) Y_{t}(h) \\
& =\left(p_{t}(h)-M C_{t}\right)\left(\frac{p_{t}(h)}{P_{t}}\right)^{-\theta} C_{t}
\end{aligned}
$$

Without nominal rigidities, in each period firm $h$ optimally chooses $p(h)$ to maximize current dividends $\mathcal{P}_{t}(h)$. Maximizing (A.26) with respect to $p(h)$ yields:

$$
p_{t}(h)=\frac{\theta}{\theta-1} M C_{t}
$$

The price of variety $h$ is equal to the marginal cost, $W_{t} / Z_{t}$, augmented by a constant markup $\theta /(\theta-1)$ that reflects the monopoly power of the firm, which in itself is a function of the substitutability between $h$ and the other varieties.

With nominal rigidities, the price $p_{t}(h)$ is set before the realization of the productivity and policy shocks, based on available information. The firm's problem is to maximize the present discounted value of expected profits $Q_{t-1, t} \mathcal{P}_{t}(h)$, where $Q_{t-1, t}$ is the households' (i.e. shareholders') discount rate:

$$
\max _{p_{t}(h)} E_{t-1}\left(Q_{t-1, t} \mathcal{P}_{t}(h)\right)=E_{t-1}\left(Q_{t-1, t}\left(p_{t}(h)-M C_{t}\right)\left(\frac{p_{t}(h)}{P_{t}}\right)^{-\theta} C_{t}\right)
$$

The first order condition is:

$$
E_{t-1}\left(Q_{t-1, t}\left(\frac{p_{t}(h)}{P_{t}}\right)^{-\theta} C_{t}\right)-\theta \frac{1}{p_{t}(h)} E_{t-1}\left(Q_{t-1, t}\left(p_{t}(h)-M C_{t}\right)\left(\frac{p_{t}(h)}{P_{t}}\right)^{-\theta} C_{t}\right)=0
$$


which can be written as:

$$
p_{t}(h)=\frac{\theta}{\theta-1} \frac{E_{t-1}\left(\begin{array}{ll}
M C_{t} & Q_{t-1, t}\left(\frac{p_{t}(h)}{P_{t}}\right)^{-\theta} C_{t}
\end{array}\right)}{E_{t-1}\left(Q_{t-1, t}\left(\frac{p_{t}(h)}{P_{t}}\right)^{-\theta} C_{t}\right)}
$$

According to the previous expression, the price under nominal rigidities is equal to the expected marginal cost, appropriately discounted. This expression can be further simplified by recalling that $Q_{t-1, t}=\beta P_{t-1} C_{t-1} / P_{t} C_{t}$, and observing that all prices $p_{t}(h)$ are symmetric, thus $p_{t}(h)=P_{t}$ :

$$
p_{t}(h)=P_{t}=\frac{\theta}{\theta-1} E_{t-1}\left(M C_{t}\right)
$$

As a corollary, the fact that — with or without nominal rigidities - all prices are symmetric and $p_{t}(h)=P_{t}$, implies that consumption of each variety is symmetric as well: $C_{t}(h, j)=C_{t}(j)=C_{t}$ (from (A.10) and (A.22)). In turn, the supply of each variety is symmetric: $Y_{t}(h)=C_{t}($ from $(\mathrm{A} .25))$ and $\ell_{t}(h)=C_{t} / Z_{t}$ (from (A.23)), or:

$$
C_{t}=Z_{t} \ell_{t}
$$

Monetary policy and the government budget constraint In our text, we define the monetary stance as $\mu_{t}=P_{t} C_{t}$. It is instructive to note that, using this definition, we can rewrite the Euler equation of the national representative consumer as follows:

$$
\frac{1}{\mu_{t}}=\beta\left(1+i_{t}\right) E_{t}\left(\frac{1}{\mu_{t+1}}\right)
$$

Integrating this expression forward, we express $\mu_{t}$ as a forward looking variable, depending on an average of current and future interest rate:

$$
\frac{1}{\mu_{t}}=E_{t} \lim _{N \rightarrow \infty} \beta^{N} \frac{1}{\mu_{t+N}} \prod_{\tau=0}^{N-1}\left(1+i_{t+\tau}\right) .
$$

Also, observe that (A.20) can be written as:

$$
\frac{M_{t}(j)}{\chi}=P_{t} C_{t} \frac{1+i_{t}}{i_{t}}=\frac{\mu_{t}}{1-\beta E_{t}\left(\mu_{t} / \mu_{t+1}\right)}
$$

As there is no public spending, the government uses seigniorage revenues and taxes to finance transfers. The public budget constraint is simply:

$$
M_{t}-M_{t-1}+\int_{0}^{1} N E T T_{t}(j) d j=0
$$

and in equilibrium money supply equals demand, or $M_{t}=\int_{0}^{1} M_{t}(j) d j$.

Finally, the bond is in zero net supply:

$$
\int_{0}^{1} B_{t}(j) d j=0
$$

so that $B_{t}=0$ in aggregate terms. 
Prices and expected labor effort Now recall the expression for $P$. Without nominal rigidities we have:

$$
P_{t}=\frac{\theta}{\theta-1} M C_{t}=\frac{\theta \kappa}{\theta-1} \frac{P_{t} C_{t}}{Z_{t}}
$$

solved by:

$$
C_{t}=\frac{\theta-1}{\theta \kappa} Z_{t}
$$

which implies that, regardless of the shocks hitting the economy, labor is always at some constant level that depends on two elements: the degree of monopoly power (the less competitive the economy, the lower the average level of labor effort), and the sensitivity of disutility to labor effort (when work is painful and $k$ is high, households will supply little labor effort). We refer to this constant as the 'potential', or 'natural' rate of employment:

$$
\bar{\ell}=\frac{\theta-1}{\theta \kappa}
$$

Correspondingly, $[(\theta-1) /(\theta \kappa)] Z$ measures potential output.

With nominal rigidities, instead, we have:

$$
P_{t}=\frac{\theta}{\theta-1} E_{t-1}\left(M C_{t}\right)=\bar{\ell}^{-1} E_{t-1}\left(\frac{P_{t} C_{t}}{Z_{t}}\right)
$$

which implies:

$$
E_{t-1}\left(\ell_{t}\right)=\bar{\ell} .
$$

Prices are set such that, on average, firms minimize deviations of output from potential and households minimize deviations of labor from the natural rate.

Macroeconomic synthesis Summing up, the macroeconomic equations of the model are:

$$
\begin{gathered}
C_{t}=Z_{t} \ell_{t} \\
\mu_{t}=P_{t} C_{t} \\
\ell_{t}^{\text {flex }}=\frac{\theta-1}{\theta \kappa} \equiv \bar{\ell} \quad \text { or } \quad P_{t}^{f l e x}=\bar{\ell}^{-1} \frac{\mu_{t}}{Z_{t}} \quad \text { under flexible prices } \\
\ell_{t}=\frac{\mu_{t} / Z_{t}}{E_{t-1}\left(\mu_{t} / Z_{t}\right)} \bar{\ell} \quad \text { or } \quad P_{t}=\bar{\ell}^{-1} E_{t-1}\left(\frac{\mu_{t}}{Z_{t}}\right) \quad \text { under sticky prices }
\end{gathered}
$$

where $Z_{t}$ and $\mu_{t}$ are exogenous variables, and $C_{t}, P_{t}$, and $\ell_{t}$ are endogenous variables.

Abstracting from real balance effects - which are unlikely to be significant - the instantaneous utility flow in (A.1) is given by $U_{t}=\ln C_{t}-\kappa \ell_{t}$. Note that the slope of the indifference curve at the equilibrium point is:

$$
\left.\frac{\partial C_{t}}{\partial \ell_{t}}\right|_{\ln C_{t}-\kappa \ell_{t}=\bar{U}}=\kappa C_{t}=\frac{\theta-1}{\theta} Z_{t}<Z_{t}
$$

This slope (marginal rate of substitution) is smaller than the slope of the production function (marginal rate of transformation) because of the distortion stemming from monopoly power. 
Optimal monetary stance We now focus on the design of optimal monetary rules - defined as rules that maximize the expected utility of the representative household - in the presence of uncertainty and one-period nominal rigidities. Once again, we disregard the utility gains from real balances, so that the optimal monetary stance $\mu_{t}$ solves the problem:

$$
\max _{\mu_{t}} E_{t-1}\left(\ln C_{t}-\kappa \ell_{t}\right)
$$

Recall that $E_{t-1}\left(\ell_{t}\right)=\bar{\ell}$, so that the second term in utility is independent of monetary policy and we need only focus on consumption. Welfare can then be written as:

$$
\begin{aligned}
& E_{t-1}\left(\ln C_{t}-\kappa \ell_{t}\right)=E_{t-1} \ln \frac{\theta-1}{\theta \kappa} \frac{\mu_{t}}{E_{t-1}\left(\mu_{t} / Z_{t}\right)}-\kappa \frac{\theta-1}{\theta \kappa} \\
= & \text { const. }+E_{t-1} \ln \mu_{t}-\ln E_{t-1}\left(\mu_{t} / Z_{t}\right)
\end{aligned}
$$

Take the first order condition for a maximum, recalling that:

$$
\frac{d f[E(g[X])]}{d X}=f^{\prime}[E(g[X])] g^{\prime}[X]
$$

and obtain:

$$
\frac{1}{\mu_{t}}-\frac{1 / Z_{t}}{E_{t-1}\left(\mu_{t} / Z_{t}\right)}=0
$$

that is:

$$
\frac{\mu_{t}}{Z_{t}}=E_{t-1}\left(\frac{\mu_{t}}{Z_{t}}\right)
$$

According to the previous expression, monetary policy responds one-to one to productivity shocks, stabilizing firms' markups.

Fiscal policy We conclude this Appendix by modifying the model in two dimensions. First, we generalize the disutility of labor effort in (A.1) as follows:

$$
\mathcal{U}_{t}(j) \equiv E_{t} \sum_{\tau=t}^{\infty} \beta^{\tau-t}\left[\ln C_{\tau}(j)-\kappa \frac{\ell_{\tau}(j)^{1+\nu}}{1+\nu}+\chi \ln \frac{M_{\tau}(j)}{P_{\tau}}\right]
$$

The key implication of this modification is that the first order condition for optimal labor effort - that is, the equivalent of (A.21) - becomes:

$$
W_{t}=\kappa P_{t} C_{t} \ell_{t}(j)^{\nu}
$$

An increase in labor effort is now associated with an increase in the real wage (and marginal cost $M C)$.

Second, we introduce public demand in the model and study the macroeconomic effects of government purchases of goods from firms. In what follows, we posit that public spending is purely dissipative, with no impact on households' utility.

Assuming that public spending falls on the same basket of varieties as private consumption, public demand for variety $h, G(h)$, is equal to:

$$
G_{t}(h)=\left(\frac{p_{t}(h)}{P_{t}}\right)^{-\theta} G_{t}
$$

where $G_{t}$ is total government consumption. The budget constraint of the public sectors is now:

$$
M_{t}-M_{t-1}+\int_{0}^{1} N E T T_{t}(j) d j=P_{t} G_{t}
$$


In equilibrium the supply of variety $h$ is equal to its demand:

$$
Y_{t}(h)=\int_{0}^{1} C_{t}(h, j) d j+G_{t}(h)
$$

and firm $h$ 's nominal dividends are now:

$$
\mathcal{P}_{t}(h)=\left(p_{t}(h)-M C_{t}\right)\left(\frac{p_{t}(h)}{P_{t}}\right)^{-\theta}\left(C_{t}+G_{t}\right)
$$

Let $g_{t}$ denote the ratio of government spending to aggregate consumption, or:

$$
g_{t}=\frac{G_{t}}{C_{t}}
$$

Hereafter and in the main text, we assume that $g_{t}$ is a random variable - government spending shock takes the form of unexpected changes in the ratio of public to private consumption.

Without nominal rigidities, equilibrium prices are still a constant markup over marginal costs:

$$
P_{t}=\frac{\theta}{\theta-1} M C_{t}=\frac{\theta \kappa}{\theta-1} \frac{P_{t} C_{t} \ell_{t}^{\nu}}{Z_{t}}
$$

Recalling that $P_{t} C_{t}=\mu_{t}$, and observing that the resource constraint can be written as:

$$
C_{t}\left(1+g_{t}\right)=Z_{t} \ell_{t}
$$

it is possible to rewrite the markup equation as:

$$
P_{t}=\frac{\theta \kappa}{\theta-1} \frac{P_{t} C_{t} \ell_{t}^{\nu}}{Z_{t}}=\left(\frac{1}{\bar{\ell}}\right) \frac{\mu_{t}}{Z_{t}}\left(\frac{1+g_{t}}{Z_{t}} \frac{\mu_{t}}{P_{t}}\right)^{\nu}
$$

where $\bar{\ell}$ is the same constant as defined in (A.40). It follows that the price level is:

$$
P_{t}=\left(\frac{1}{\bar{\ell}}\right)^{\frac{1}{1+\nu}}\left(\frac{\mu_{t}}{Z_{t}}\right)\left(1+g_{t}\right)^{\frac{\nu}{1+\nu}}
$$

so that:

$$
Y_{t}=Z_{t}(\bar{\ell}(1+g))^{\frac{1}{1+\nu}}, \quad \ell_{t}=\left(\bar{\ell}\left(1+g_{t}\right)\right)^{\frac{1}{1+\nu}}
$$

implying that both the natural rate of employment and output are a function of fiscal variables.

With nominal rigidities, instead, $p(h)$ is set at:

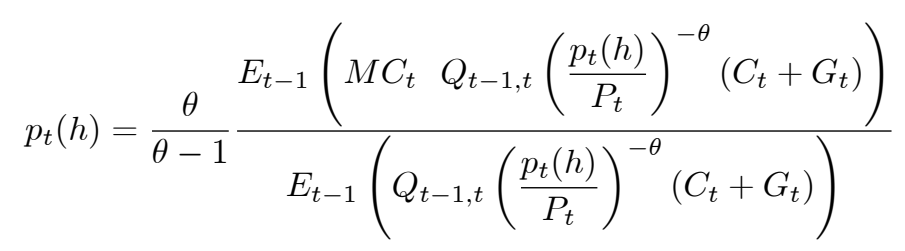

or:

$$
p_{t}(h)=P_{t}=\frac{\theta}{\theta-1} \frac{E_{t-1}\left[M C_{t}\left(1+g_{t}\right)\right]}{E_{t-1}\left(1+g_{t}\right)}=\left(\frac{1}{\bar{\ell}}\right) \frac{E_{t-1}\left[P_{t} C_{t} \ell_{t}^{\nu}\left(1+g_{t}\right) / Z_{t}\right]}{E_{t-1}\left(1+g_{t}\right)}
$$

Solving for the price level, we obtain:

$$
P_{t}^{1+\nu}=\left(\frac{1}{\bar{\ell}}\right) \frac{E_{t-1}\left[\left(\mu_{t}\left(1+g_{t}\right) / Z_{t}\right)^{1+\nu}\right]}{E_{t-1}\left(1+g_{t}\right)}
$$


Summing up, the macroeconomic equations of the model are:

$$
\begin{gathered}
G_{t}=g_{t} C_{t} \\
C_{t}\left(1+g_{t}\right)=Z_{t} \ell_{t} \\
\mu_{t}=P_{t} C_{t} \\
\ell_{t}^{\text {flex }}=\left[\bar{\ell}\left(1+g_{t}\right)\right]^{\frac{1}{1+\nu}} \text { or } P_{t}^{\text {flex }}=\left(\frac{1}{\bar{\ell}}\right)^{\frac{1}{1+\nu}} \frac{\mu_{t}}{Z_{t}}\left(1+g_{t}\right)^{\frac{\nu}{1+\nu}} \\
\ell_{t}=\bar{\ell}^{\frac{1}{1+\nu}} \frac{\mu_{t}}{Z_{t}}\left(1+g_{t}\right)\left(\frac{E_{t-1}\left(1+g_{t}\right)}{E_{t-1}\left[\left(\mu_{t}\left(1+g_{t}\right) / Z_{t}\right)^{1+\nu}\right]}\right)^{\frac{1}{1+\nu}} \\
\text { or } P_{t}=\left(\frac{1}{\bar{\ell}}\right)^{\frac{1}{1+\nu}}\left(\frac{E_{t-1}\left[\left(\mu_{t}\left(1+g_{t}\right) / Z_{t}\right)^{1+\nu}\right]}{E_{t-1}\left(1+g_{t}\right)}\right)^{\frac{1}{1+\nu}} \text { under flexible prices }
\end{gathered}
$$

where $Z_{t}, \mu_{t}$ and $g_{t}$ are exogenous variables, $C_{t}, P_{t}$, and $\ell_{t}$ endogenous.

The analysis above would be identical if we assumed that government spending enters households' utility in an additively separable way, so that an increase in public spending has no effect on the marginal utility of consumption or the marginal disutility of labor effort. Shocks to spending would then also affect utility directly. However, a welfare maximizing fiscal authority would prevent random fluctuation of government spending. As for monetary policy, optimal fiscal spending will also tend to be expansionary in response to positive productivity shocks, and contractionary in response to negative productivity shocks.

\section{Appendix 2 Algebra of the two-country model}

Consider the open-economy extension of the model analyzed above. The world economy consists now of two symmetric countries, Home and Foreign. In each country there are households, firms, and a government. Home households and firms are defined over a continuum of unit mass, with indexes $j \in[0,1]$ and $h \in[0,1]$ as in the closed-economy model. Foreign households and firms are also defined over a continuum of unit mass, with indexes $j^{*} \in[0,1]$ and $f \in[0,1]$.

Households are immobile across countries and they own national firms. Firms in each country specialize in the production of a country-specific good. Each firm produces a variety (brand) of the national good which is an imperfect substitute to all other varieties under conditions of monopolistic competition.

We develop our analysis assuming that markets are complete, so that households can efficiently share consumption risk.

Home and Foreign households The utility of household $j$ is the same as in (A.1):

$$
U_{t}(j)=\ln C_{t}(j)-\kappa \ell_{t}(j)+\chi \ln \frac{M_{t}(j)}{P_{t}}
$$

where $C_{t}(j)$ is now a Cobb-Douglas basket (that is, a CES basket with unit elasticity) of the Home and Foreign goods with equal weights $(1 / 2,1 / 2)$ :

$$
C_{t}(j)=C_{H, t}(j)^{1 / 2} C_{F, t}(j)^{1 / 2}
$$


and $C_{H, t}(j)$ and $C_{F, t}(j)$ are CES baskets of, respectively, Home and Foreign varieties:

$$
C_{H, t}(j)=\left(\int_{0}^{1} C_{t}(h, j)^{1-\frac{1}{\theta}} d h\right)^{\frac{\theta}{\theta-1}} \quad C_{F, t}(j)=\left(\int_{0}^{1} C_{t}(f, j)^{1-\frac{1}{\theta}} d f\right)^{\frac{\theta}{\theta-1}}
$$

For simplicity, the elasticity of substitution across varieties, $\theta$, is the same across countries. This specification implies that the degree of substitution between domestic goods and imports is lower than the degree of substitution among varieties $(1<\theta)$.

Foreign households are analogously characterized. The utility of household $j^{*}$ is:

$$
U_{t}^{*}\left(j^{*}\right)=\ln C_{t}^{*}\left(j^{*}\right)-\kappa \ell_{t}^{*}\left(j^{*}\right)+\chi \ln \frac{M_{t}^{*}\left(j^{*}\right)}{P_{t}^{*}}
$$

where $C_{t}^{*}\left(j^{*}\right)$ is a Cobb-Douglas basket:

$$
C_{t}^{*}\left(j^{*}\right)=C_{H, t}^{*}\left(j^{*}\right)^{1 / 2} C_{F, t}^{*}\left(j^{*}\right)^{1 / 2}
$$

and $C_{H, t}^{*}\left(j^{*}\right), C_{F, t}^{*}\left(j^{*}\right)$ are CES baskets of, respectively, Home and Foreign varieties:

$$
C_{H, t}^{*}\left(j^{*}\right)=\left(\int_{0}^{1} C_{t}^{*}\left(h, j^{*}\right)^{1-\frac{1}{\theta}} d h\right)^{\frac{\theta}{\theta-1}} \quad C_{F, t}^{*}\left(j^{*}\right)=\left(\int_{0}^{1} C_{t}^{*}\left(f, j^{*}\right)^{1-\frac{1}{\theta}} d f\right)^{\frac{\theta}{\theta-1}}
$$

For given Home-currency prices of the varieties, $p_{t}(h)$ and $p_{t}(f)$, the utility-based CPI, $P_{t}$, is now defined as:

$$
P_{t}=2 P_{H, t}^{1 / 2} P_{F, t}^{1 / 2}
$$

where:

$$
P_{H, t}=\left(\int_{0}^{1} p_{t}(h)^{1-\theta} d h\right)^{\frac{1}{1-\theta}} \quad P_{F, t}=\left(\int_{0}^{1} p_{t}(f)^{1-\theta} d f\right)^{\frac{1}{1-\theta}} .
$$

Following the same steps as in Appendix 1, one can show that $P_{t}$ is the minimum expenditure associated with consumption of one unit of the index $C_{t}$. Also, the Home-country individual demand curves for varieties $h$ and $f$ are, respectively:

$$
\begin{aligned}
& C_{t}(h, j)=\left(\frac{p_{t}(h)}{P_{H, t}}\right)^{-\theta} \frac{1}{2}\left(\frac{P_{H, t}}{P_{t}}\right)^{-1} C_{t}(j) \\
& C_{t}(f, j)=\left(\frac{p_{t}(f)}{P_{F, t}}\right)^{-\theta} \frac{1}{2}\left(\frac{P_{F, t}}{P_{t}}\right)^{-1} C_{t}(j)
\end{aligned}
$$

and the optimal composition of nominal spending is:

$$
P_{H, t} C_{H, t}(j)=P_{F, t} C_{F, t}(j)=\frac{1}{2} P_{t} C_{t}(j)
$$

Similar expressions hold in the Foreign country. The CPI is:

$$
P_{t}^{*}=2 P_{H, t}^{* 1 / 2} P_{F, t}^{* 1 / 2}
$$

and national price indexes are:

$$
P_{H, t}^{*}=\left(\int_{0}^{1} p_{t}^{*}(h)^{1-\theta} d h\right)^{\frac{1}{1-\theta}} \quad P_{F, t}^{*}=\left(\int_{0}^{1} p_{t}^{*}(f)^{1-\theta} d f\right)^{\frac{1}{1-\theta}} .
$$


Individual demands for varieties are therefore:

$$
\begin{aligned}
C_{t}\left(h, j^{*}\right) & =\left(\frac{p_{t}^{*}(h)}{P_{H, t}^{*}}\right)^{-\theta} \frac{1}{2}\left(\frac{P_{H, t}^{*}}{P_{t}^{*}}\right)^{-1} C_{t}^{*}\left(j^{*}\right) \\
C_{t}\left(f, j^{*}\right) & =\left(\frac{p_{t}^{*}(f)}{P_{F, t}^{*}}\right)^{-\theta} \frac{1}{2}\left(\frac{P_{F, t}^{*}}{P_{t}^{*}}\right)^{-1} C_{t}^{*}\left(j^{*}\right) \\
P_{H, t}^{*} C_{H, t}^{*}\left(j^{*}\right) & =P_{F, t}^{*} C_{F, t}^{*}\left(j^{*}\right)=\frac{1}{2} P_{t}^{*} C_{t}^{*}\left(j^{*}\right)
\end{aligned}
$$

As in the closed-economy case, Home households own the portfolio of Home firms, hold the Home currency, $M$, receive wages and profits from the firms and pay non-distortionary (lump-sum) net taxes NETT, denominated in Home currency. Different from the closed economy case, however, we now assume complete markets - households have access to a full set of Arrow-Debreu securities. Using a sequential formulation (see e.g. Ljungqvist and Sargent (2000)), let $Q\left(s_{t+1} \mid s_{t}\right)$ denote the price of one unit of Home currency delivered in period $t+1$ contingent on the state of nature at $t+1$ being $s_{t+1}$. With complete markets, $Q\left(s_{t+1} \mid s_{t}\right)$ is the same for all individuals. Let $B_{t}\left(s_{t+1}, j\right)$ denote the claim to $B_{t}\left(s_{t+1}, j\right)$ units of Home currency at time $t+1$ in the state of nature $s_{t+1}$, that household $j$ buys at time $t$ and brings into time $t+1 . B_{t}^{*}\left(s_{t}, j\right)$ and $Q^{*}\left(s_{t+1} \mid s_{t}\right)$ are similarly defined in terms of units of Foreign currency.

The individual flow budget constraint for household $j$ in the Home country is:

$$
\begin{aligned}
& M_{t}(j)+\sum_{s_{t+1}} B_{t}\left(s_{t+1}, j\right) Q\left(s_{t+1} \mid s_{t}\right)+\mathcal{E}_{t} \sum_{s_{t+1}} B_{t}^{*}\left(s_{t+1}, j\right) Q^{*}\left(s_{t+1} \mid s_{t}\right) \leq M_{t-1}(j) \\
& +B_{t-1}\left(s_{t}, j\right)+\mathcal{E}_{t} B_{t-1}^{*}\left(s_{t}, j\right)+W_{t} \ell_{t}(j)+\mathcal{P}_{t}(j)-N E T T_{t}(j)-P_{t} C_{t}(j)
\end{aligned}
$$

In the expression above, $\mathcal{E}_{t}$ denotes the nominal exchange rate (defined as Home currency per unit of Foreign currency). The utility function and the budget constraint of the Foreign representative household is similarly defined.

Home household $j$ maximizes utility subject to (B.17). The first order conditions with respect to $C_{t}(j), M_{t}(j)$ and $\ell_{t}(j)$ are identical to (A.16), (A.20) and (A.21) above. Without loss of generality, we focus only on Home-currency securities. The first order conditions with respect to each Arrow-Debreu security yield:

$$
Q\left(s_{t+1} \mid s_{t}\right)=\beta \cdot \operatorname{Pr}\left(s_{t+1} \mid s_{t}\right) \frac{\partial U_{t+1} / \partial C_{t+1}}{\partial U_{t} / \partial C_{t}} \frac{P_{t}}{P_{t+1}}
$$

where $\operatorname{Pr}\left(s_{t+1} \mid s_{t}\right)$ denotes the probability of state $s_{t+1}$ at time $t+1$ conditional on the realization of state $s_{t}$ at $t$. Similar results hold for the representative Foreign household. Namely, the first order conditions with respect to the Arrow-Debreu securities yield:

$$
\frac{\mathcal{E}_{t+1}}{\mathcal{E}_{t}} Q\left(s_{t+1} \mid s_{t}\right)=\beta \cdot \operatorname{Pr}\left(s_{t+1} \mid s_{t}\right) \frac{\partial U^{*} / \partial C_{t+1}^{*}}{\partial U^{*} / \partial C_{t}^{*}} \frac{P_{t}^{*}}{P_{t+1}^{*}}
$$

By combining the two expressions above we obtain:

$$
\frac{\partial U_{t+1} / \partial C_{t+1}}{\partial U_{t} / \partial C_{t}}=\frac{\partial U_{t+1}^{*} / \partial C_{t+1}^{*}}{\partial U_{t}^{*} / \partial C_{t}^{*}} \frac{\mathcal{E}_{t} P_{t}^{*} / P_{t}}{\mathcal{E}_{t+1} P_{t+1}^{*} / P_{t+1}}
$$

and therefore:

$$
\frac{P_{t} C_{t}}{P_{t+1} C_{t+1}}=\frac{\mathcal{E}_{t} P_{t}^{*} C_{t}^{*}}{\mathcal{E}_{t+1} P_{t+1}^{*} C_{t+1}^{*}}
$$


The rate of growth of marginal utility is equal to the rate of real depreciation (the rate of growth of the real exchange rate). Using the definitions $\mu=P C$ and $\mu^{*}=P^{*} C^{*}$, we can also write the above as

$$
\frac{\mu_{t}}{\mu_{t+1}}=\frac{\mathcal{E}_{t} \mu_{t}^{*}}{\mathcal{E}_{t+1} \mu_{t+1}^{*}}
$$

Iterating the above expression we can rewrite the above with respect to some initial date 0 :

$$
\mu_{t}=\left(\frac{\mu_{0}}{\mathcal{E}_{0} \mu_{0}^{*}}\right) \mathcal{E}_{t} \mu_{t}^{*}=\text { constant } \cdot \mathcal{E}_{t} \mu_{t}^{*}
$$

In a symmetric world, Home and Foreign consumption are ex ante identical, hence the constant in the above expression is equal to one. The equilibrium exchange rate is therefore equal to the ratio of Home to Foreign monetary stance:

$$
\mathcal{E}_{t}=\frac{\mu_{t}}{\mu_{t}^{*}}
$$

and

$$
P_{t} C_{t}=\mathcal{E}_{t} P_{t}^{*} C_{t}^{*}
$$

Using the equilibrium discount factor, it is easy to price one period nominal bonds that are traded internationally. In the case of bonds denominated in domestic currency, yielding the nominal interest rate $i$, we have:

$$
-D_{t}+\beta\left(1+i_{t}\right) E_{t} D_{t+1}=0
$$

which is identical to (A.19). In the case of bonds denominated in Foreign currency, and yielding $i^{*}$ we have

$$
-D_{t} \mathcal{E}_{t}+\beta\left(1+i_{t}^{*}\right) E_{t} D_{t+1} \mathcal{E}_{t+1}=0
$$

which can also be written as:

$$
\frac{1}{C_{t}}=\beta\left(1+i_{t}^{*}\right) E_{t}\left(\frac{1}{C_{t+1}} \frac{1}{1+\pi_{t+1}} \frac{\mathcal{E}_{t+1}}{\mathcal{E}_{t}}\right)
$$

Firms The production functions in the two countries are linear in labor:

$$
Y_{t}(h)=Z_{t} \ell_{t}(h) \quad Y_{t}^{*}(f)=Z_{t}^{*} \ell_{t}^{*}(f)
$$

where $Z_{t}$ and $Z_{t}^{*}$ are two country-specific productivity processes. Note that the resource constraint for Home variety $h$ is now:

$$
Y_{t}(h)=\int_{0}^{1} C_{t}(h, j) d j+\int_{0}^{1} C_{t}^{*}\left(h, j^{*}\right) d j^{*}
$$

and similarly for Foreign variety $f$ :

$$
Y_{t}^{*}(f)=\int_{0}^{1} C_{t}(f, j) d j+\int_{0}^{1} C_{t}^{*}\left(f, j^{*}\right) d j^{*}
$$

Aggregating across $j$-agents we obtain total Home demand for variety $h$ :

$$
\int_{0}^{1} C_{t}(h, j) d j=\left(\frac{p_{t}(h)}{P_{H, t}}\right)^{-\theta} \int_{0}^{1} C_{H, t}(j) d j=\left(\frac{p_{t}(h)}{P_{H, t}}\right)^{-\theta} C_{H, t}
$$


Similarly, total Foreign demand for variety $h$ is obtained by aggregating over $j^{*}$-agents:

$$
\int_{0}^{1} C_{t}^{*}\left(h, j^{*}\right) d j^{*}=\left(\frac{p_{t}^{*}(h)}{P_{H, t}^{*}}\right)^{-\theta} \int_{0}^{1} C_{H, t}^{*}\left(j^{*}\right) d j^{*}=\left(\frac{p_{t}^{*}(h)}{P_{H, t}^{*}}\right)^{-\theta} C_{H, t}^{*}
$$

so that Home firm $h$ faces the following demand schedule for its product:

$$
Y_{t}(h)=\left(\frac{p_{t}(h)}{P_{H, t}}\right)^{-\theta}\left(\frac{P_{H, t}}{P_{t}}\right)^{-1} \frac{1}{2} C_{t}+\left(\frac{p_{t}^{*}(h)}{P_{H, t}^{*}}\right)^{-\theta}\left(\frac{P_{H, t}^{*}}{P_{t}^{*}}\right)^{-1} \frac{1}{2} C_{t}^{*}
$$

Similarly we can obtain total demand for Foreign variety $f$.

International price setting Recalling that the Home marginal cost is given by (A.24) as before, and accounting for the downward-sloping demand for its products (B.34), Home firm $h$ 's nominal profits can be written as:

$$
\begin{aligned}
& \mathcal{P}_{t}(h)=p_{t}(h) \int_{0}^{1} C_{t}(h, j) d j+\mathcal{E}_{t} p_{t}^{*}(h) \int_{0}^{1} C_{t}\left(h, j^{*}\right) d j^{*}-W_{t} \ell_{t}(h) \\
& =p_{t}(h) \int_{0}^{1} C_{t}(h, j) d j+\mathcal{E}_{t} p_{t}^{*}(h) \int_{0}^{1} C_{t}\left(h, j^{*}\right) d j^{*} \\
& -\frac{W_{t}}{Z_{t}}\left(\int_{0}^{1} C_{t}(h, j) d j+\int_{0}^{1} C_{t}^{*}\left(h, j^{*}\right) d j^{*}\right) \\
& =\left(p_{t}(h)-M C_{t}\right) \int_{0}^{1} C_{t}(h, j) d j+\left(\mathcal{E}_{t} p_{t}^{*}(h)-M C_{t}\right) \int_{0}^{1} C_{t}\left(h, j^{*}\right) d j^{*} \\
& =\left(p_{t}(h)-M C_{t}\right)\left(\frac{p_{t}(h)}{P_{H, t}}\right)^{-\theta} C_{H, t}+\left(\mathcal{E}_{t} p_{t}^{*}(h)-M C_{t}\right)\left(\frac{p_{t}^{*}(h)}{P_{H, t}^{*}}\right)^{-\theta} C_{H, t}^{*}
\end{aligned}
$$

In the absence of nominal rigidities, Home firms set prices to maximize $\mathcal{P}_{t}(h)$ with respect to $p_{t}(h)$ and $p_{t}^{*}(h)$. This implies:

$$
p_{t}(h)=\mathcal{E}_{t} p_{t}^{*}(h)=\frac{\theta}{\theta-1} M C_{t}
$$

Both prices are equal to the marginal cost augmented by a constant markup $\theta /(\theta-1)$. The law of one price holds, as the same good $h$ sells at the same price in both markets when expressed in terms of the same currency.

With nominal rigidities, firms set the price(s) at which they sell their good in the Home and Foreign countries at time $t$ before observing the realization of the macroeconomic shocks - based on available information at time $t-1$ - by maximizing $E_{t-1}\left(Q_{t-1, t} \mathcal{P}_{t}(h)\right)$. The Home-currency price $p(h)$ is set as in the closed-economy case. In fact, the first order condition is:

$$
E_{t-1}\left(Q_{t-1, t}\left(\frac{p_{t}(h)}{P_{H, t}}\right)^{-\theta} C_{H, t}\right)=\theta \frac{1}{p_{t}(h)} E_{t-1}\left(Q_{t-1, t}\left(p_{t}(h)-M C_{t}\right)\left(\frac{p_{t}(h)}{P_{H, t}}\right)^{-\theta} C_{H, t}\right)
$$

This expression can be further simplified by recalling that $Q_{t-1, t}=\beta P_{t-1} C_{t-1} / P_{t} C_{t}, C_{H, t}=$ $P_{t} C_{t} / 2 P_{H, t}$, and observing that all prices $p_{t}(h)$ are symmetric, thus $p_{t}(h)=P_{H, t}$ :

$$
p_{t}(h)=P_{H, t}=\frac{\theta}{\theta-1} E_{t-1}\left(M C_{t}\right)
$$


The Foreign-currency price $p_{t}^{*}(h)$ can be set in two different ways, depending on the specific currency in which Home exports are priced. If exports are priced and invoiced in domestic (producer's) currency, firm $h$ maximizes $E_{t-1}\left(Q_{t-1, t} \mathcal{P}_{t}(h)\right)$ with respect to $\mathcal{E}_{t} p_{t}^{*}(h)$, setting the price of variety $h$ according to:

$E_{t-1}\left(Q_{t-1, t}\left(\frac{\mathcal{E}_{t} p_{t}^{*}(h)}{\mathcal{E}_{t} P_{H, t}^{*}}\right)^{-\theta} C_{H, t}^{*}\right)=\frac{\theta}{\mathcal{E}_{t} p_{t}^{*}(h)} E_{t-1}\left(Q_{t-1, t}\left(\mathcal{E}_{t} p_{t}^{*}(h)-M C_{t}\right)\left(\frac{\mathcal{E}_{t} p_{t}^{*}(h)}{\mathcal{E}_{t} P_{H, t}^{*}}\right)^{-\theta} C_{H, t}^{*}\right)$

or:

$$
\mathcal{E}_{t} p_{t}^{*}(h)=\frac{\theta}{\theta-1} \frac{E_{t-1}\left(Q_{t-1, t} M C_{t}\left(\frac{\mathcal{E}_{t} p_{t}^{*}(h)}{\mathcal{E}_{t} P_{H, t}^{*}}\right)^{-\theta} C_{H, t}^{*}\right)}{E_{t-1}\left(Q_{t-1, t}\left(\frac{\mathcal{E}_{t} p_{t}^{*}(h)}{\mathcal{E}_{t} P_{H, t}^{*}}\right)^{-\theta} C_{H, t}^{*}\right)}
$$

Recalling that $Q_{t-1, t}=\beta P_{t-1} C_{t-1} / P_{t} C_{t}, C_{H, t}^{*}=\mathcal{E}_{t} P_{t}^{*} C_{t}^{*} / 2\left(\mathcal{E}_{t} P_{H, t}^{*}\right)$, and observing that all prices $\mathcal{E}_{t} p_{t}^{*}(h)$ are symmetric, thus $\mathcal{E}_{t} p_{t}^{*}(h)=\mathcal{E}_{t} P_{H, t}^{*}$, we obtain:

$$
\begin{aligned}
\mathcal{E}_{t} p_{t}^{*}(h) & =\mathcal{E}_{t} P_{H, t}^{*}=\frac{\theta}{\theta-1} \frac{E_{t-1}\left(M C_{t} \frac{\mathcal{E}_{t} P_{t}^{*} C_{t}^{*}}{P_{t} C_{t}} \frac{1}{\mathcal{E}_{t} P_{H, t}^{*}}\right)}{E_{t-1}\left(\frac{\mathcal{E}_{t} P_{t}^{*} C_{t}^{*}}{P_{t} C_{t}} \frac{1}{\mathcal{E}_{t} P_{H, t}^{*}}\right)} \\
& =\frac{\theta}{\theta-1} \frac{E_{t-1}\left(M C_{t} \frac{\mathcal{E}_{t} P_{t}^{*} C_{t}^{*}}{P_{t} C_{t}}\right)}{E_{t-1}\left(\frac{\mathcal{E}_{t} P_{t}^{*} C_{t}^{*}}{P_{t} C_{t}}\right)}=\frac{\theta}{\theta-1} E_{t-1}\left(M C_{t}\right)
\end{aligned}
$$

The previous expression implies that Foreign-currency prices $P_{H, t}^{*}$ move one-to-one with the nominal exchange rate, leaving the export price $\mathcal{E}_{t} P_{H, t}^{*}$ unchanged when expressed in Home currency (in other words, there is full exchange rate pass-through).

If the export price is set instead in Foreign currency, firm $h$ maximizes expected discounted profits $E_{t-1}\left(Q_{t-1, t} \mathcal{P}_{t}(h)\right)$ with respect to $p_{t}^{*}(h)$. The first order condition is:

$$
E_{t-1}\left(Q_{t-1, t} \mathcal{E}_{t}\left(\frac{p_{t}^{*}(h)}{P_{H, t}^{*}}\right)^{-\theta} C_{H, t}^{*}\right)=\frac{\theta}{p_{t}^{*}(h)} E_{t-1}\left(Q_{t-1, t}\left(\mathcal{E}_{t} p_{t}^{*}(h)-M C_{t}\right)\left(\frac{p_{t}^{*}(h)}{P_{H, t}^{*}}\right)^{-\theta} C_{H, t}^{*}\right)
$$

which can be written as:

$$
\begin{aligned}
p_{t}^{*}(h) & =P_{H, t}^{*}=\frac{\theta}{\theta-1} \frac{E_{t-1}\left(M C_{t} Q_{t-1, t}\left(\frac{1}{P_{H, t}^{*}}\right)^{-\theta} C_{H, t}^{*}\right)}{E\left(Q_{t-1, t} \mathcal{E}_{t}\left(\frac{1}{P_{H, t}^{*}}\right)^{-\theta} C_{H, t}^{*}\right)} \\
& =\frac{\theta}{\theta-1} \frac{E_{t-1}\left(\frac{M C_{t}}{\mathcal{E}_{t}} \frac{P_{t}^{*} C_{t}^{*} \mathcal{E}_{t}}{P_{t} C_{t}}\right)}{E\left(\frac{\mathcal{E}_{t} P_{t}^{*} C_{t}^{*}}{P_{t} C_{t}}\right)}=\frac{\theta}{\theta-1} E_{t-1}\left(\frac{M C_{t}}{\mathcal{E}_{t}}\right)
\end{aligned}
$$

According to this expression, Home export prices expressed in Foreign currency do not move when the exchange rate changes (zero pass-through). Similar results hold for Foreign firms. 
Resource constraints and policy The resource constraint for the Home output is:

$$
\begin{aligned}
& Z_{t} \ell_{t}=C_{H, t}+C_{H, t}^{*}=\frac{1}{2}\left(\frac{P_{t} C_{t}}{P_{H, t}}+\frac{P_{t}^{*} C_{t}^{*}}{P_{H, t}^{*}}\right) \\
& =\frac{1}{2}\left(\frac{P_{t} C_{t}}{P_{H, t}}+\frac{P_{t} C_{t}}{\mathcal{E}_{t} P_{H, t}^{*}}\right)=\frac{P_{t}}{2}\left(\frac{1}{P_{H, t}}+\frac{1}{\mathcal{E}_{t} P_{H, t}^{*}}\right) C_{t}
\end{aligned}
$$

which can be written synthetically as:

$$
C_{t}=Z_{t} \ell_{t} \tau_{t}
$$

where:

$$
\frac{1}{\tau_{t}} \equiv \frac{P_{t}}{2}\left(\frac{1}{P_{H, t}}+\frac{1}{\mathcal{E}_{t} P_{H, t}^{*}}\right)
$$

The variable $\tau_{t}$ is an index of international spillovers, reflecting the macroeconomic impact of fluctuations of relative prices and terms of trade on the Home economy. Similarly,

$$
C_{t}^{*}=Z_{t}^{*} \ell_{t}^{*} \tau_{t}^{*}
$$

and:

$$
\frac{1}{\tau_{t}^{*}} \equiv \frac{P_{t}^{*}}{2}\left(\frac{1}{P_{F, t}^{*}}+\frac{\mathcal{E}_{t}}{P_{F, t}}\right)
$$

As before, each government sets the national money stance by controlling the domestic nominal interest rate, and finances net transfers with seigniorage revenue.

A digression on an alternative specification of our model It is worth noting that our model would yield exactly the same equilibrium allocation if, instead of assuming complete markets, we assume that only one period nominal bonds are traded internationally, and net foreign wealth is initially zero. To see this, rewrite the budget constraints (B.17) including only international bonds, $B$ and $B^{*}$, denominated in either domestic or foreign currency. These nominal bonds are in zero net-supply worldwide, so that:

$$
\int_{0}^{1} B_{t}(j) d j+\int_{0}^{1} B_{t}\left(j^{*}\right) d j^{*}=\int_{0}^{1} B_{t}^{*}(j) d j+\int_{0}^{1} B_{t}^{*}\left(j^{*}\right) d j^{*}=0 .
$$

Aggregating the budget constraint across $j$-agents, and accounting for the government budget constraint (A.36), we would then obtain :

$$
P_{t} C_{t} \leq W_{t} \ell_{t}+\mathcal{P}_{t}+\left(1+i_{t-1}\right) B_{t-1}-B_{t}-\left(1+i_{t-1}^{*}\right) \mathcal{E}_{t} B_{t-1}^{*}+\mathcal{E}_{t} B_{t}^{*}
$$

where bond holdings are defined as:

$$
B_{t}=\int_{0}^{1} B_{t}(j) d j \quad B_{t}^{*}=\int_{0}^{1} B_{t}^{*}\left(j^{*}\right) d j^{*} .
$$

and aggregate profits are:

$$
\begin{aligned}
\mathcal{P}_{t} & =P_{H, t} C_{H, t}+\mathcal{E}_{t} P_{H, t}^{*} C_{H, t}^{*}-M C_{t}\left(C_{H, t}+C_{H, t}^{*}\right) \\
& =\frac{1}{2} P_{t} C_{t}+\frac{1}{2} \mathcal{E}_{t} P_{t}^{*} C_{t}^{*}-W_{t} \ell_{t}
\end{aligned}
$$


Under the assumption that at time $t=0$ the net asset position of the country is zero, or $B_{0}-\mathcal{E}_{0} B_{0}^{*}=0$, it can be shown that, for all $t \geq 0$, the equilibrium conditions are solved by the allocation:

$$
\begin{gathered}
B_{t}=\mathcal{E}_{t} B_{t}^{*}=0 \quad t \geq 0 . \\
P_{t} C_{t}=\mathcal{E}_{t} P_{t}^{*} C_{t}^{*}
\end{gathered}
$$

implying that nominal spending is equalized between the two countries when expressed in terms of the same currency. The nominal exchange rate moves to offset any imbalances in relative nominal spending, and since the latter is equal to the ratio of the monetary stances, the nominal exchange rate is the channel through which monetary policies are transmitted internationally:

$$
\mathcal{E}_{t}=\frac{\mu_{t}}{\mu_{t}^{*}}
$$

This is exactly the same solution for the exchange rate that we derived in our model above.

Macroeconomic synthesis of the two-country model To summarize: given the exogenous variables $Z_{t}, Z_{t}^{*}, \mu_{t}, \mu_{t}^{*}$ and the prices $P_{H, t}, P_{F, t}, P_{H, t}^{*}, P_{F, t}^{*}$, the macroeconomics of the two-country model is described by the system of 13 equations in 13 endogenous variables $\mathcal{E}_{t}, P_{t}, P_{t}^{*}, C_{t}, C_{t}^{*}, \tau_{t}, \tau_{t}^{*}, \ell_{t}, \ell_{t}^{*}, C_{H, t}, C_{F, t}, C_{H, t}^{*}$, and $C_{F, t}^{*}$ :

$$
\begin{array}{ll} 
& \mathcal{E}_{t}=\mu_{t} / \mu_{t}^{*} \\
& \\
P_{t}=2 P_{H, t}^{1 / 2} P_{F, t}^{1 / 2} & P_{t}^{*}=2 P_{H, t}^{* 1 / 2} P_{F, t}^{* 1 / 2} \\
\mu_{t}=P_{t} C_{t} & \mu_{t}^{*}=P_{t}^{*} C_{t}^{*} \\
\frac{1}{\tau_{t}} \equiv \frac{P_{t}}{2}\left(\frac{1}{P_{H, t}}+\frac{1}{\mathcal{E} P_{H, t}^{*}}\right) & \frac{1}{\tau_{t}^{*}} \equiv \frac{P_{t}^{*}}{2}\left(\frac{1}{P_{F, t}^{*}}+\frac{\mathcal{E}_{t}}{P_{F, t}}\right) \\
C_{t}=Z_{t} \ell_{t} \tau_{t} & C_{t}^{*}=Z_{t}^{*} \ell_{t}^{*} \tau_{t}^{*} \\
P_{H, t} C_{H, t}=\frac{1}{2} P_{t} C_{t} & P_{F, t} C_{F, t}=\frac{1}{2} P_{t} C_{t} \\
P_{H, t}^{*} C_{H, t}^{*}=\frac{1}{2} P_{t}^{*} C_{t}^{*} & P_{F, t}^{*} C_{F, t}^{*}=\frac{1}{2} P_{t}^{*} C_{t}^{*}
\end{array}
$$

The model is closed by providing endogenous expressions for the four prices. In the absence of nominal rigidities, we have:

$$
\begin{aligned}
& P_{H, t}=\frac{\theta \kappa}{\theta-1} \frac{\mu_{t}}{Z_{t}} \\
& P_{H, t}^{*}=\frac{P_{H, t}}{\mathcal{E}_{t}}=\frac{1}{\mathcal{E}_{t}} \frac{\theta \kappa}{\theta-1} \frac{\mu_{t}}{Z_{t}} \quad P_{F, t}^{*}=\frac{\theta \kappa}{\theta-1} \frac{\mu_{t}^{*}}{Z_{t}^{*}}
\end{aligned}
$$

With nominal rigidities, if export prices are set in the producer's currency (PCP), we have:

$$
\begin{array}{ll}
P_{H, t}=\frac{\theta \kappa}{\theta-1} E_{t-1}\left(\frac{\mu_{t}}{Z_{t}}\right) & P_{F, t}=\mathcal{E}_{t} P_{F, t}^{*}=\mathcal{E}_{t} \frac{\theta \kappa}{\theta-1} E_{t-1}\left(\frac{\mu_{t}^{*}}{Z_{t}^{*}}\right) \\
P_{H, t}^{*}=\frac{P_{H, t}}{\mathcal{E}_{t}}=\frac{1}{\mathcal{E}_{t}} \frac{\theta \kappa}{\theta-1} E_{t-1}\left(\frac{\mu_{t}}{Z_{t}}\right) & P_{F, t}^{*}=\frac{\theta \kappa}{\theta-1} E_{t-1}\left(\frac{\mu_{t}^{*}}{Z_{t}^{*}}\right)
\end{array}
$$

If export prices are set in the consumer's currency (LCP), we have:

$$
\begin{aligned}
& P_{H, t}=\frac{\theta \kappa}{\theta-1} E_{t-1}\left(\frac{\mu_{t}}{Z_{t}}\right) \quad P_{F, t}=\frac{\theta \kappa}{\theta-1} E_{t-1}\left(\frac{\mu_{t}}{Z_{t}^{*}}\right) \\
& P_{H, t}^{*}=\frac{\theta \kappa}{\theta-1} E_{t-1}\left(\frac{\mu_{t}^{*}}{Z_{t}}\right) \quad P_{F, t}^{*}=\frac{\theta \kappa}{\theta-1} E_{t-1}\left(\frac{\mu_{t}^{*}}{Z_{t}^{*}}\right)
\end{aligned}
$$


Finally, if world export prices are set in only one currency (say, the Home country's currency), we have:

$$
\begin{aligned}
P_{H, t} & =\frac{\theta \kappa}{\theta-1} E_{t-1}\left(\frac{\mu_{t}}{Z_{t}}\right) & P_{F, t} & =\frac{\theta \kappa}{\theta-1} E_{t-1}\left(\frac{\mu_{t}}{Z_{t}^{*}}\right) \\
P_{H, t}^{*} & =\frac{P_{H, t}}{\mathcal{E}_{t}}=\frac{1}{\mathcal{E}_{t}} \frac{\theta \kappa}{\theta-1} E_{t-1}\left(\frac{\mu_{t}}{Z_{t}}\right) & P_{F, t}^{*} & =\frac{\theta \kappa}{\theta-1} E_{t-1}\left(\frac{\mu_{t}^{*}}{Z_{t}^{*}}\right)
\end{aligned}
$$

Transmission of productivity and monetary shocks Consider the implications of the price-setting scenarios above. Absent nominal rigidities, there is full employment in both economies regardless of the shocks:

$$
\ell_{t}=\ell_{t}^{*}=\frac{\theta-1}{\theta \kappa}=\bar{\ell}
$$

In the presence of nominal rigidities, instead, full employment holds only on average:

$$
E_{t-1}\left(\ell_{t}\right)=E_{t-1}\left(\ell_{t}^{*}\right)=\bar{\ell}
$$

Under PCP we have:

$$
\ell_{t}=\frac{\mu_{t} / Z_{t}}{E_{t-1}(\mu / Z)} \bar{\ell}, \quad \quad \ell_{t}^{*}=\frac{\mu_{t}^{*} / Z_{t}^{*}}{E_{t-1}\left(\mu_{t}^{*} / Z_{t}^{*}\right)} \bar{\ell}
$$

and the effects of changes in relative prices are captured by:

$$
\tau_{t}=\frac{1}{2}\left(\frac{E_{t-1}\left(\mu_{t} / Z_{t}\right)}{E_{t-1}\left(\mu_{t}^{*} / Z_{t}^{*}\right)} \frac{1}{\mathcal{E}_{t}}\right)^{1 / 2}, \quad \tau_{t}^{*}=\frac{1}{2}\left(\frac{E_{t-1}\left(\mu_{t}^{*} / Z_{t}^{*}\right)}{E_{t-1}\left(\mu_{t} / Z_{t}\right)} \mathcal{E}_{t}\right)^{1 / 2}
$$

Incidentally, note that if Home and Foreign consumption baskets had different elasticities of substitution, $\theta \neq \theta^{*}$, or national residents had different sensitivities to labor effort, $\kappa \neq \kappa^{*}$, the indexes $\tau$ and $\tau^{*}$ would be multiplied by $\left\{[\theta \kappa /(\theta-1)] /\left[\theta^{*} \kappa^{*} /\left(\theta^{*}-1\right)\right]\right\}^{1 / 2}$ and $\left\{[\theta \kappa /(\theta-1)] /\left[\theta^{*} \kappa^{*} /\left(\theta^{*}-1\right)\right]\right\}^{-1 / 2}$, respectively.

In each country, the labor gap is a function of domestic shocks only. This implies that monetary policies have no spillovers on output abroad. A depreciation of $\mathcal{E}_{t}$ deteriorates the terms of trade at Home and improves them abroad. Consumption moves symmetrically across countries, and in welfare terms the transmission of monetary policy is positive:

$$
C_{t}=C_{t}^{*}=\frac{\theta-1}{\theta \kappa} \frac{\mu_{t}^{1 / 2} \mu_{t}^{* 1 / 2}}{2\left[E_{t-1}\left(\mu_{t} / Z_{t}\right)\right]^{1 / 2}\left[E_{t-1}\left(\mu_{t}^{*} / Z_{t}^{*}\right)\right]^{1 / 2}}
$$

In the $\mathbf{L C P}$ case instead we have

$$
\begin{aligned}
& \ell_{t}=\frac{1}{2}\left(\frac{\mu_{t} / Z_{t}}{E_{t-1}\left(\mu_{t} / Z_{t}\right)}+\frac{\mu_{t}^{*} / Z_{t}}{E_{t-1}\left(\mu_{t}^{*} / Z_{t}\right)}\right) \bar{\ell} \\
& \ell_{t}^{*}=\frac{1}{2}\left(\frac{\mu_{t}^{*} / Z_{t}^{*}}{E_{t-1}\left(\mu_{t}^{*} / Z_{t}^{*}\right)}+\frac{\mu_{t} / Z_{t}^{*}}{E_{t-1}\left(\mu_{t} / Z_{t}^{*}\right)}\right) \bar{\ell}
\end{aligned}
$$

and the expressions for $\tau_{t}$ and $\tau_{t}^{*}$ are:

$$
\tau_{t}=\frac{\left(\frac{E_{t-1}\left(\mu_{t} / Z_{t}\right)}{E_{t-1}\left(\mu_{t} / Z_{t}^{*}\right)}\right)^{1 / 2}}{1+\frac{E_{t-1}\left(\mu_{t} / Z_{t}\right)}{E_{t-1}\left(\mu_{t}^{*} / Z_{t}\right)} \frac{1}{\mathcal{E}_{t}}} \quad \tau_{t}^{*}=\frac{\left(\frac{E_{t-1}\left(\mu_{t}^{*} / Z_{t}^{*}\right)}{E_{t-1}\left(\mu_{t}^{*} / Z_{t}\right)}\right)^{1 / 2}}{1+\frac{E_{t-1}\left(\mu_{t}^{*} / Z_{t}^{*}\right)}{E_{t-1}\left(\mu_{t} / Z_{t}^{*}\right)} \mathcal{E}_{t}}
$$


Under a scenario of low pass-through worldwide, monetary policies in one country affect output and employment overseas. A depreciation of $\mathcal{E}_{t}$ now increases Home exporters' sales revenue and reduces Foreign exporters' sales revenue, without effects on consumer prices. Thus, a depreciation of $\mathcal{E}_{t}$ has now a positive impact on $\tau_{t}$ and negative on $\tau_{t}^{*}$. Consumption changes asymmetrically across countries, implying a negative, 'beggar-thyneighbor' transmission of monetary policy:

$$
\begin{aligned}
C_{t} & =\frac{\theta-1}{\theta \kappa} \frac{\mu_{t}}{2\left[E_{t-1}\left(\mu_{t} / Z_{t}\right)\right]^{1 / 2}\left[E_{t-1}\left(\mu_{t} / Z_{t}^{*}\right)\right]^{1 / 2}} \\
C^{*} & =\frac{\theta-1}{\theta \kappa} \frac{\mu_{t}^{*}}{2\left[E_{t-1}\left(\mu_{t}^{*} / Z_{t}^{*}\right)\right]^{1 / 2}\left[E_{t-1}\left(\mu_{t}^{*} / Z_{t}\right)\right]^{1 / 2}}
\end{aligned}
$$

Finally, if world exports are all invoiced in the Home currency, macroeconomic shocks have asymmetric effects on the two economies:

$$
\begin{gathered}
\ell_{t}=\frac{\mu_{t} / Z_{t}}{E_{t-1}\left(\mu_{t} / Z_{t}\right)} \frac{\theta-1}{\theta \kappa} \\
\ell_{t}^{*}=\frac{1}{2}\left(\frac{\mu_{t}^{*} / Z_{t}^{*}}{E_{t-1}\left(\mu_{t}^{*} / Z_{t}^{*}\right)}+\frac{\mu_{t} / Z_{t}^{*}}{E_{t-1}\left(\mu_{t} / Z_{t}^{*}\right)}\right) \frac{\theta-1}{\theta \kappa} \\
\tau_{t}=\frac{\left[E_{t-1}\left(\mu_{t} / Z_{t}\right)\right]^{1 / 2}}{2\left[E_{t-1}\left(\mu_{t} / Z_{t}^{*}\right)\right]^{1 / 2}} \quad \tau_{t}^{*}=\frac{\left(\mathcal{E}_{t} \frac{E_{t-1}\left[\mu_{t}^{*} / Z_{t}^{*}\right]}{E_{t-1}\left[\mu_{t} / Z_{t}\right]}\right)^{1 / 2}}{1+\frac{E_{t-1}\left[\mu_{t}^{*} / Z_{t}^{*}\right]}{E_{t-1}\left[\mu_{t} / Z_{t}^{*}\right]} \mathcal{E}_{t}}
\end{gathered}
$$

and:

$$
\begin{aligned}
C_{t} & =\frac{\theta-1}{\theta \kappa} \frac{\mu_{t}}{2\left[E_{t-1}\left(\mu_{t} / Z\right)\right]^{1 / 2}\left[E_{t-1}\left(\mu_{t} / Z_{t}^{*}\right)\right]^{1 / 2}} \\
C_{t}^{*} & =\frac{\theta-1}{\theta \kappa} \frac{\mu_{t}^{1 / 2} \mu_{t}^{* 1 / 2}}{2\left[E_{t-1}\left(\mu_{t}^{*} / Z_{t}^{*}\right)\right]^{1 / 2}\left[E_{t-1}\left(\mu_{t} / Z_{t}\right)\right]^{1 / 2}}
\end{aligned}
$$

Now a depreciation of $\mathcal{E}$ has no macroeconomic effects in the Home country: output, consumption, and terms of trade are all insulated from external shocks. The implications for the Foreign economy are more complex. On the one hand, a depreciation of $\mathcal{E}$ lowers import prices in the Foreign country and improves $\tau^{*}$ (this effect is captured by the numerator of (B.73)). On the other hand, the same depreciation reduces sales revenue of Foreign exporters and lowers $\tau^{*}$ (an effect captured by the denominator of (B.73)). Which effect prevails depends on the sign of $\mathcal{E}_{t}^{-1 / 2}-\mathcal{E}_{t}^{1 / 2} E_{t-1}\left(\mu_{t}^{*} / Z_{t}^{*}\right) / E_{t-1}\left(\mu_{t} / Z_{t}^{*}\right)$. Yet, when evaluated in a non-stochastic equilibrium, the previous expression is zero. Thus, we conclude that a depreciation of $\mathcal{E}$ has no first-order effects on $\tau^{*}$. Home monetary policy has spillovers for both Foreign output and consumption: if labor increases by, say, $\Delta \ell^{*}$, consumption increases by $Z^{*} \Delta \ell^{*}$.

Optimal monetary policy and international policy coordination Using the 2country model under PCP, we derive the optimal Home monetary policy under uncertainty that maximizes the expected utility of the representative Home residents by solving:

$$
\max _{\mu_{t}} E_{t-1}\left(\ln C_{t}-\kappa \ell_{t}\right)
$$


Recall that $E_{t-1}\left(\ell_{t}\right)=\bar{\ell}$, so that the second term in utility is independent of monetary policy and we need focus on consumption only. In fact, welfare can be written as:

$$
\begin{aligned}
& E_{t-1}\left(\ln C_{t}-\kappa \ell_{t}\right)=E_{t-1} \ln \frac{\theta-1}{\theta \kappa} \frac{\mu_{t}^{1 / 2} \mu_{t}^{* 1 / 2}}{2\left[E_{t-1}\left(\mu_{t} / Z_{t}\right)\right]^{1 / 2}\left[E_{t-1}\left(\mu_{t}^{*} / Z_{t}^{*}\right)\right]^{1 / 2}}-\kappa \frac{\theta-1}{\theta \kappa} \\
& =\text { const. }+\frac{1}{2} E_{t-1} \ln \mu_{t}+\frac{1}{2} E_{t-1} \ln \mu_{t}^{*}-\frac{1}{2} \ln E_{t-1}\left(\mu_{t} / Z_{t}\right)-\frac{1}{2} \ln E_{t-1}\left(\mu_{t}^{*} / Z_{t}^{*}\right)
\end{aligned}
$$

Take the first order condition for a maximum, and obtain:

$$
\frac{1}{2} \frac{1}{\mu_{t}}-\frac{1}{2} \frac{1 / Z_{t}}{E_{t-1}\left(\mu_{t} / Z_{t}\right)}=0
$$

precisely the same expression we obtained for a closed economy. Home monetary policy responds one-to one to real shocks, stabilizing Home firms' markups. Foreign firms' markups are unaffected by Home shocks, so that an inward-looking policy in the Home country does not have repercussions abroad. There is no need for coordination, as the optimal monetary policies in a Nash equilibrium deliver a worldwide first best (conditional on the presence of monopolistic distortions).

Under LCP, instead, Home welfare is:

$$
\begin{aligned}
& E_{t-1}\left(\ln C_{t}-\kappa \ell_{t}\right)=E_{t-1} \ln \frac{\theta-1}{\theta \kappa} \frac{\mu_{t}}{2\left[E_{t-1}\left(\mu_{t} / Z_{t}\right)\right]^{1 / 2}\left[E_{t-1}\left(\mu_{t} / Z_{t}^{*}\right)\right]^{1 / 2}}-\kappa \frac{\theta-1}{\theta \kappa} \\
& =\text { const. }+E_{t-1} \ln \mu_{t}-\frac{1}{2} \ln E_{t-1}\left(\mu_{t} / Z_{t}\right)-\frac{1}{2} \ln E_{t-1}\left(\mu_{t} / Z_{t}^{*}\right)
\end{aligned}
$$

Take the first order condition for a maximum, and obtain:

$$
\frac{1}{\mu_{t}}-\frac{1}{2} \frac{1 / Z_{t}}{E_{t-1}\left(\mu_{t} / Z_{t}\right)}-\frac{1}{2} \frac{1 / Z_{t}^{*}}{E_{t-1}\left(\mu_{t} / Z_{t}^{*}\right)}=0
$$

Home monetary policy now responds to both Home and Foreign shocks, but not to Foreign monetary shocks. In other words, even in the case of LCP there is no monetary interdependence, thus no need for policy coordination. In the Foreign country, the optimal policy will solve:

$$
\frac{1}{\mu_{t}^{*}}-\frac{1}{2} \frac{1 / Z_{t}^{*}}{E_{t-1}\left(\mu_{t}^{*} / Z_{t}^{*}\right)}-\frac{1}{2} \frac{1 / Z_{t}}{E_{t-1}\left(\mu_{t}^{*} / Z_{t}\right)}=0
$$

The system of two equations above is solved by a common policy $\mu_{t}=\mu_{t}^{*}$ that responds to the same average of Home and Foreign shocks while keeping the nominal and real exchange rate constant.

When world exports are priced in Home currency, Home welfare is still equal to (B.79), so that Home optimal monetary policy is still described by (B.80). Instead, in the Foreign country welfare is:

$$
\begin{aligned}
& E_{t-1}\left(\ln C_{t}^{*}-\kappa \ell_{t}^{*}\right)=E_{t-1} \ln \frac{\theta-1}{\theta \kappa} \frac{\mu_{t}^{1 / 2} \mu_{t}^{* 1 / 2}}{2\left[E_{t-1}\left(\mu_{t}^{*} / Z_{t}^{*}\right)\right]^{1 / 2}\left[E_{t-1}\left(\mu_{t} / Z_{t}\right)\right]^{1 / 2}}-\kappa \frac{\theta-1}{\theta \kappa} \\
& =\text { const. }+\frac{1}{2} E_{t-1} \ln \mu_{t}+\frac{1}{2} E_{t-1} \ln \mu_{t}^{*}-\frac{1}{2} \ln E_{t-1}\left(\mu_{t}^{*} / Z_{t}^{*}\right)-\frac{1}{2} \ln E_{t-1}\left(\mu_{t} / Z_{t}\right)
\end{aligned}
$$

and optimal policy is:

$$
\frac{1}{2} \frac{1}{\mu_{t}^{*}}-\frac{1}{2} \frac{1 / Z_{t}^{*}}{E_{t-1}\left(\mu_{t}^{*} / Z_{t}^{*}\right)}=0
$$

In a Nash equilibrium, the country that issues the vehicle currency (Home) optimally responds to shocks hitting the global economy, while the country that uses the vehicle currency (Foreign) only needs to stabilize domestic prices and markups. 